\title{
Detecção de objetos por reconhecimento de grafos-chave
}

\author{
Marcelo Hashimoto
}

TESE APRESENTADA

$\mathrm{AO}$

Instituto DE MatemÁticA E EstatísticA

DA

UniversidAde DE SÃO PAUlO

PARA

OBTENÇÃO DO TÍTULO

$\mathrm{DE}$

Doutor EM CiÊnCIAS

\author{
Programa: Ciência da Computação \\ Orientador: Prof. Dr. Roberto Marcondes Cesar Junior
}

Durante o desenvolvimento deste trabalho o autor recebeu auxílio financeiro da FAPESP (processo $\mathrm{n}^{\circ}$ 007/56288-1)

São Paulo, abril de 2012 



\title{
Detecção de objetos por reconhecimento de grafos-chave
}

\author{
Esta versão da tese contém as correções e alterações sugeridas \\ Comissão Julgadora durante a defesa da versão original do trabalho, \\ realizada em 27/04/2012. Uma cópia da versão original está disponível no \\ Instituto de Matemática e Estatística da Universidade de São Paulo.
}

Comissão Julgadora:

- Prof. Dr. Roberto Marcondes Cesar Junior (orientador) - IME-USP

- Prof. Dr. Carlos Hitoshi Morimoto - IME-USP

- Prof. Dr. Ricardo da Silva Torres - IC-UNICAMP

- Prof. Dr. João Paulo Papa - FC-UNESP

- Prof. Dr. Odemir Martinez Bruno - IFSC-USP 



\section{Agradecimentos}

Ao meu orientador Roberto, por todo o apoio oferecido e pela compreensão durante momentos particularmente difíceis da minha vida.

A todos os membros das minhas bancas de qualificação e defesa, pelas valiosas sugestões.

À Profa. Dra. Valérie Gouet-Brunet e todos os demais pesquisadores do CNAM, pelo apoio e hospitalidade.

A todos os colegas de pós-graduação no IME-USP, pela companhia que me sustentou ao longo dos últimos anos.

Aos amigos próximos: Livy, Ricardo, Felipe, Gordana, Cardonha, Marcel e Cris. Por serem meu porto seguro durante as tempestades.

Aos preciosos colegas da Maison du Brésil, pela enorme diferença positiva que fizeram em minha vida.

Finalmente, à meus pais e meus irmãos, por confiarem no caminho que escolhi, e à minha irmã de convivência Clara, por ser a minha melhor amiga.

Este trabalho recebeu apoio da FAPESP, CNPq, CAPES, FINEP e CNAM. 



\section{Resumo}

\section{Detecção de objetos por reconhecimento de grafos-chave}

Detecção de objetos é um problema clássico em visão computacional, presente em aplicações como vigilância automatizada, análise de imagens médicas e recuperação de informação. Dentre as abordagens existentes na literatura para resolver esse problema, destacam-se métodos baseados em reconhecimento de pontos-chave que podem ser interpretados como diferentes implementações de um mesmo arcabouço.

O objetivo desta pesquisa de doutorado é desenvolver e avaliar uma versão generalizada desse arcabouço, na qual reconhecimento de pontoschave é substituído por reconhecimento de grafos-chave. O potencial da pesquisa reside na riqueza de informação que um grafo pode apresentar antes e depois de ser reconhecido. A dificuldade da pesquisa reside nos problemas que podem ser causados por essa riqueza, como maldição da dimensionalidade e complexidade computacional.

Três contribuições serão incluídas na tese: a descrição detalhada de um arcabouço para deteç̧ão de objetos baseado em grafos-chave, implementações fiéis que demonstram sua viabilidade e resultados experimentais que demonstram seu desempenho.

Palavras-chave: deteç̧ão de objetos, correspondência de pontos-chave, isomorfismo de grafos, reconhecimento estrutural de padrões. 



\section{Abstract \\ Object detection by keygraph recognition}

Object detection is a classic problem in computer vision, present in applications such as automated surveillance, medical image analysis and information retrieval. Among the existing approaches in the literature to solve this problem, we can highlight methods based on keypoint recognition that can be interpreted as different implementations of a same framework.

The objective of this $\mathrm{PhD}$ thesis is to develop and evaluate a generalized version of this framework, on which keypoint recognition is replaced by keygraph recognition. The potential of the research resides in the information richness that a graph can present before and after being recognized. The difficulty of the research resides in the problems that can be caused by this richness, such as curse of dimensionality and computational complexity.

Three contributions are included in the thesis: the detailed description of a keygraph-based framework for object detection, faithful implementations that demonstrate its feasibility and experimental results that demonstrate its performance.

Keywords: object detection, keypoint correspondences, graph isomorphism, structural pattern recognition. 



\section{Sumário}

Lista de Figuras $\quad 3$

Lista de Tabelas $\quad 5$

1 Introdução 7

1.1 Considerações iniciais . . . . . . . . . . . . . . . . . . . . . . . 7

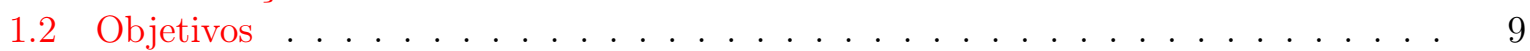

1.3 Contribuições . . . . . . . . . . . . . . . . . . . . . . . . . . . . 10

1.4 Organização do texto . . . . . . . . . . . . . . . . . . . . . 10

2 Revisão da literatura $\quad 11$

2.1 Pontos-chave . . . . . . . . . . . . . . . . . . . . . 11

2.2 Análise estrutural . . . . . . . . . . . . . . . . . . . . . . . . 15

2.3 Análise estrutural de pontos-chave . . . . . . . . . . . . . . . . . . 16

2.4 Precursores de grafos-chave . . . . . . . . . . . . . . . . . 16

3 Arcabouço de grafos-chave $\quad 17$

3.1 Visão geral do arcabouço de grafos-chave . . . . . . . . . . . . . . . . . . . . . 17

3.1 .1 Definição de grafo-chave . . . . . . . . . . . . . . . . . . . . . 18

3.1.2 Definição de correspondência de grafos-chave . . . . . . . . . . . . . . . 18

3.2 Tuplas-chave . . . . . . . . . . . . . . . . . . . . . . 20

3.3 Deteç̧ão de grafos-chave . . . . . . . . . . . . . . . . . . . . . . 22

3.4 Descrição de grafos-chave . . . . . . . . . . . . . . . . . . . . 25

3.5 Seleção de correspondências e estimação de pose . . . . . . . . . . . . . 27

4 Resultados experimentais $\quad 29$

4.1 Implementação . . . . . . . . . . . . . . . . . . . . . . . . . . . . . . . . 29

4.2 Experimento preliminar . . . . . . . . . . . . . . . . . . . . . 29

4.3 Experimento exaustivo . . . . . . . . . . . . . . . . . . . 33

4.4 Detecção em tempo real . . . . . . . . . . . . . . . . . . . . . . . 37

4.5 Aplicação em localização . . . . . . . . . . . . . . . . . . . . . . . . 41

4.6 Aplicação em recuperação . . . . . . . . . . . . . . . . . . . . . . 46

5 Conclusão $\quad 53$

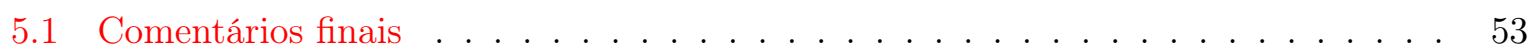

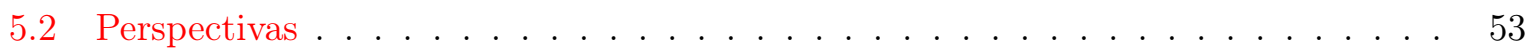

Referências Bibliográficas $\quad 55$ 



\section{Lista de Figuras}

1.1 Exemplos de modelo e cena. . . . . . . . . . . . . . . . . . . . . 7

1.2 Possíveis definições de pose. . . . . . . . . . . . . . . . 7

1.3 Ilustração dos algoritmos baseados em correspondências de pontos-chave . . . . . 8

1.4 Ilustração do arcabouço baseado em correspondências de grafos-chave . . . . . . . 9

2.1 Ilustração do arcabouço de pontos-chave . . . . . . . . . . . . . . . . . . . 12

2.2 Imagens dos trabalhos de Moravec, Harris e Stephens . . . . . . . . . . . . . . . . . . 13

2.3 Imagens do trabalho de Shi e Tomasi . . . . . . . . . . . . . . . . . . . 13

2.4 Imagens do trabalho de Lowe . . . . . . . . . . . . . . . . . . . . . 13

2.5 Imagens do trabalho de Matas et al. . . . . . . . . . . . . . . . . . . . 14

2.6 Imagem do trabalho de Belongie et al. . . . . . . . . . . . . . . . . 15

2.7 Imagem do trabalho de Lowe . . . . . . . . . . . . . . . . . . . . 15

3.1 Ilustração do arcabouço de grafos-chave . . . . . . . . . . . . . . . . . . 18

3.2 Exemplo de multi-comparabilidade . . . . . . . . . . . . . . . . . . . 19

3.3 Exemplo de tuplas-chave . . . . . . . . . . . . . . . . . . . . 22

3.4 As três estruturas escolhidas e suas respectivas matrizes . . . . . . . . . . . 23

3.5 Exemplo de perfil de intensidade . . . . . . . . . . . . . . . . 23

3.6 Potencial dos critérios geométricos para reduzir o número de grafos-chave . . . . 24

3.7 Exemplo de triangulação de Delaunay . . . . . . . . . . . . . . . . . 25

3.8 Obtendo um circuito de quatro vértices . . . . . . . . . . . . . . . . . 25

3.9 Média de perfis de intensidade . . . . . . . . . . . . . . . . . . . 27

3.10 Seleção de correspondências de grafos-chave . . . . . . . . . . . . . . . 27

4.1 Conjunto de imagens bark . . . . . . . . . . . . . . . . . . . . . . . . . . . . 29

4.2 Conjunto de imagens bikes . . . . . . . . . . . . . . . . . . . 30

4.3 Conjunto de imagens boat . . . . . . . . . . . . . . . . 30

4.4 Conjunto de imagens graf . . . . . . . . . . . . . . . . . 30

4.5 Conjunto de imagens leuven . . . . . . . . . . . . . . . . . . . . . . . 31

4.6 Conjunto de imagens trees . . . . . . . . . . . . . . . . . . . 31

4.7 Conjunto de imagens $u b c \ldots \ldots \ldots \ldots$. . . . . . . . . . . . . . . . . . 31

4.8 Conjunto de imagens wall . . . . . . . . . . . . . . . . . . 32

4.9 Pares de imagens utilizados no primeiro experimento . . . . . . . . . . . 32

4.10 Resultados para as duas sequências de medidas do primeiro experimento . . . . . 33

4.11 Modelos para o segundo experimento . . . . . . . . . . . . . . . . 34

4.12 Resultados para as duas sequências de medidas no segundo experimento . . . . . 34

4.13 Resultados para o segundo experimento, especificamente para Hessian-Affine . . . 35

4.14 Resultados para o segundo experimento, especificamente para MSER . . . . . . . 36

4.15 Resultados para as duas sequências de medidas no segundo experimento . . . . . 37

4.16 Resultados para o segundo experimento, especificamente para Hessian-Affine . . . 38 
4.17 Resultados para o segundo experimento, especificamente para MSER . . . . . . . 39

4.18 Capturas de tela da detecção de objeto com uma câmera de laptop fixa. . . . . . . 40

4.19 Capturas de tela da deteç̧ão de objeto com uma câmera PlayStation Eye. . . . . 41

4.20 Exemplos de imagens capturadas pela câmera . . . . . . . . . . . . . . . . . 42

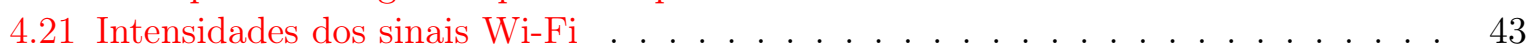

4.22 Exemplos de modelos das placas do corredor . . . . . . . . . . . . . . . . . 43

4.23 Exemplo de fórmula que mapeia razões de área a distâncias . . . . . . . . . . . . 44

4.24 Interface da localização por detecção de placas . . . . . . . . . . . . . . . 45

4.25 Robustez da detecção de uma placa . . . . . . . . . . . . . . . . . . . 45

4.26 Precisão da localização por detecção de placas . . . . . . . . . . . . . . . . 46

4.27 Exemplos da coleção $\mathrm{DB}_{600} \ldots \ldots \ldots \ldots \ldots \ldots \ldots$. . . . . . . . . . . . 48

4.28 Exemplos do Oxford Buildings Dataset . . . . . . . . . . . . . . . . 49

4.29 Gráfico de revocação-precisão para o $\mathrm{DB}_{600} \ldots \ldots \ldots \ldots$. . . . . . . . 50

4.30 Exemplos de histogramas de distância . . . . . . . . . . . . . . . 51

4.31 Comparação dos histogramas de distâncias de arcos . . . . . . . . . . . . . . . 51 


\section{Lista de Tabelas}

2.1 Sequência de passos do arcabouço de pontos-chave . . . . . . . . . . . . . . . . . 11

3.1 Sequência de passos do arcabouço de grafos-chave . . . . . . . . . . . . . . . 17

3.2 Versão assimétrica do arcabouço de grafos-chave . . . . . . . . . . . . . . . 20

3.3 Adaptação da versão assimétrica do arcabouço de grafos-chave a tuplas-chave . . 21 



\section{Capítulo 1}

\section{Introdução}

\subsection{Considerações iniciais}

Detecção de objetos é um problema clássico de visão computacional que definimos em termos gerais da seguinte maneira:

dadas duas imagens, um modelo representando um objeto e uma cena, decidir se existem instâncias do objeto na cena e, se existirem, estimar a pose de cada uma.

A definição de pose varia de acordo com o objetivo da aplicação. A Figura 1.1 mostra exemplos de modelo e cenas e a Figura 1.2 mostra possíveis definições de pose.

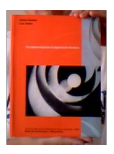

(a)

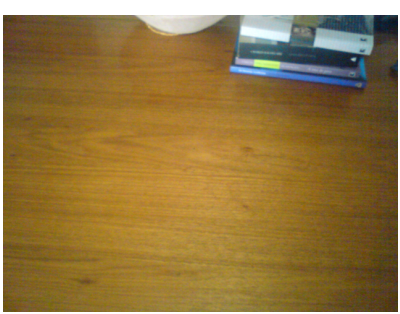

(b)

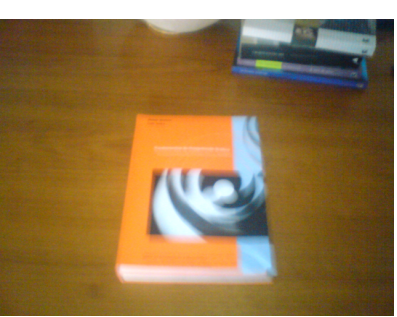

(c)

Figura 1.1. Exemplos de modelo e cena. (a) Modelo representando um livro. (b) Cena na qual não existem instâncias do livro. (c) Cena na qual existe uma instância do livro.

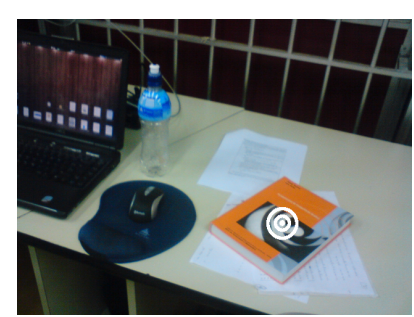

(a)

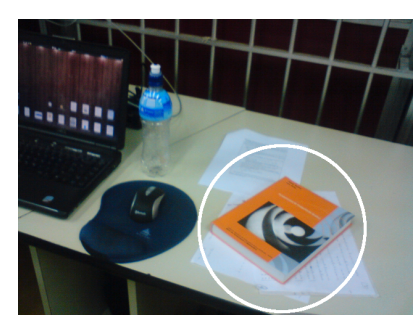

(b)

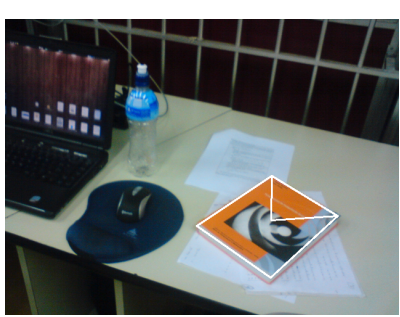

(c)

Figura 1.2. Possíveis definições de pose para o modelo da Figura 1.1. (a) Centroide da instância. (b) Região compacta que contém a instância. (c) Homografia que mapeia o modelo à instância.

Ambas as figuras também evidenciam os desafios do problema: primeiramente, a instância do objeto pode ser completamente diferente do modelo em termos de escala, rotação, perspectiva, brilho e contraste. Além disso, o processo de aquisição das imagens está sujeito a limitações como borramento e ruído. Por fim, a própria cena pode ser arbitrariamente desordenada e conter 
instâncias de outros objetos com aparência similar. Existe inclusive a possibilidade de oclusão: a instância desejada pode estar apenas parcialmente exposta.

Para demonstrar a importância de superar tais desafios, destacamos as seguintes aplicações:

- realidade aumentada, como a renderização realística de elementos virtuais sobre elementos reais em um jogo eletrônico;

- realidade diminuída, como a remoção de objetos específicos em vídeos por motivo de censura ou direito autoral;

- recuperação de imagens baseada em conteúdo, como a busca a partir de outras imagens em vez de palavras-chave;

- acessibilidade, como a orientação de deficientes visuais a partir da identificação de marcos por dispositivos móveis;

Dentre os algoritmos de detecção de objetos disponíveis na literatura, são particularmente bem-sucedidos os baseados em correspondências de pontos-chave [45, 38, 6, 53]. Informalmente, esses baseiam-se em: detectar pontos de interesse no modelo e na cena, selecionar correspondências entre os dois conjuntos de pontos analisando a similaridade de descritores fotométricos e aplicar um algoritmo de ajuste sobre tais correspondências. A Figura 1.3 ilustra o processo.

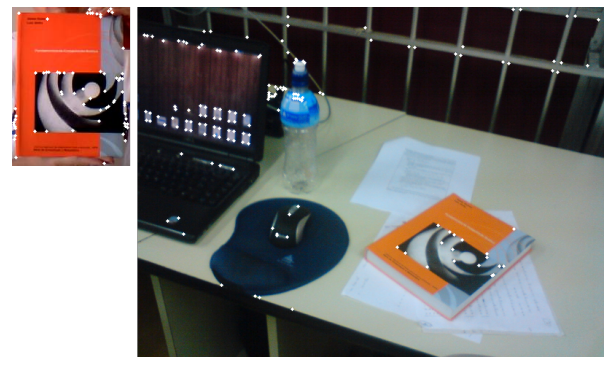

(a)

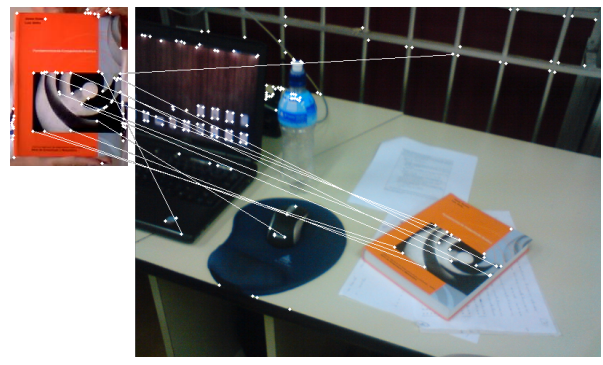

(b)
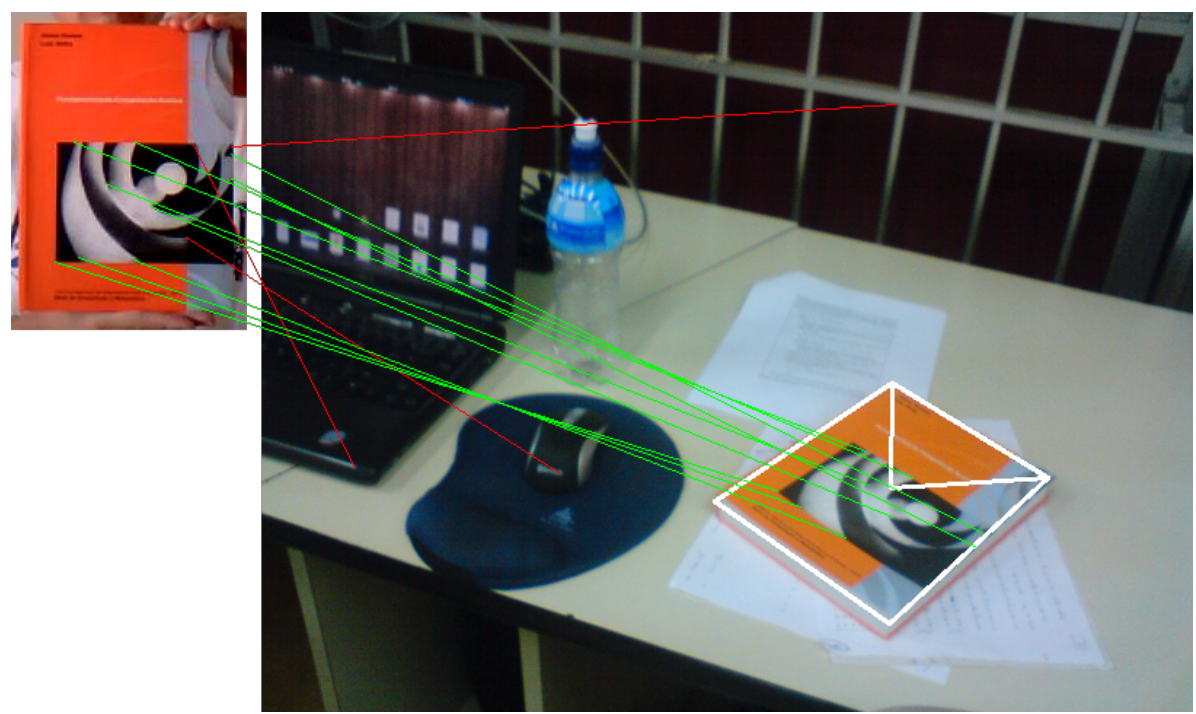

(c)

Figura 1.3. Ilustração dos algoritmos baseados baseados em correspondências de pontos-chave. (a) Pontos de interesse do modelo e da cena. (b) Correspondências entre os dois conjuntos de pontos. (c) Resultado do algoritmo de ajuste: uma homografia e a identificação das correspondências corretas. 
Em particular, a Figura 1.3c ilustra um aspecto fundamental: não é necessário selecionar apenas correspondências corretas, pois as correspondências incorretas podem ser descartadas por algoritmos de ajuste robustos a outliers. Algoritmos como a transformada de Hough [31] e o RANSAC [20] foram especificamente projetados para proporções pequenas de inliers. Essa localidade é a principal vantagem dos pontos-chave: além de garantir robustez natural à oclusão, permite considerar objetos tridimensionais.

De fato, pontos-chave foram bem-sucedidos não apenas em deteç̧ão de objetos, como também em navegação de robôs [52], rastreamento de características [46, 79, 67], correspondência estéreo [46, 48, 78], recuperação de imagens [65], reconstrução 3D [6] e odometria visual [1].

\subsection{Objetivos}

Neste doutorado, propomos uma generalização do arcabouço implementado pelos algoritmos baseados em correspondências de pontos-chave. Tal generalização consiste em substituir pontoschave por grafos cujos vértices são pontos-chave, como ilustrado pela Figura 1.4.
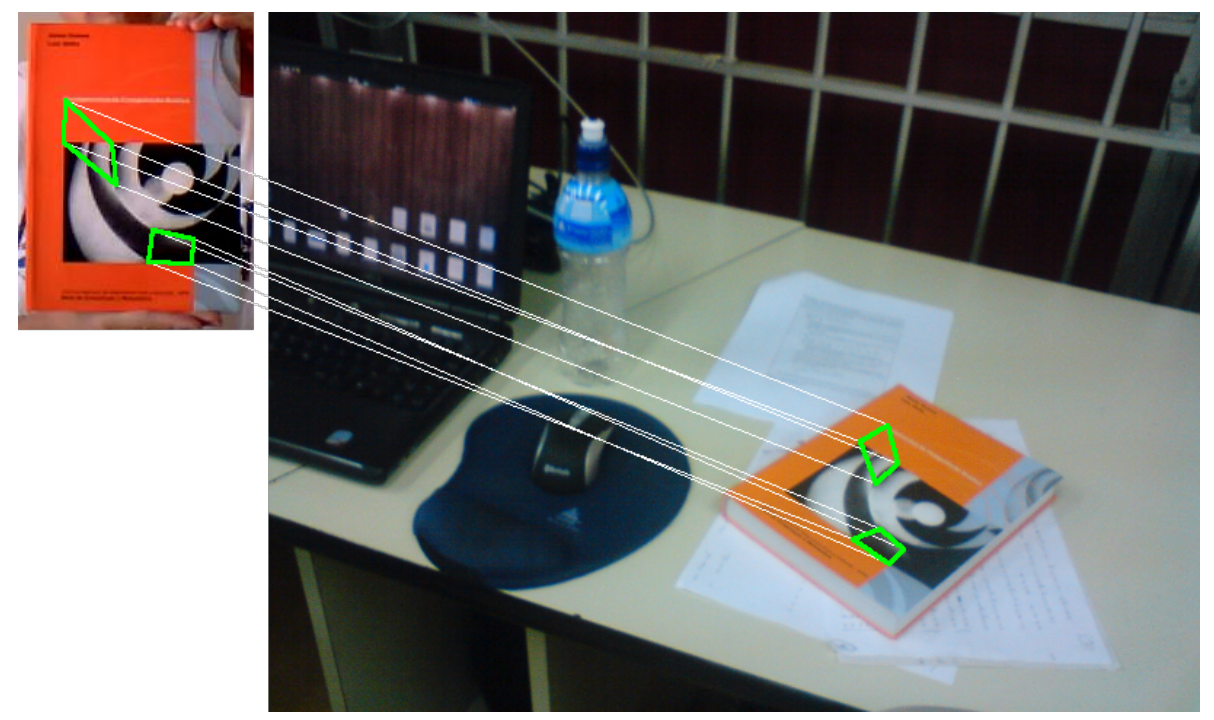

Figura 1.4. Ilustração do arcabouço baseado em correspondências de grafos-chave.

A motivação para essa generalização é explorar informação estrutural que não pode ser obtida a partir da análise individual de vértices. Consideramos duas questões em particular.

1. Podemos explorar informação estrutural para obter correspondências de grafos-chave mais precisas do que correspondências de pontos-chave?

2. Podemos explorar informação estrutural para aumentar a eficiência da estimação de pose?

Por outro lado, o desafio é realizar a substituição por grafos levando em consideração:

1. a possível explosão combinatória, visto que o tamanho do conjunto de grafos pode ser assintoticamente intratável;

2. a possível perda de localidade, visto que os vértices de um grafo podem estar distantes.

Para obter respostas positivas às questões, é necessário formalizar um arcabouço, especificar um algoritmo a partir desse arcabouço, implementar tal algoritmo e validá-lo experimentalmente. 


\subsection{Contribuições}

As contribuições deste doutorado podem ser diretamente mapeadas às necessidades listadas no final da seção anterior.

1. Formalização de um arcabouço de deteç̧ão de objetos baseado em correspondências de grafos-chave. Substituir pontos por grafos no arcabouço original não é trivial, pois mesmo conceitos básicos como grafo-chave e correspondência podem ser definidos de múltiplas maneiras. O desafio é escolher definições que permitam precisão e eficiência, porém sem restringir excessivamente o conjunto de algoritmos que podem ser especificados.

2. Especificação de um algoritmo a partir do arcabouço formalizado. Em particular, especificação suficientemente detalhada para análise de complexidade.

3. Implementação do algoritmo especificado.

4. Validação experimental da implementação.

\subsection{Organização do texto}

A lista apresentada a seguir mostra como o restante do texto está organizado, descrevendo sucintamente o conteúdo dos próximos capítulos.

- O Capítulo 2 apresenta uma revisão da literatura, contendo a formalização do arcabouço para métodos baseados em reconhecimento de pontos-chave e um histórico desses métodos.

- O Capítulo 3 apresenta a formalização do arcabouço para métodos baseados em reconhecimento de grafos-chave, esclarece suas vantagens, propõe estratégias de melhoria e menciona detalhes específicos das implementações que estão sendo desenvolvidas.

- O Capítulo 4 apresenta resultados experimentais dessas implementações, depois de especificar o protocolo sob o qual os testes estão sendo realizados.

- O Capítulo 5 apresenta a conclusão: um resumo das realizações até o momento, um cronograma para as próximas atividades, futuras possibilidades de pesquisa e considerações finais. 


\section{Capítulo 2}

\section{Revisão da literatura}

Neste capítulo, apresentamos uma revisão dos trabalhos que possuem relação com o arcabouço de grafos-chave proposto nesta tese. Como mencionado no Capítulo 1, essa proposta pode ser definida como uma generalização do arcabouço de pontos-chave baseada em análise estrutural. A estrutura do capítulo é estabelecida a partir dessa definição. Primeiramente, apresentamos na Seção 2.1, um breve histórico dos métodos baseados em pontos-chave. Em seguida, mencionamos na Seção 2.2, algumas abordagens particularmente relevantes em análise estrutural. Na Seção 2.3, citamos métodos que se baseiam em analisar pontos-chave estruturalmente mas de maneiras conceitualmente distintas de grafos-chave. Finalmente, descrevemos na Seção 2.4 abordagens conceitualmente similares que podem ser consideradas precursoras diretas dos grafos-chave.

\section{$2.1 \quad$ Pontos-chave}

Para facilitar a apresentação do histórico dos métodos baseados em pontos-chave, vamos descrever o arcabouço mais detalhadamente. A Tabela 2.1 divide em passos a descrição informal dada no Capítulo 1, enquanto a Figura 2.1 ilustra a visão geral.

\begin{tabular}{|l|l|}
\hline 1 & detectar pontos-chave do modelo $\mathcal{P}_{m}$ e pontos-chave da cena $\mathcal{P}_{s}$ \\
\hline 2 & computar o descritor de cada ponto-chave \\
\hline 3 & selecionar correspondências de pontos-chave \\
\hline 4 & estimar a pose utilizando as correspondências selecionadas \\
\hline
\end{tabular}

Tabela 2.1. Sequência de passos do arcabouço de pontos-chave

Mais detalhadamente, o arcabouço pode ser descrito da seguinte maneira:

1. Detecção. Extrair um subconjunto de $\mathbb{N}$ que corresponda a todos os pixels da imagem que satisfaçam certos critérios fotométricos. Na literatura há exemplos de critérios baseados em fórmulas fechadas, procedimentos iterativos e aprendizado computacional. Cabe também mencionar que alguns desses critérios não buscam pontos propriamente ditos: alguns buscam blobs uniformes, definidos por exemplo por elipses, e outros regiões exatas, definidas por um conjunto de pixels que representa o contorno. Nesses casos, pontos podem ser obtidos calculando-se o centroide.

2. Descrição. Para cada ponto-chave, calcular um vetor de características em $\mathbb{R}^{d}$ a partir de uma análise fotométrica da região ao redor do ponto. Na literatura há descritores naturalmente robustos a variações como escala e rotação, mas também há descritores que partem da suposição de que a região foi normalizada. 
3. Seleção. Para cada ponto-chave do modelo $p_{m}$ e cada ponto-chave da cena $p_{s}$, decidir se $p_{m}$ corresponde a $p_{s}$ a partir de seus descritores. Essa conclusão pode ser a partir de uma comparação direta, por exemplo tomando-se a distância euclidiana, ou reconhecimento de padrões, associando cada ponto do modelo a uma classe.

4. Estimação. Calcular a função que define a pose partindo da suposição de que as correspondências selecionadas representam amostragens dessa função. Nenhum trabalho da literatura supõe que a seleção é perfeita: é necessário que o procedimento de ajuste seja robusto a outliers. Logo, esse passo permite não apenas estimar a pose, como também saber exatamente quais correspondências foram incorretamente selecionadas.

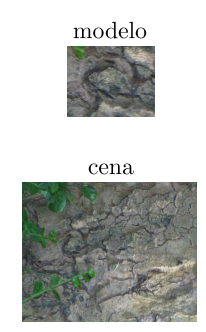

(a)

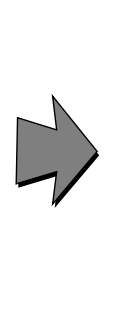

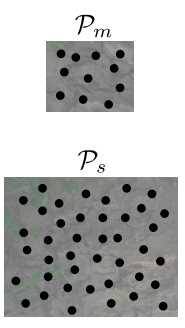

(b)

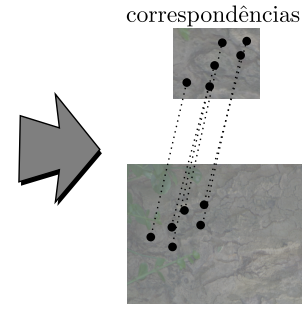

(c)

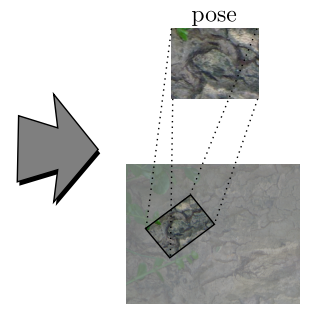

(d)

Figura 2.1. Ilustração do arcabouço de pontos-chave. (a) Modelo e cena. (b) Detecção dos conjuntos de pontos-chave $\mathcal{P}_{m}$ e $\mathcal{P}_{s}$. (c) Seleção de correspondências. (d) Estimação de pose.

A maioria dos trabalhos da literatura de pontos-chave não apresenta algoritmos novos para todos os passos. Normalmente, eles se baseiam em algoritmos previamente descritos, mas em contextos ou aplicações diferentes. Em particular, a maioria não apresenta ideias significativamente novas para estimação de pose. Podemos, portanto, dividir o histórico entre os três primeiros passos: detectores, descritores e algoritmos para seleção de correspondências.

\section{Detectores}

A revisão a seguir busca enfatizar popularidade, importância histórica e estado da arte. Para uma discussão mais exaustiva, recomendamos o estudo comparativo de Mikolajczyk et al. [51] e a revisão de Tuytelaars e Mikolajczyk [80].

Um dos primeiros detectores de pontos-chave foi apresentado em 1980 por Moravec [52], como parte de um sistema automatizado de navegação para robôs. Para esse propósito, eram particularmente interessantes os pontos cuja vizinhança apresentasse variação significativa em todas as direções. Moravec mediu essa variação, comparando várias janelas ao redor dos pontos, e observou que sob tal critério os pontos-chave correspondiam a cantos. Em 1988, Harris e Stephens [27] refinaram essas ideias a partir de uma modelagem matemática baseada em autovalores e desenvolveram um detector de cantos rápido e robusto, cuja aplicação ainda pode ser vista em muitos trabalhos atuais. A Figura 2.2 mostra imagens desses trabalhos.

Na década de 90, outro detector foi apresentado como parte do algoritmo de rastreamento KLT [46, 79]. Esse algoritmo consiste em rastrear pontos estimando o deslocamento das janelas ao redor deles. Tal estimativa é obtida a partir de um método iterativo que utiliza a diferença entre janelas como custo a ser minimizado. A partir da modelagem matemática desse custo, formalizou-se um critério cujo propósito é selecionar os pontos cujas janelas são adequadas para rastreamento. Tal critério foi refinado por Shi e Tomasi [67] e tornou-se a base do detector Good Features To Track. A Figura 2.3 mostra imagens desse trabalho.

Os detectores citados até o momento são adequados para muitas aplicações, mas compartilham uma limitação significativa: por serem baseados na análise de uma vizinhança de tamanho 


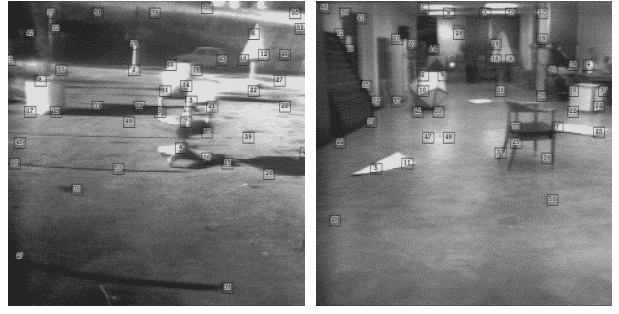

(a)

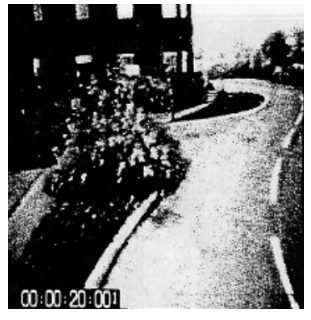

(b)

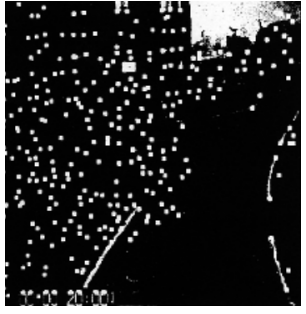

Figura 2.2. Imagens dos trabalhos de Moravec [52] e Harris e Stephens [27]. (a) Resultados da aplicação do detector de Moravec sobre duas imagens distintas. (b) Entrada e saída, respectivamente, do detector de Harris e Stephens.
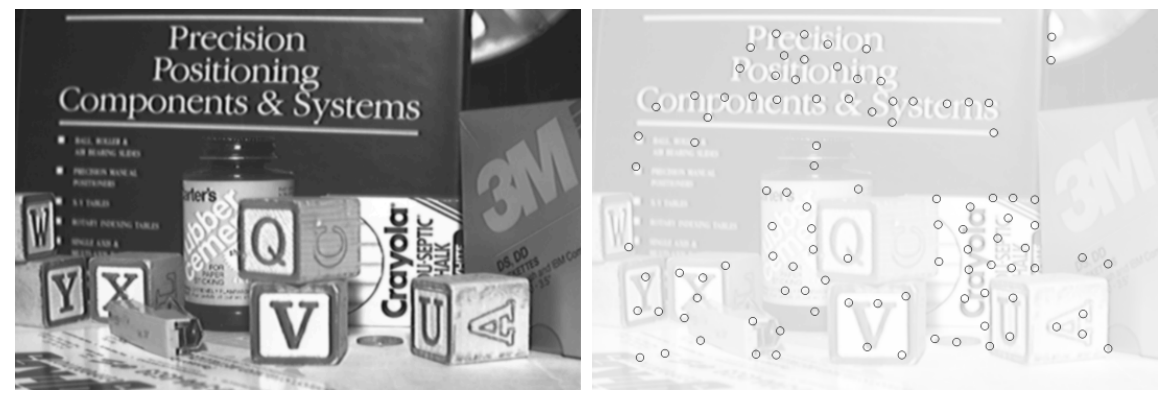

Figura 2.3. Imagens do trabalho de Shi e Tomasi [67]. Entrada e saída do detector de pontos Good Features To Track.

fixo, não são robustos a variações de escala. Uma abordagem natural para evitar esse problema é unir conjuntos de pontos-chave do modelo em diferentes escalas [16, 18], mas essa abordagem resulta em conjuntos de pontos-chave densos e redundantes.

Os primeiros passos para superar essa limitação foram dados por Lindeberg [40, 42], que utilizou a teoria de espaço de escalas [41] para não apenas detectar pontos-chave independentemente de escala, como também associar um valor de escala a cada ponto. Partindo da mesma ideia, Lowe [45] propôs um algoritmo eficiente baseado na seleção de pontos extremos na pirâmide de escalas gerada por diferenças de gaussianas. A Figura 2.4 mostra imagens desse trabalho.
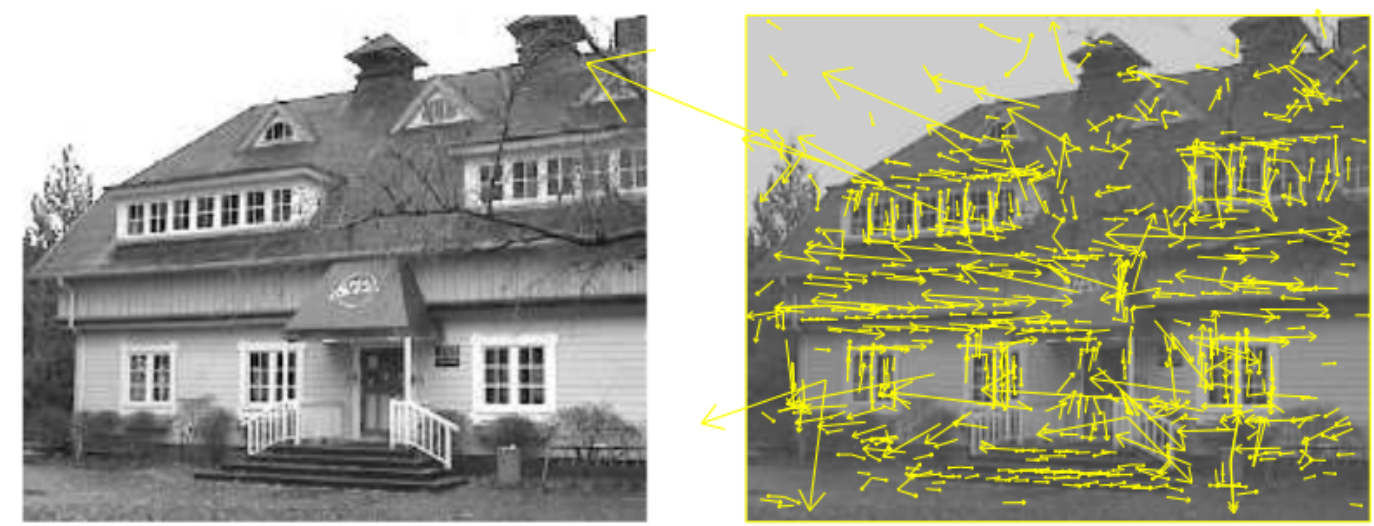

Figura 2.4. Imagens do trabalho de Lowe [45], baseado na seleção de pontos extremos do espaço de escalas. O tamanho das setas representa as escalas características dos pontos.

Independentemente, Mikolajczyk e Schmid [49] também se inspiraram na teoria de espaços de escala para desenvolver um algoritmo interativo de seleção de escala. Combinando esse algoritmo com o detector de Harris e Stephens, eles desenvolveram o detector Harris-Laplace. Combinando- 
o com matrizes hessianas, eles desenvolveram o detector Hessian-Laplace. Posteriormente, esse algoritmo iterativo foi estendido para se tornar invariante também a transformações afins. Essa extensão resultou nos algoritmos Harris-Affine e Hessian-Affine.

Paralelamente a todos os métodos diferenciais mencionados acima, também houve o desenvolvimento de métodos baseados em variação de intensidade, como os detectores de cantos SUSAN [72] e FAST [64], métodos baseados em bordas como o Edge-Based Regions (EBR) [81] e métodos baseados em intensidade como o Intensity-Based Regions (IBR) [82] e o Maximally Stable Extremal Regions (MSER) [48]. O último, em particular, tornou-se bastante popular nos últimos anos devido a sua robustez e rapidez. Informalmente, o MSER consiste em selecionar regiões estáveis cujos pontos são todos mais claros ou todos mais escuros que os pontos ao redor. A Figura 2.5 mostra imagens desse trabalho.
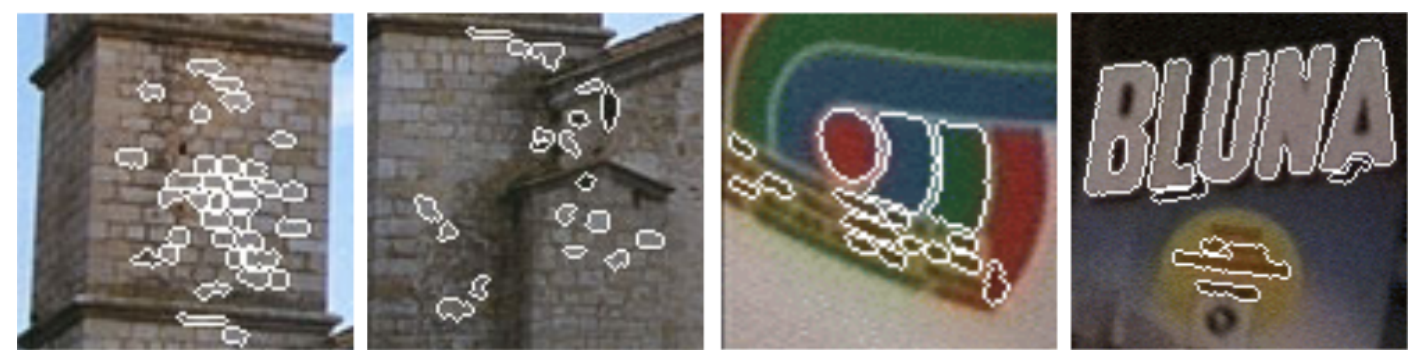

Figura 2.5. Imagens do trabalho de Matas et al. [48] Alguns exemplos de regiões selecionadas pelo detector MSER

Muitos dos detectores recentes foram desenvolvidos com um forte foco em eficiência. Alguns exemplos desses são o SURF [6], o CenSurE [1] e o SUSurE [19].

\section{Descritores}

O histórico dos descritores é significativamente mais complexo que o histórico dos detectores: como a vizinhança de um ponto é um caso particular de imagem, qualquer procedimento para extrair características de uma imagem pode ser considerado um descritor, incluindo procedimentos clássicos como histogramas de cores, momentos estatísticos e transformada de Fourier.

Considerando apenas os descritores que foram desenvolvidos no contexto de reconhecimento de pontos, podemos citar o trabalho seminal de Schmid e Mohr [65] que apresentou um descritor invariante baseado em derivadas. Também merece destaque o conhecido trabalho de Belongie, Malik e Puzicha [7]e que apresentou o Shape Context. Esse último é bastante popular em aplicações que envolvem análise de formas em imagens binárias e consiste em um histograma de distribuição espacial de pontos. A Figura 2.6 mostra uma imagem desse trabalho.

Um dos marcos mais importantes na história dos descritores, no entanto, foi o Scale-Invariant Feature Transform (SIFT) de Lowe [45]. Esse descritor consiste em um histograma de gradientes, ilustrado na Figura 2.7, cuja eficácia foi comprovada em muitas aplicações diferentes. Alguns dos trabalhos desenvolvidos posteriormente, como o PCA-SIFT [34] e o Gradient Location and Orientation Histogram (GLOH) [50], foram diretamente baseados nas ideias que ele introduziu.

De fato, diversas pesquisas recentes como o SURF [6], o MU-SURF [1], o SUSurE [19] e o $D A I S Y$ [78] podem ser interpretados como versões melhoradas do SIFT, com forte ênfase em velocidade. Para uma revisão mais detalhada, recomendamos o estudo comparativo de Mikolajczyk and Schmid [50]. 


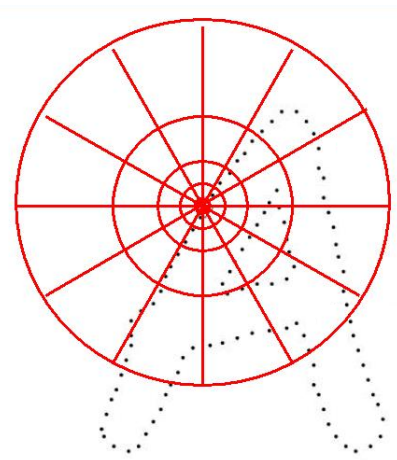

Figura 2.6. Imagem do trabalho de Belongie et al. [7]: exemplo de shape context. Cada região corresponde a um bin do histograma e o valor associado ao bin é o número de pontos que estão contidos nela.

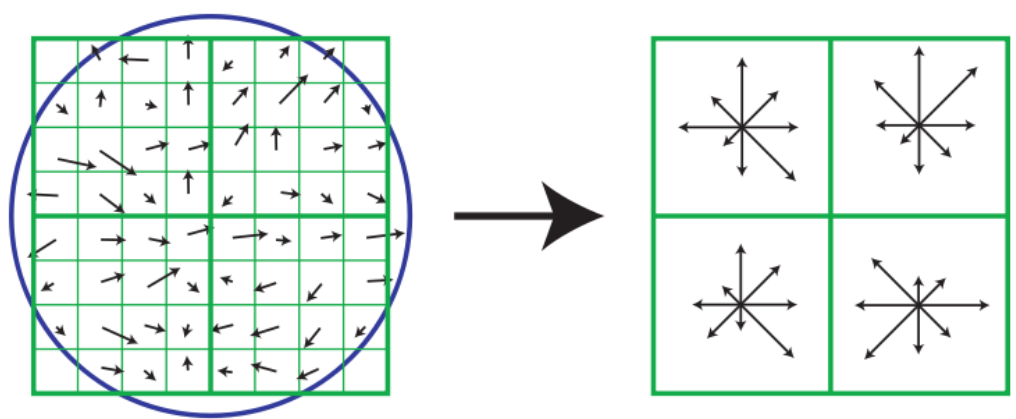

Figura 2.7. Imagem do trabalho de Lowe [45]: descrição do descritor SIFT. À esquerda, uma vizinhança de tamanho $8 \times 8$ e o gradiente em cada ponto. À direita, uma partição dessa vizinhança em quatro regiões e o histograma de gradientes correspondente a cada uma delas. A partir da união dos 4 histogramas com 8 bins, obtemos um descritor cuja dimensão é 32.

\section{Seleção de correspondências}

A maioria dos trabalhos da literatura seleciona correspondências simplesmente limiarizando o valor dado por uma função de dissimilaridade. Geralmente, essa função é uma distância tradicional, como a Euclidiana ou a Mahalanobis. Mas cabe mencionar o trabalho de Rabin et al. [63], que obteve melhorias significativas no desempenho de um descritor SIFT ao utilizar uma versão circular da Earth Mover's Distance.

As abordagens que não utilizam limiarização são baseadas em aprendizado computacional. Dois exemplos conhecidos são o trabalho de Rosten e Drummond [64] que utiliza árvores de decisão e o trabalho de Lepetit e Fua [38] que utiliza árvores aleatorizadas. Essas abordagens são particularmente relevantes porque supõem disponibilidade de tempo para treinamento. Fazemos a mesma suposição no Capítulo 3.

\section{$2.2 \quad$ Análise estrutural}

De maneira geral, a proposta do arcabouço de grafos-chave pode ser resumida como considerar uma estrutura de partes em vez de partes individuais. Essa ideia foi utilizada com sucesso em abordagens estatísticas para categorização de imagens como o modelo de constelação proposto por Weber et al. [85], os spatial priors propostos por Crandall et al. [15], a árvore multiescala proposta por Bouchard e Triggs [9] e os modelos flexíveis esparsos propostos por Carneiro e Lowe [13]. A abordagem de Leordeanu et al. [37] é particularmente relevante por compartil- 
har a ideia genérica de utilizar descritores que são individualmente robustos e coletivamente discriminativos.

\subsection{Análise estrutural de pontos-chave}

A ideia de explorar informação relativa e estrutural em correspondência de pontos-chave não é nova. O artigo seminal de Schmid e Mohr [65], por exemplo, já reconhecia a importância de critérios geométricos para seleção de correspondências. Um exemplo mais recente é o popular descritor shape context [7], originalmente definido como um histograma de posições relativas de pontos. A diferença desta tese é obter a informação a partir de grafos com tamanho fixo, enquanto os autores mencionados consideram vizinhanças com tamanho variável.

Estruturas de pontos-chave também foram bem-sucedidas em recuperação de imagem baseada em conteúdo, particularmente em trabalhos baseados em palavras visuais [71, 60], nos quais descritores são quantizados em um vocabulário visual a partir de classificação não-supervisionada. Esse processo também é conceitualmente relacionado ao Capítulo 3: a classificação pode ser interpretado como uma simplificação dos descritores, enquanto as estruturas podem ser interpretadas como uma tentativa de utilizar coletividade para recuperar a distintividade perdida na quantização. Exemplos relevantes são os doublets propostos por Sivic et al. [70], as frases visuais propostas por Yuan et al. [86], o TSR proposto por Punitha e Guru [62] e o $\Delta$-TSR proposto Hoang et al. [30]. Outra abordagem bem-sucedida baseada em introduzir uma estrutura para compensar a limitação dos descritores é o casamento de pirâmides espaciais [36].

Por fim, há os trabalhos que utilizam grafos cujos vértices são pontos-chave. Podemos citar o trabalho de Tang e Tao [75], que consiste em aplicar procedimentos de casamento de grafos [35, 12, 33] sobre grafos cujos vértices são pontos-chave SIFT [44, 45] para detectar objetos, e o trabalho de Sirmacek e Unsalan [69], que consiste em aplicar procedimentos de corte de grafos também sobre grafos cujos vértices são pontos-chave SIFT para detectar áreas urbanas em fotografias aéreas. Essas abordagens, no entanto, são globais: o objetivo é obter um único grafo grande. Nossa abordagem, em contraste, é local: o objetivo é obter múltiplos grafos pequenos.

\subsection{Precursores de grafos-chave}

Considerando tal localidade, os artigos de Tell e Carlsson [76, 77] e Kanazawa e Uemura [32] estão mais próximos. O primeiro não apenas introduziu a ideia de computar descritores a partir de perfis de intensidade de pares de pontos-chave, que utilizamos no Capítulo 3, mas também mostrou a importância de pares de pontos-chave, que utilizamos na última seção do Capítulo 3. As correspondências de pares de Tell e Carlsson e as correspondências de triplets de Kanazawa e Uemura podem ser consideradas precursores de correspondências de grafos-chave, mas sua utilidade para estimação de pose é limitada por uma tabela de votação que as transforma em um conjunto ordinário de correspondências de pontos-chave independentes. Os Natural 3D Markers (N3M) propostos por Hinterstoisser et al. [29] não possuem essa limitação e são talvez o conceito mais próximo de grafos-chave atualmente disponível na literatura. No entanto, Hinterstoisser et al. não analisam Natural 3D Markers diretamente como fazemos com grafos-chave: em vez disso, eles selecionam correspondências de pontos-chave independentes e verificam quais correspondências de N3M são implícitas por essas. 


\section{Capítulo 3}

\section{Arcabouço de grafos-chave}

\subsection{Visão geral do arcabouço de grafos-chave}

A comparação entre a Tabela 2.1 e a Tabela 3.1 ilustra a analogia entre o arcabouço de pontos-chave existente e o arcabouço de grafos-chave proposto nesta tese.

\begin{tabular}{|l|l|}
\hline 1 & $\begin{array}{l}\text { detectar pontos-chave do modelo } \mathcal{P}_{m} \text { e pontos-chave da cena } \mathcal{P}_{s} \\
\text { detectar grafos-chave do modelo } \mathcal{G}_{m} \text { e grafos-chave da cena } \mathcal{G}_{s}\end{array}$ \\
\hline 2 & computar o descritor de cada grafo-chave \\
\hline 3 & selecionar correspondências de grafos-chave \\
\hline 4 & estimar a pose utilizando as correspondências selecionadas \\
\hline
\end{tabular}

Tabela 3.1. Sequência de passos do arcabouço de grafos-chave

A numeração representa os quatro passos que ambos os arcabouços analogamente possuem: detecção, descrição, seleção e estimação. A detecção de pontos-chave é a primeira tarefa de ambos os arcabouços e a única tarefa que não exige adaptação para o arcabouço de grafos-chave: podemos utilizar diretamente os algoritmos existentes.

A Figura 3.1 ilustra a sequência de passos definida pelo arcabouço proposto. Mais detalhadamente, o arcabouço pode ser descrito da seguinte maneira:

1. Detecção. Depois da extração de pontos-chave, extrair um subconjunto de grafos cujos vértices são pontos-chave que satisfaçam certos critérios combinatórios e geométricos. Esse passo é detalhado na Seção 3.3.

2. Descrição. Para cada grafo-chave, calcular um conjunto de vetores de características. $\mathrm{O}$ arcabouço não impede que apenas um vetor, que descreve o grafo globalmente, seja considerado. Mas nesse trabalho em particular calculamos um conjunto de descrições locais. Esse passo é detalhado na Seção 3.4.

3. Seleção. Para cada grafo-chave do modelo $g_{m}$ e cada grafo-chave da cena $g_{s}$, decidir se $g_{m}$ corresponde a $g_{s}$ a partir de seus conjuntos de descritores. Se esses conjuntos contêm mais que um descritor, a comparação pode ser global ou local. Comparações globais tendem a ser mais robustas, enquanto comparações locais tendem a ser mais rápidas porque permitem descartar correspondências sem que todos os descritores sejam analisados. Esse passo é detalhado na Seção 3.5.

4. Estimação. Esse passo é quase igual ao do arcabouço de pontos-chave, mas a diferença fundamental está no fato de que uma única correspondência de grafos-chave pode gerar múltiplas amostragens da função a ser estimada. Esse passo é detalhado na Seção 3.5. 


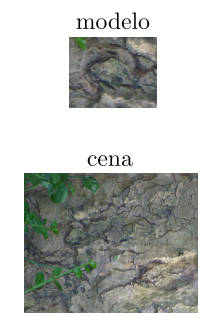

(a)

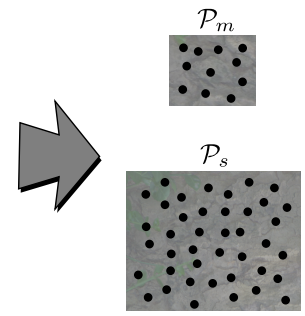

(b)

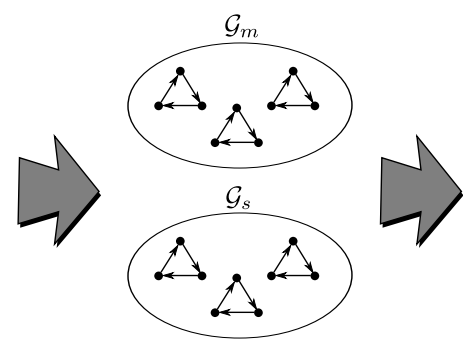

(c)

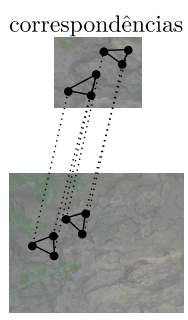

(d)

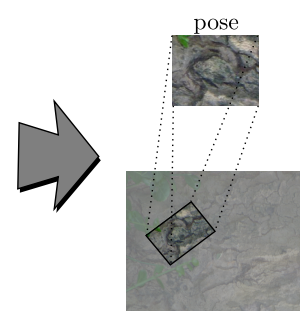

(e)

Figura 3.1. Ilustração do arcabouço de grafos-chave. (a) Modelo e cena. (b) Detecção dos conjuntos de pontos-chave $\mathcal{P}_{m}$ e $\mathcal{P}_{s}$. (c) Deteç̧ão dos conjuntos de grafos-chave $\mathcal{G}_{m}$ e $\mathcal{G}_{s}$. (d) Seleção de correspondências. (e) Estimação de pose.

Em nossa implementação, um descritor não é global em relação ao grafo: computamos descritores locais e selecionamos correspondências por análise parte-a-parte.

\subsubsection{Definição de grafo-chave}

Grafos-chave são grafos dirigidos isomorfos cujos vértices são pontos-chave. Mais formalmente:

- cada grafo-chave é um $\operatorname{par}(\mathcal{V}, \mathcal{A})$, onde o conjunto de vértices $\mathcal{V}$ é um subconjunto de pontos-chave e o conjunto de $\operatorname{arcos} \mathcal{A}$ é um subconjunto de $\{(v, w): v, w \in \mathcal{V}$ e $v \neq w\}$;

- para quaisquer grafos-chave $G_{1}=\left(\mathcal{V}_{1}, \mathcal{A}_{1}\right)$ e $G_{2}=\left(\mathcal{V}_{2}, \mathcal{A}_{2}\right)$, existe uma bijeção $\iota: \mathcal{V}_{1} \rightarrow \mathcal{V}_{2}$ com preservação de arcos: $(a, b) \in \mathcal{A}_{1}$ se e somente se $(\iota(a), \iota(b)) \in \mathcal{A}_{2}$. Tal bijeção é chamada de isomorfismo de $G_{1}$ a $G_{2}$.

A exigência de isomorfismo é nossa solução proposta para o problema de comparabilidade: diferente de um par de pontos, um par de grafos pode apresentar diferenças estruturais e portanto exige critérios estruturais para podermos decidir se é comparável. Propomos a bijeção como critério para intencionalmente evitar o mapeamento de múltiplos pontos-chave do modelo a um único ponto-chave da cena. Isso contrasta, por exemplo, com trabalhos nos quais grafos de super-segmentação são mapeados a grafos de segmentação [14]: em tais trabalhos, sobrejeções são mais adequadas. O critério de preservação de arcos, por sua vez, evita mapear um arco a um par que não é um arco. Isso garante a análise parte-a-parte previamente mencionada: o isomorfismo estabelece qual vértice do modelo deve ser comparado a cada vértice da cena e qual arco do modelo deve ser comparado a cada arco da cena.

Note que o arcabouço de grafos-chave é uma generalização do arcabouço de pontos-chave: um ponto-chave por ser interpretado como um grafo-chave com um único vértice e de um grafo com apenas um vértice a outro existe sempre um isomorfismo.

\subsubsection{Definição de correspondência de grafos-chave}

Uma correspondência de grafos-chave é uma tripla $\left(G_{m}, G_{s}, \iota\right)$, onde $G_{m}$ é um grafo-chave do modelo, $G_{s}$ é um grafo-chave da cena e $\iota$ é um isomorfismo de $G_{m}$ a $G_{s}$. Especificar o isomorfismo é nossa solução proposta para o problema de multi-comparabilidade: de um grafo a outro pode existir mais do que um isomorfismo. A Figura 3.2 mostra um exemplo.

Em contraste, uma correspondência de pontos-chave é simplesmente um par $\left(p_{m}, p_{s}\right)$, onde $p_{m}$ é um ponto-chave do modelo e $p_{s}$ é um ponto-chave da cena. Note que a correspondência de 

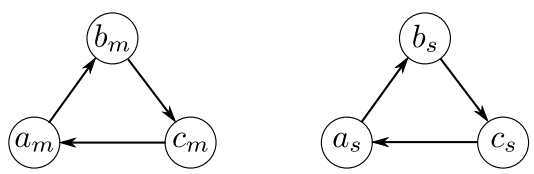

(a)
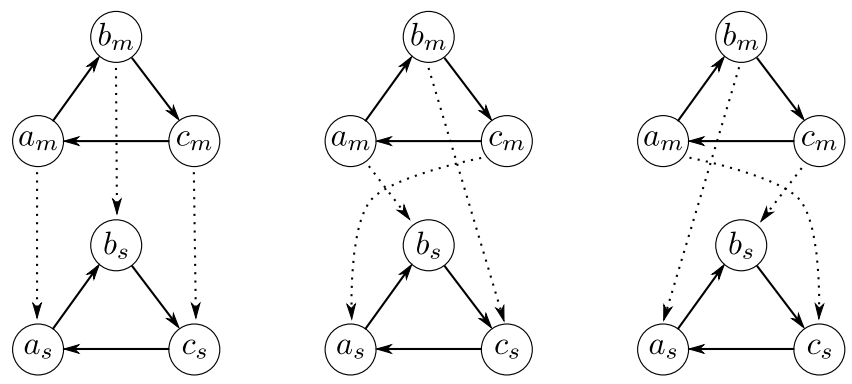

(b)
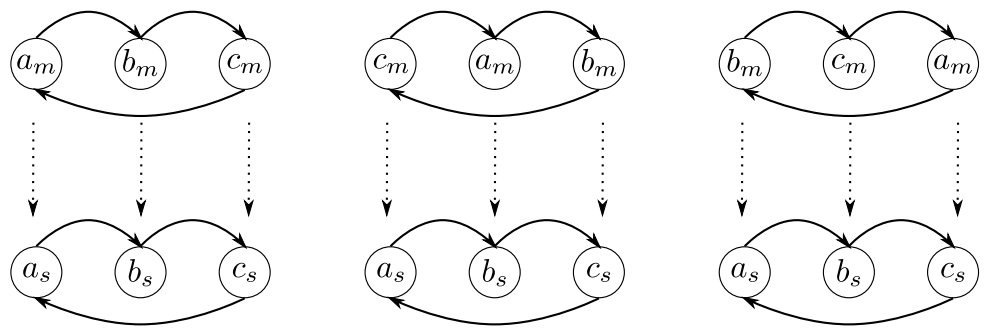

(c)

Figura 3.2. Exemplo de multi-comparabilidade. (a) Um grafo-chave do modelo com vértices $a_{m}, b_{m}, c_{m}$ e um grafo-chave da cena com vértices $a_{s}, b_{s}, c_{s}$. (b) Representação visual de três isomorfismos do grafo-chave do modelo ao grafo-chave da cena: para cada isomorfismo $\iota$, a seta tracejada de um vértice do modelo $v$ a um vértice da cena $w$ ilustra que $\iota(v)=w$. (c) A mesma representação, após reposicionar os vértices para enfatizar preservação de arcos.

grafos-chave $\left(G_{m}, G_{s}, \iota\right)$ implica o conjunto de correspondências de pontos-chave

$$
\left\{(v, \iota(v)): v \text { é um vértice de } G_{m}\right\}
$$

e portanto um conjunto de correspondências de grafos-chave $\Gamma$ implica o conjunto de correspondências de pontos-chave

$$
\Pi:=\bigcup_{\left(G_{m}, G_{s}, \iota\right) \in \Gamma}\left\{(v, \iota(v)): v \text { é um vértice de } G_{m}\right\}
$$

A primeira implicação é particularmente relevante para estimação de pose usando RANSAC, como mostrado na Seção 3.5, e a segunda implicação é particularmente relevante para analisar nossos resultados experimentais, como mostrado no Capítulo 4.

Em nossa implementação, supomos poucos modelos e muitas cenas: isso é aceitável para aplicações como rastreamento em vídeo e recuperação de imagem baseada em conteúdo. Sob essa suposição, detectar grafos-chave do modelo, computar seus respectivos descritores e armazenar para uso subsequente é mais adequado que repetir os processos de detecção e descrição para cada cena. Portanto, implementamos a versão assimétrica do arcabouço vista na Tabela 3.2.

Também supomos disponibilidade de tempo para esse armazenamento: apenas a seleção de correspondências e a estimação de pose devem ser tão rápidas quanto possível. Tal suposição nos permite processar os grafos-chave do modelo e seus respectivos descritores para tornar a seleção de 


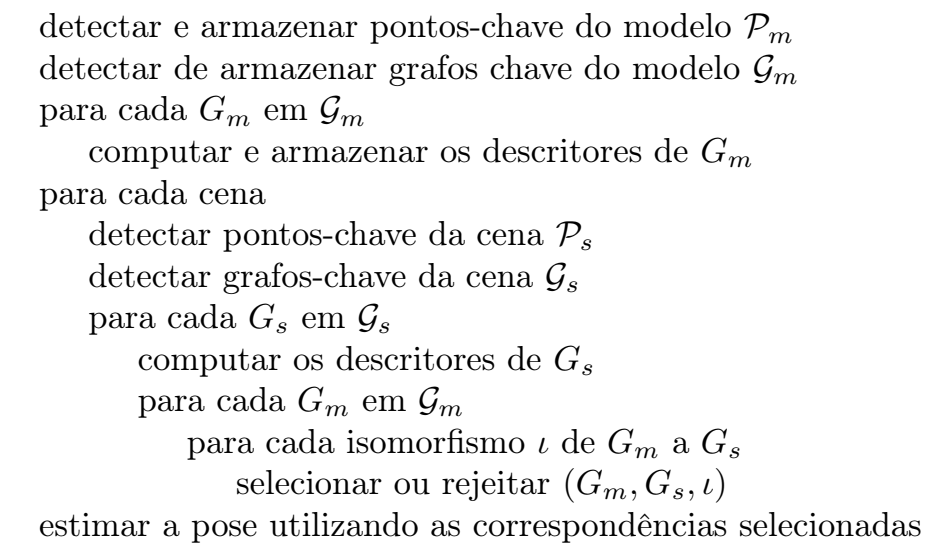

Tabela 3.2. Versão assimétrica do arcabouço de grafos-chave

correspondências mais rápida. Esse paradigma foi bem-sucedido na literatura de correspondência de pontos-chave, em particular em trabalhos baseados em estruturas de indexação [44, 45] e aprendizado de máquina [38, 64].

Portanto, ao longo desta tese nós priorizamos exaustividade quando extraindo dados do modelo e priorizamos velocidade quando extraindo dados da cena. Tal paradigma pode ser resumido como a seguir:

- sacrificar, por velocidade, a maior parte da informação da cena;

- extrair exaustivamente o máximo de informação possível do modelo, para garantir que toda informação da cena referente a uma instância do objeto possa ser mapeada ao modelo.

Isso é particularmente relevante para a detecção de grafos-chave, como visto na Seção 3.3, e também é relevante na Seção 3.2.

\subsection{Tuplas-chave}

Dado um conjunto de grafos-chave do modelo e um conjunto de grafos-chave da cena, obter correspondências não é trivial porque a bijeção do conjunto de vértices de um grafo do modelo ao conjunto de vértices de um grafo da cena pode não ser um isomorfismo. Na Figura 3.2, por exemplo, os três isomorfismos representam apenas metade das seis bijeções possíveis. Isso causa um problema:

- por um lado, a verificação exaustiva de todas as bijeções é cara: se os grafos-chave possuem $k$ vértices, existem $k$ ! bijeções possíveis;

- por outro lado, um isomorfismo a um grafo da cena não pode ser armazenado quando apenas grafos do modelo estão disponíveis.

Para resolver esse problema, introduzimos o conceito de tuplas-chave. Seja $G=(\mathcal{V}, \mathcal{A})$ um grafo-chave com $k$ vértices, $\left(v_{1}, \ldots, v_{k}\right)$ uma ordenação de $\mathcal{V}$ e $\sigma$ uma matriz $k \times k$ binária. Dizemos que $\left(v_{1}, \ldots, v_{k}\right)$ é uma tupla-chave de $G$ em relação a $\sigma$ se

$$
\sigma_{i j}= \begin{cases}1 & \text { se }\left(v_{i}, v_{j}\right) \text { pertence a } \mathcal{A} \\ 0 & \text { caso contrário. }\end{cases}
$$

Em outras palavras, $\sigma$ estabelece para cada $i, j$ se há um arco em $G$ do $i$-ésimo ao $j$-ésimo vértice da tupla-chave. Na Figura 3.2, por exemplo, $\left(a_{m}, b_{m}, c_{m}\right),\left(c_{m}, a_{m}, b_{m}\right),\left(b_{m}, c_{m}, a_{m}\right)$ são 


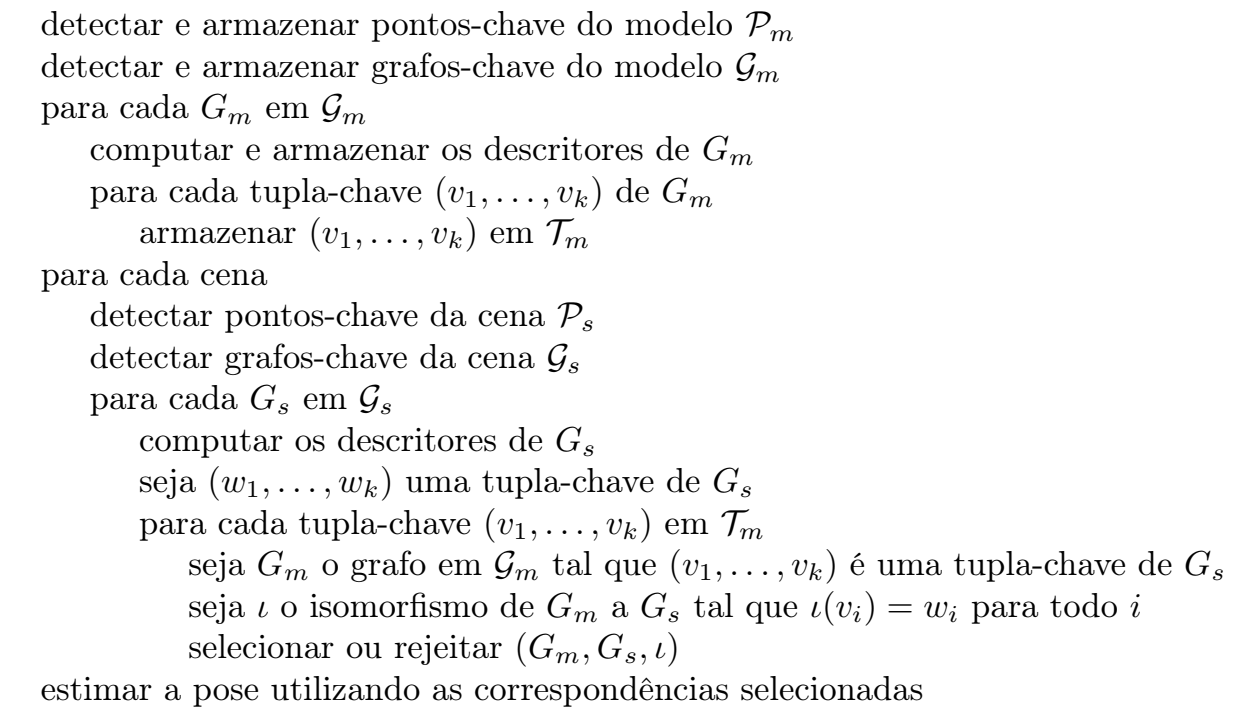

Tabela 3.3. Adaptação da versão assimétrica do arcabouço de grafos-chave a tuplas-chave.

tuplas-chave do grafo-chave do modelo em relação a

$$
\left[\begin{array}{lll}
0 & 1 & 0 \\
0 & 0 & 1 \\
1 & 0 & 0
\end{array}\right]
$$

porque essa matriz estabelece que existem arcos do primeiro ao segundo vértice, do segundo ao terceiro vértice e do terceiro ao primeiro vértice.

A partir da definição de isomorfismo e da definição de tuplas-chave, é simples provar a seguinte proposição.

Proposição. Sejam $G_{m}=\left(\mathcal{V}_{m}, \mathcal{A}_{m}\right), G_{s}=\left(\mathcal{V}_{s}, \mathcal{A}_{s}\right)$ grafos-chave, $\sigma$ uma matriz, $\left(w_{1}, \ldots, w_{k}\right)$ uma tupla-chave de $G_{s}$ em relação a $\sigma$ e $\mathcal{T}$ o conjunto de tuplas-chave de $G_{m}$ em relação a $\sigma$. Então uma bijeção $\iota: \mathcal{V}_{m} \rightarrow \mathcal{V}_{s}$ é um isomorfismo de $G_{m}$ a $G_{s}$ se e somente se existe uma tupla-chave $\left(v_{1}, \ldots, v_{k}\right)$ em $\mathcal{T}$ tal que $\iota\left(v_{i}\right)=w_{i}$ para todo $i$.

Isso permite um procedimento trivial para obter todos os isomorfismos de um grafo-chave do modelo $G_{m}$ a um grafo-chave da cena $G_{s}$ dada uma matriz $\sigma$ :

1. seja $\mathcal{T}_{m}$ o conjunto de todas as tuplas-chave de $G_{m}$ em relação a $\sigma$;

2. seja $\left(w_{1}, \ldots, w_{k}\right)$ uma tupla-chave de $G_{s}$ em relação a $\sigma$;

3. para cada tupla-chave $\left(v_{1}, \ldots, v_{1}\right)$ em $\mathcal{T}_{m}$, seja $\iota$ a bijeção de $G_{m}$ a $G_{s}$ tal que $\iota\left(v_{i}\right)=w_{i}$ para todo $i$. Pela proposição, essa bijeção é um isomorfismo.

Tal procedimento encaixa-se adequadamente no paradigma de priorizar exaustividade quando extraindo dados do modelo e priorizar velocidade quando extraindo dados da cena: o Passo 1 considera todas as tuplas-chave do modelo, enquanto o Passo 2 escolhe uma única tupla-chave da cena. A proposição garante que a escolha pode ser arbitrária.

A Figura 3.3 mostra um exemplo de tuplas-chave e a Tabela 3.3 mostra uma adaptação do arcabouço assimétrico a elas.

Note que essa adaptação substituiu um laço duplo nos grafos-chave e isomorfismos por um único laço nas tuplas-chave. 

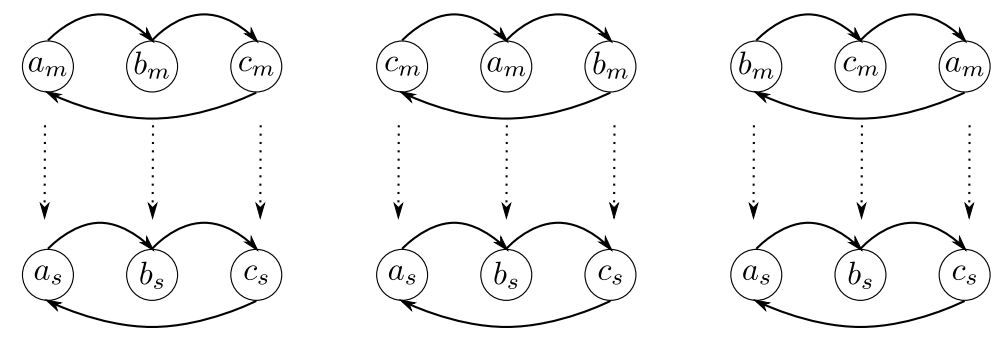

(a)

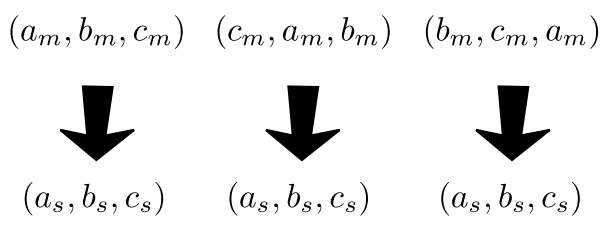

(b)

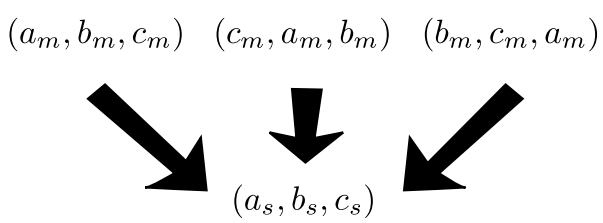

(c)

Figura 3.3. Continuação da Figura 3.2 para obter um exemplo de tuplas-chave. As setas tracejadas na ilustração (a) não são necessárias porque os isomorfismos estão implícitos pela ordenação dos vértices. A ilustração (b) é mais simples mas ainda redundante porque a mesma tupla-chave da cena é repetida. A ilustração (c) enfatiza a assimetria.

\subsection{Detecção de grafos-chave}

Em um primeiro trabalho [28], a implementação utilizou o algoritmo Good Features To Track [67] para detectar pontos-chave, visto que ele fornecia um bom equilíbrio entre acurácia e velocidade para os experimentos. A versão final utiliza os algoritmos Hessian-Affine [49, 51] e MSER [48]. O primeiro é baseado em extremos de determinantes de Hessianas em múltiplas escalas e o segundo é baseado em regiões extremais que são maximalmente estáveis. Ambos na verdade são detectores de regiões covariantes, convertidos para detectores de pontos-chave tomando-se os centroides das regiões.

Esses detectores foram escolhidos porque eles fornecem os melhores resultados no mencionado estudo comparativo de Mikolajczyk et al. [51]. Decidimos utilizar ambos porque nenhum deles consistentemente supera o outro em todos os experimentos de tal estudo. As vantagens e desvantagens de cada um influenciaram os resultados experimentais apresentados no Capítulo 4.

Além disso, seguindo o paradigma de priorizar exaustividade quando extraindo dados do modelo e priorizar velocidade quando extraindo dados da cena, utilizamos um subconjunto dos pontos-chave da cena. Esse subconjunto é obtido escolhendo-se aleatoriamente um conjunto maximal de pontos tal que nenhum par está excessivamente próximo de acordo com a distância de Chebyshev. Mais formalmente: dados dois pontos-chave $\left(x_{1}, y_{1}\right)$ e $\left(x_{2}, y_{2}\right)$,

$$
\max \left\{\left|x_{2}-x_{1}\right|,\left|y_{2}-y_{2}\right|\right\}
$$

não pode ser menor do que um certo valor. Em nossos experimentos, o valor adotado é 10 pixels.

O detector de grafos-chave é baseado em critérios combinatórios e geométricos. A maior parte de tais critérios é aplicada tanto sobre os grafos do modelo como sobre os grafos da cena, 
mas alguns deles são aplicados apenas sobre a cena. Começamos descrevendo os critérios compartilhados e concluímos a seção com os critérios específicos para a cena.

O critério combinatório é a estrutura dos grafos-chave. A Figura 3.4 mostra as três estruturas escolhidas para nossos experimentos, e as respectivas matrizes escolhidas para definir tuplaschave.

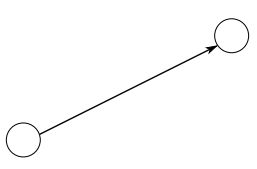

$$
\left[\begin{array}{ll}
0 & 1 \\
0 & 0
\end{array}\right]
$$

(a)

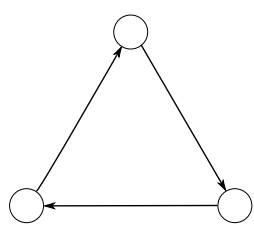

$$
\left[\begin{array}{lll}
0 & 1 & 0 \\
0 & 0 & 1 \\
1 & 0 & 0
\end{array}\right]
$$

(b)

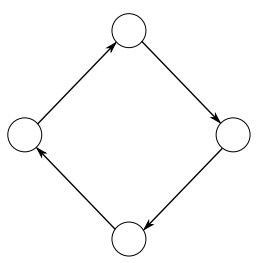

$$
\left[\begin{array}{llll}
0 & 1 & 0 & 0 \\
0 & 0 & 1 & 0 \\
0 & 0 & 0 & 1 \\
1 & 0 & 0 & 0
\end{array}\right]
$$

(c)

Figura 3.4. As três estruturas escolhidas e suas respectivas matrizes. (a) Dois vértices e o arco de um a outro. (b) Circuito com três vértices. (c) Circuito com quatro vértices.

Tais estruturas e matrizes foram escolhidas porque obter tuplas-chave delas é trivial e rápido: para a primeira estrutura a tupla-chave é única e para a segunda e terceira estruturas uma tuplachave é sempre uma permutação cíclica de outra tupla-chave. Circuitos maiores poderiam ter sido utilizados, mas os resultados experimentais do Capítulo 4 sugerem que o possível ganho em acurácia não justificaria a perda em velocidade.

Os critérios geométricos, por outro lado, são três. O primeiro critério é distância mínima: dois vértices de um grafo-chave não podem estar excessivamente próximos de acordo com a distância de Chebyshev. Esse critério foi escolhido porque, como visto na Seção 3.4, computamos descritores a partir de perfis de intensidade. Um perfil de intensidade é a sequência de valores dos pixels intersectados pela linha entre os dois vértices de um arco, como mostra a Figura 3.5 Nossa implementação utiliza o algoritmo de Bresenham [11] para obter esses valores. Como o comprimento de um perfil obtido com tal algoritmo é a distância de Chebyshev entre os respectivos vértices, o critério evita arcos curtos e portanto descritores pobres. Em nossos experimentos, utilizamos uma distância mínima de 10 pixels escolhida empiricamente. A mesma distância é utilizada para amostrar os pontos-chave da cena.

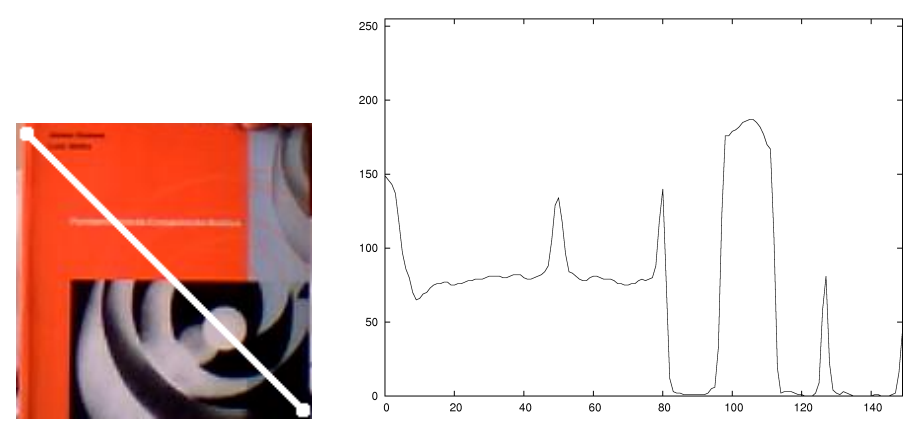

Figura 3.5. Exemplo de perfil de intensidade.

O segundo critério geométrico é distância máxima. Esse critério foi escolhido para evitar arcos longos e portanto as consequências de perda de localidade: perfis de intensidade curtos 
são mais robustos a transformações de perspectiva e mais adequados para objetos não-planares. Para os grafos-chave do modelo, utilizamos uma distância máxima de 100 pixels escolhia empiricamente. Para os grafos-chave da cena, não utilizamos uma distâncias máxima porque em nossos experimentos a instância do objeto na cena pode ser bem maior que a do modelo.

Finalmente, o terceiro critério é posicionamento relativo: se o grafo é um dos dois circuitos, seus arcos devem possuir direção horária. esse critério foi escolhido porque estamos supondo que espelhamento não é uma das distorções possíveis que uma instância do objeto pode sofrer na cena. Sob essa suposição, mapear um circuito horário a um circuito anti-horário não faz sentido. Decidir se um circuito é horário exige apenas uma trivial e rápida operação de produto vetorial.

Note que os critérios geométricos podem aliviar a explosão combinatória reduzindo o número de grafos, como ilustrado pela Figura 3.6.

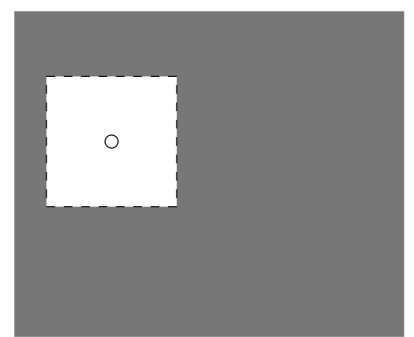

(a)

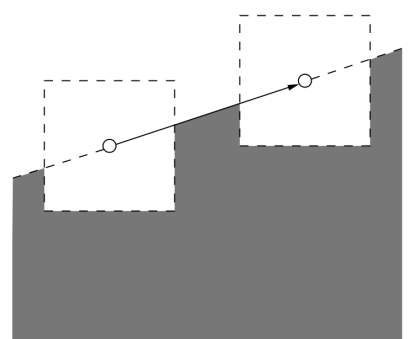

(b)

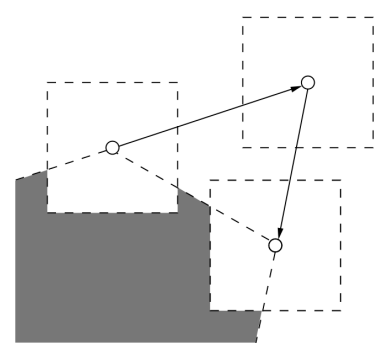

(c)

Figura 3.6. Potencial dos critérios geométricos para reduzir o número de grafos-chave. Especificamente, distância mínima e posicionamento relativo. (a) Após escolher o primeiro vértice, o conjunto cinza de pontos que podem ser o segundo vértice é limitado pela distância mínima. (b) Após escolher o segundo, o conjunto de pontos que podem ser o terceiro é limitado pela distância mínima e pelo posicionamento relativo. Note que mais da metade do plano Euclidiano não pertence ao conjunto nesse estágio. (c) Após escolher o terceiro, o conjunto que pode ser o quarto é ainda mais limitado.

Sob um ponto de vista teórico, os critérios combinatórios e geométricos mencionados são suficientes para manter o número de grafos-chave do modelo tratável. Como grafos-chave são isomorfos, as estruturas escolhidas garantem que tal número é $O\left(n^{2}\right), O\left(n^{3}\right)$ ou $O\left(n^{4}\right)$, onde $n$ é o número de pontos-chave. Em nossa implementação, armazenamos os descritores em uma estrutura de indexação que permite seleção de correspondências em tempo esperado $O(\log n)$. Portanto, como $\log n^{k}=k \log n$, a seleção de correspondências é sublinear nos pontos-chave independentemente da estrutura escolhida. Um número superlinear de pontos-chave da cena, no entanto, não é tratável. Portanto, para esses grafos-chave escolhemos um critério geométrico adicional: eles devem ser obtidos das arestas e faces de uma triangulação de Delaunay [17] dos pontos-chave. A Figura 3.7 mostra um exemplo. Obter a primeira estrutura das arestas e a segunda estrutura das faces é trivial. A terceira estrutura pode ser obtida a partir das arestas internas, como ilustrado pela Figura 3.8.

Como a triangulação de Delaunay é um grafo planar, a fórmula de Euler pode ser utilizada para provar que o número de arestas e faces é $O(n)$ [17]. Além disso, tal triangulação pode ser obtida em tempo $O(n \log n)$ [21].

Note que para detectores de pontos-chave densos, como o Hessian-Affine, a triangulação de Delaunay pode ter um número excessivo de arestas curtas e portanto uma redução excessiva no número de grafos-chave. Isso explica porque amostramos os pontos-chave da cena de acordo com a distância mínima. Note também que, embora a triangulação não seja robusta a transformações de perspectiva, ela não precisa ser: não nos importamos se o grafo planar inteiro pode ser mapeado a grafos-chave do modelo, apenas se cada grafo-chave da cena individualmente pode. Novamente, priorizamos exaustividade quando extraindo dados do modelo e priorizamos velocidade quando 


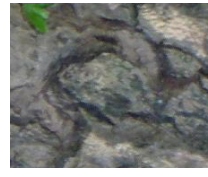

(a)

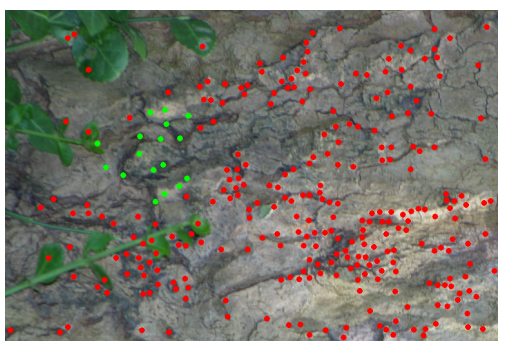

(c)

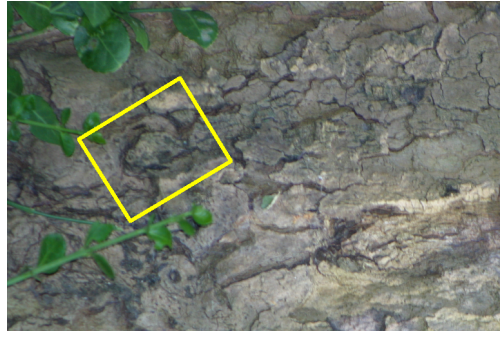

(b)

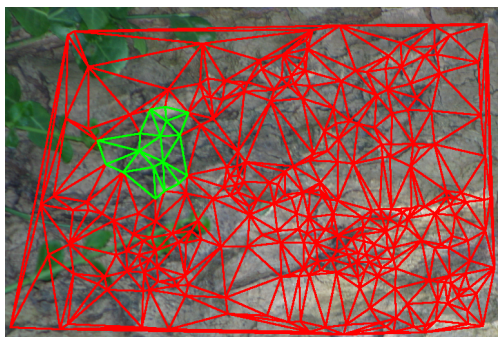

(d)

Figura 3.7. Exemplo de triangulação de Delaunay (a) Modelo. (b) Cena e pose da instância do objeto na cena. (c) Pontos-chave da cena: pontos que podem ser mapeados ao modelo são enfatizados. (d) Triangulação de Delaunay dos pontos-chave: arestas e faces que podem ser mapeadas ao modelo são enfatizadas em verde.

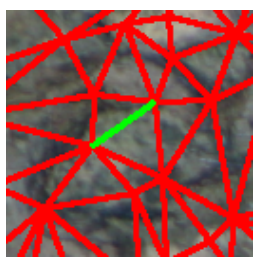

(a)

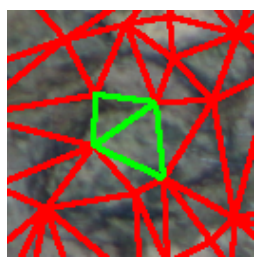

(b)

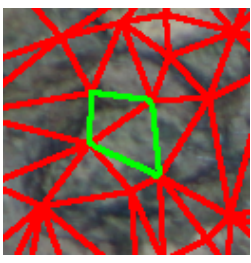

(c)

Figura 3.8. Obtendo um circuito de quatro vértices a partir da aresta interna de uma triangulação de Delaunay. (a) A aresta interna. (b) As duas faces que compartilham a aresta interna. (c) A diferença simétrica dos conjuntos de arestas das duas faces.

extraindo dados da cena.

\subsection{Descrição de grafos-chave}

Em nossa implementação, como visto na Seção 3.1, selecionamos correspondência por análise parte-a-parte e o isomorfismo estabelece qual vértice do modelo deve ser comparado com cada vértice da cena e qual arco do modelo deve ser comparado com cada arco da cena. O descritor utilizado para os vértices é o conhecido SIFT [44, 45], que é baseado em um histograma ponderado de orientações de gradiente e fornece os melhores resultados no estudo comparativo de Mikolajczyk e Schmid [50]. O descritor escolhido para os arcos é baseado em coeficientes de Fourier do perfil de intensidade e foi inspirado por Tell e Carlsson [76, 77]: dado um perfil de intensidade $f:\{0, \ldots, l-1\} \rightarrow\{0, \ldots, 255\}$, sua transformada discreta de Fourier é a função $F:\{0, \ldots, l-1\} \rightarrow \mathbb{C}$ definida por

$$
F(x)=\sum_{y=0}^{l-1} e^{-\frac{2 \pi i}{l} x y} f(y)
$$


e seu descritor é definido por

$$
\left(a_{1}, b_{1}, \ldots, a_{m}, b_{m}\right) \text { onde } F(x)=a_{x}+b_{x} i .
$$

Escolher apenas os coeficientes das menores frequências garante tanto um descritor de comprimento mais curto como uma maior robustez a ruído.

Perfis de intensidade são naturalmente invariantes a rotação. Eles não são invariantes a transformações perspectivas, mas são suficientemente robustos sob o critério de distância máxima mostrado na Seção 3.3. Descartar $F(0)$ garante invariância a brilho e dividir por

$$
\sqrt{\sum_{x=1}^{m}\left(a_{x}^{2}+b_{x}^{2}\right)}
$$

garante invariância a contraste. Em nossos experimentos, escolhemos $m=3$ empiricamente e portanto um descritor de arco tem dimensão 6.

Descritores baseados em perfil são inerentemente mais pobres que descritores baseados em região, mas também possuem vantagens inerentes.

- Computação rápida. SIFT é conhecido como um dos descritores mais precisos na literatura, mas também é conhecido por ser lento de computar. O foco de muitos trabalhos recentes $[6,1,19,78]$ é manter a precisão e reduzir o tempo de execução. Isso torna a simplicidade de perfis de intensidade particularmente interessante.

- Baixa dimensionalidade. Além de ser lento de computar, o SIFT também possui a alta dimensionalidade de 128. Isso torna difícil construir estruturas de indexação devido à maldição da dimensionalidade, o aumento exponencial do volume do espaço de características que reduz a significância de funções de dissimilaridade. De fato, descritores SIFT têm sido usados como dados experimentais para propostas de estrutura de indexação [68, 56] e estudos de avaliação de descritores [5, 4]. Os trabalhos previamente citados com foco em reduzir tempo de execução fornecem descritores com dimensionalidade menor, e mesmo procedimentos explícitos de redução de dimensionalidade já foram utilizados na literatura [34, 50]. Isso torna a simplicidade de perfis de intensidade ainda mais interessante.

- Robustez natural. Como regiões não são naturalmente invariantes à rotação como perfis de intensidade, invariância deve ser fornecida pelo descritor. SIFT e SURF [6], por exemplo, atribuem uma orientação a cada ponto-chave e adaptam-se de acordo. Além disso, perfis de intensidade possuem um conceito bem-definido de tamanho para normalização: a distância entre os dois vértices do respectivo arco. Em contraste, nem todos os detectores de pontoschave possuem tal conceito: embora existam detectores que associam valores de escala [44, 45, 6], regiões elípticas [49, 51] e contornos completos [48], há também descritores que não associam nada [27].

- Discriminação fraca. Individualmente, regiões são mais discriminativas que perfis. No entanto, essa aparente vantagem torna-se um problema em análise parte-a-parte: se descritores foram especificamente projetados para serem o mais discriminativos quanto possível individualmente, eles podem ser excessivamente discriminativos quando considerados coletivamente. Por exemplo: usar a distância entre descritores SIFT para decidir se dois pontos-chave são parecidos tem uma grande chance de sucesso, mas usar o mesmo critério para comparar dois conjuntos de pontos-chave pode ser muito rígido. 
Para robustez adicional, aplicamos três procedimentos de suavização sobre os perfis de intensidade antes de computar a transformada de Fourier. Primeiramente, um filtro Gaussiano é aplicado sobre a imagem. Depois, a média de perfis de intensidade paralelos é computada, como ilustrado pela Figura 3.9. Finalmente, o perfil médio obtido a partir desse procedimento é redimensionado a um comprimento $l$ através de interpolação linear. Em nossos experimentos, escolhemos empiricamente $l=30$.

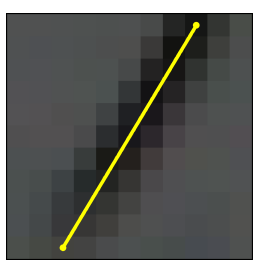

(a)

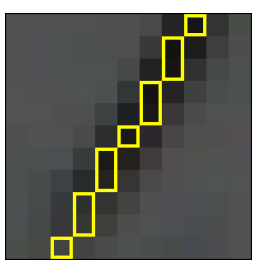

(b)

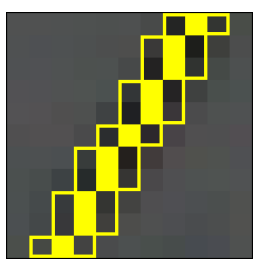

(c)

Figura 3.9. Média de perfis de intensidade. (a) A linha reta entre dois vértices de um arco. (b) A sequência de pixels intersectada pela linha. (c) Os mesmos pixels, destacados pelos retângulos cheios, e uma sequência paralela adicional em cada lado: a transformada de Fourier é calculada a partir de uma média redimensionada das três sequências.

\subsection{Seleção de correspondências e estimação de pose}

O procedimento para selecionar ou rejeitar uma correspondência de grafos-chave em nossa implementação é uma simples limiarização. Para cada correspondência de pontos-chave implicada pelo isomorfismo, uma função de dissimilaridade é aplicada sobre os descritores e a correspondência é rejeitada se uma das dissimilaridades for maior que um certo limiar. A mesma verificação é feita para os arcos, como ilustrado pela Figura 3.10.

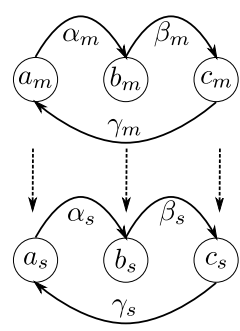

(a) descritores

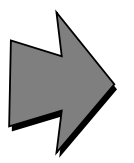

(b) dissimilaridade

$\delta_{\gamma}:=\delta\left(\gamma_{m}, \gamma_{s}\right)$

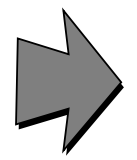

$\max \left\{\delta_{\alpha}, \delta_{\beta}, \delta_{\gamma}\right\}<t$

(c) limiar

Figura 3.10. Exemplo de seleção de correspondências de grafos-chave usando limiarização na dissimilaridade dos arcos. (a) Um isomorfismo de um grafo-chave do modelo com descritores de arco $\alpha_{m}, \beta_{m}, \gamma_{m}$ a um grafo-chave da cena com descritores de arco $\alpha_{s}, \beta_{s}, \gamma_{s}$. (b) As três dissimilaridades de arco implicadas pelo isomorfismo. (c) A condição de limiarização para selecionar uma correspondência.

Note que tal procedimento permite mais do que uma correspondência por grafo-chave do modelo ou grafo-chave da cena. A estimação de pose baseada em RANSAC é responsável por reconhecer as correspondências que foram incorretamente selecionadas e ignorá-las. RANSAC é um procedimento de ajuste probabilístico, especificamente projetado para lidar com altas proporções de outliers. Em termos gerais, é baseado em iterativamente escolher conjuntos aleatórios de correspondências: para cada conjunto, um candidato a pose é estimado e o número de correspondências que são inliers em relação a tal candidato é armazenado como sua qualidade. O número de iterações é probabilisticamente adaptado de acordo com a melhor qualidade: um alto número de inliers implica um menor número esperado de iterações antes de encontrar um 
candidato ótimo. O número verdadeiro eventualmente atinge esse número esperado ou um limitante superior, especificado para evitar consumo de tempo excessivo. Se a melhor qualidade é suficientemente boa quando isso acontece, o respectivo candidato é escolhido como pose.

Dado um conjunto de correspondências de pontos-chave $\Gamma$, um procedimento trivial para estimar a pose é aplicar RANSAC sobre as correspondências definidas na equação (3.2) ou sobre um conjunto de correspondências de pontos-chave mais frequentes, obtido através de uma tabela de votação [76, 77, 32]. Entretanto, ambos os procedimentos descartam uma informação valiosa: se uma correspondência de grafos-chave está correta, então todas as correspondências de pontoschave que ela implica estão corretas ao mesmo tempo. Em nossa implementação, aplicamos RANSAC sobre uma família de conjuntos como na equação (3.1). Isso reduz significativamente o número esperado iterações do RANSAC, como mostrado no Capítulo 4. 


\section{Capítulo 4}

\section{Resultados experimentais}

\subsection{Implementação}

Nossa implementação foi escrita em $\mathrm{C}++$ e baseada na biblioteca OpenCV [10]. A triangulação de Delaunay é computada com a biblioteca Triangle [66] e a transformada de Fourier é computada com a biblioteca FFTW [22]. No final do RANSAC, o melhor candidato é refinado com o algoritmo de Levenberg-Marquardt [39, 47].

\subsection{Experimento preliminar}

Em nosso primeiro experimento, utilizamos pares de imagens obtidos manualmente do conjunto de imagens compartilhado por Mikolajczyk e Schmid [50]. Essa base é particionada em 8 subconjuntos: cada subconjunto contém um modelo, cinco cenas e cinco homografias que modelam as respectivas poses. As cinco cenas representam diferentes graus de uma distorção específica. As Figuras 4.1, 4.2, 4.3, 4.4, 4.5, 4.6, 4.7 e 4.8 mostram os conjuntos.
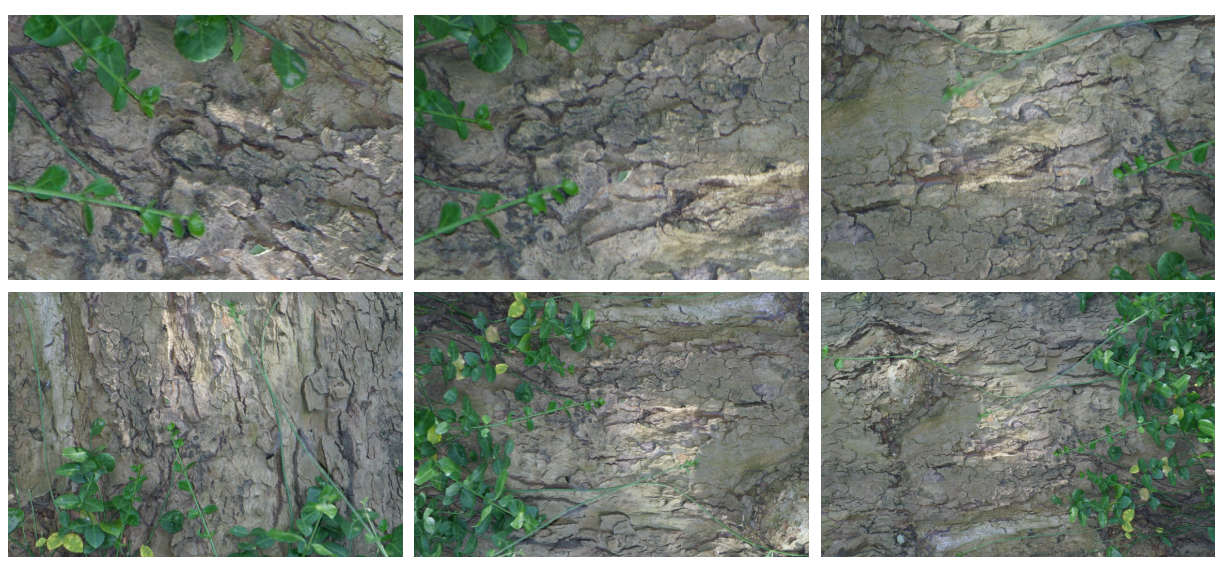

Figura 4.1. Conjunto de imagens bark: imagens texturizadas com variação de escala e rotação.

Escolhemos 6 subconjuntos e, para cada um, obtivemos a cena representando o menor grau de distorção e uma sub-imagem recortada manualmente do modelo. A Figura 4.9 mostra os pares de imagens.

O objetivo do experimento foi comparar a acurácia das três diferentes estruturas mostradas na Seção 3.3 para diferentes imagens. Estávamos interessados em descobrir a melhor estrutura para distorções baixas antes de considerar distorções altas. Os 2 subconjuntos não escolhidos 

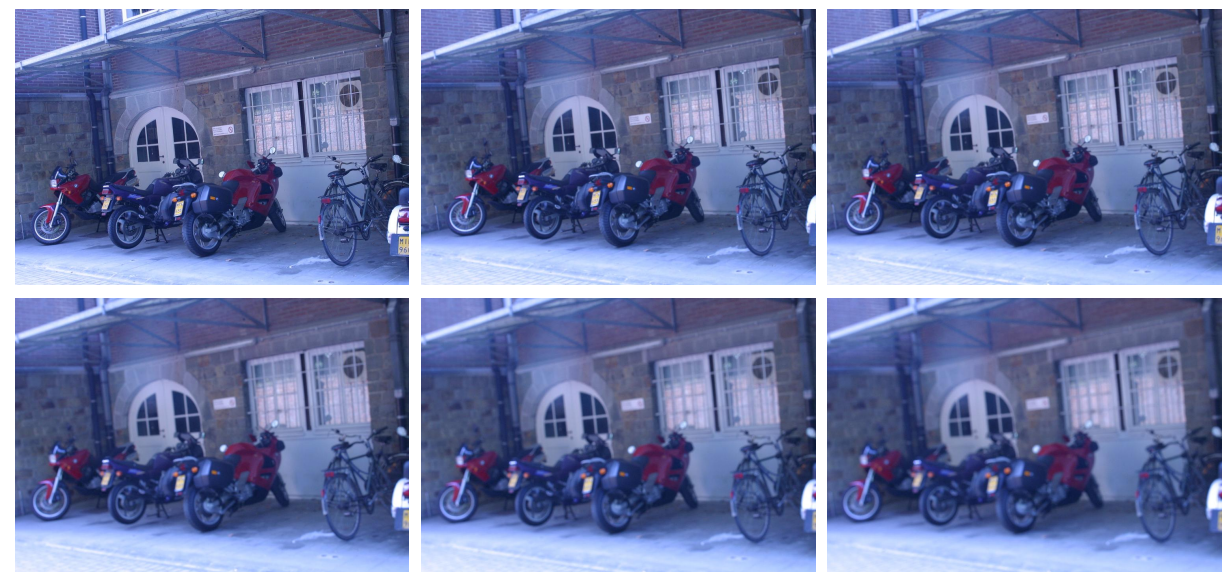

Figura 4.2. Conjunto de imagens bikes imagens estruturadas com variação de borramento.
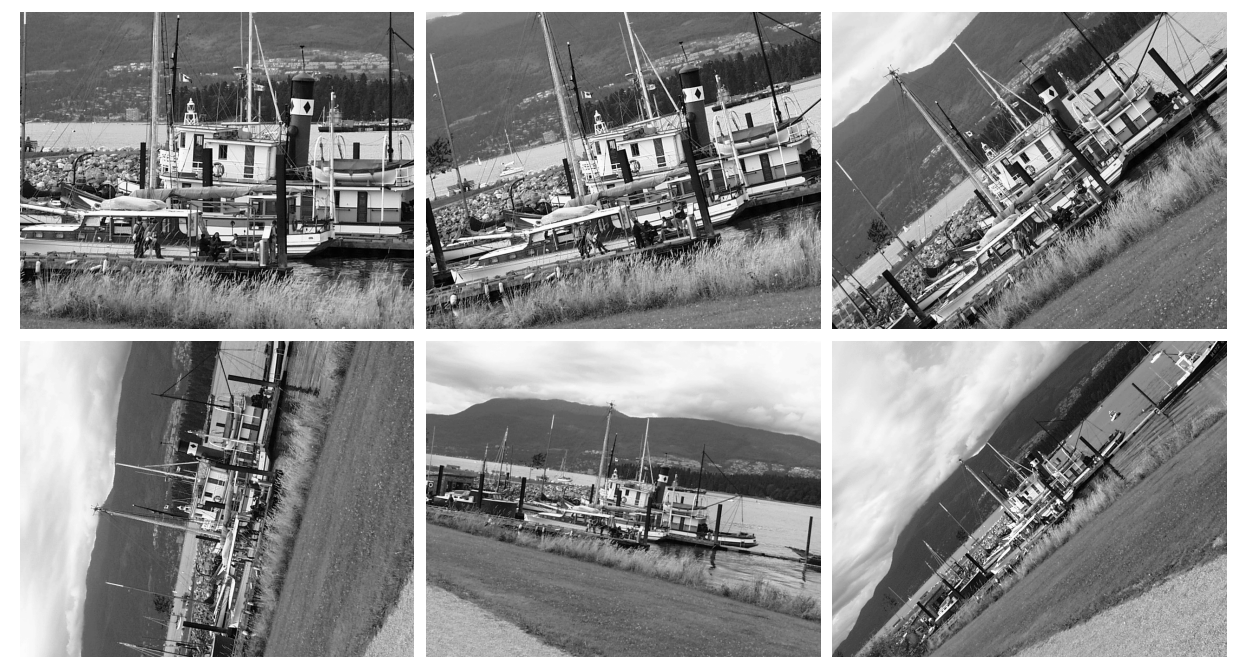

Figura 4.3. Conjunto de imagens boat imagens estruturadas com variação de escala e rotação.
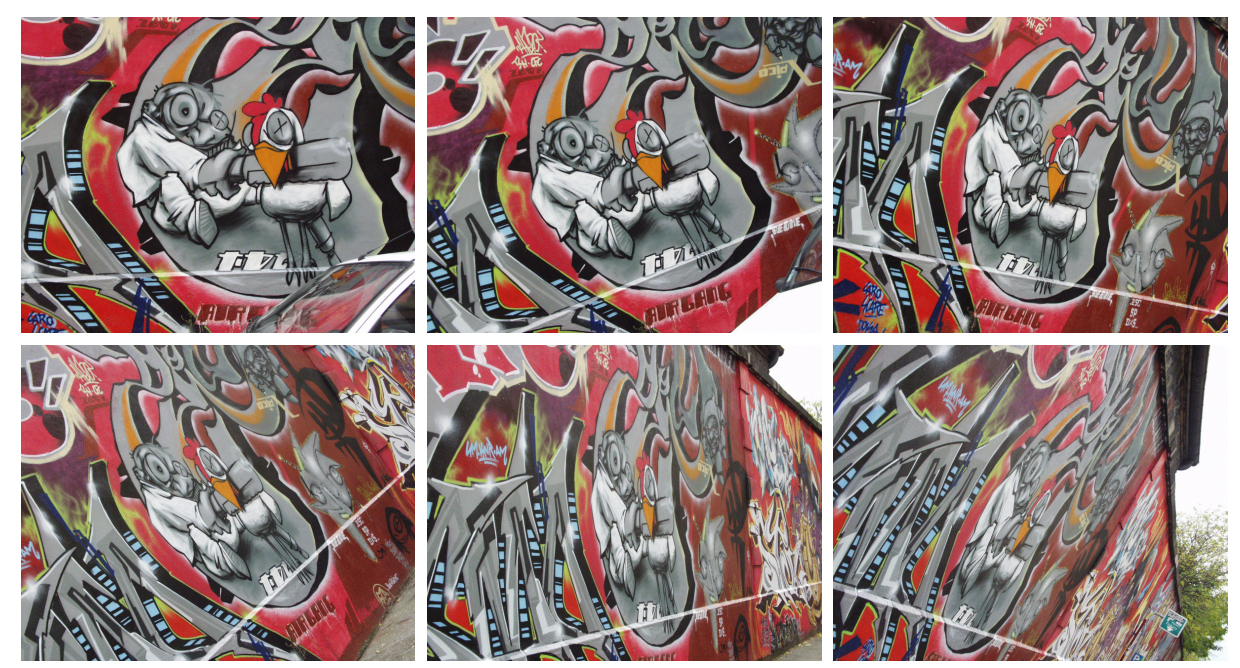

Figura 4.4. Conjunto de imagens graf imagens estruturadas com variação de perspectiva.

foram trees ubc. Ambas foram descartadas por fornecerem resultados excessivamente diferentes: bem melhores para o primeiro e bem piores para o segundo. 


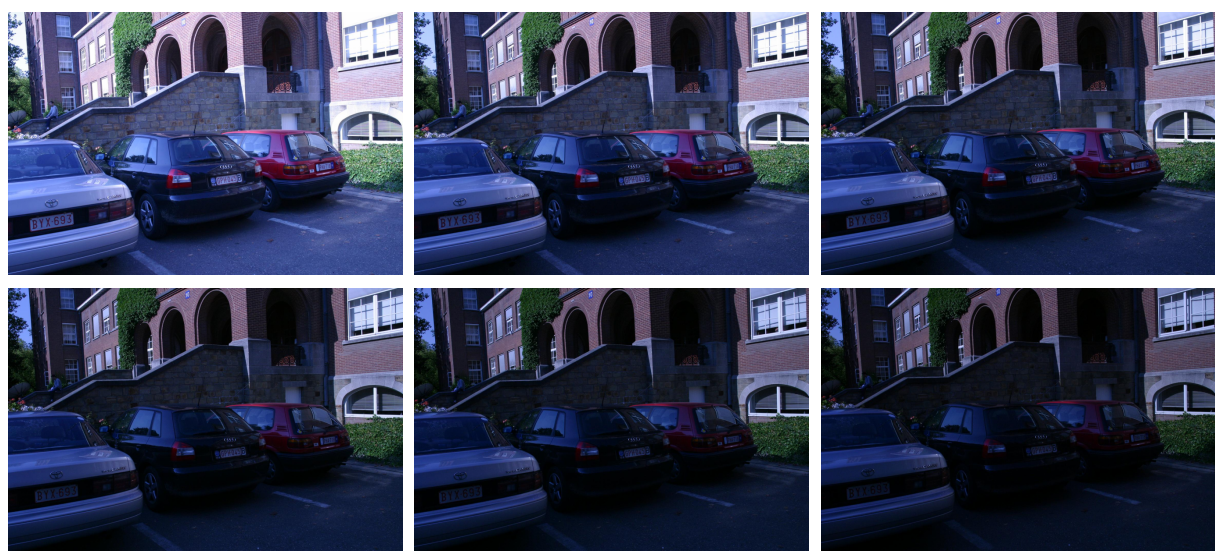

Figura 4.5. Conjunto de imagens leuven imagens com variação de iluminação.

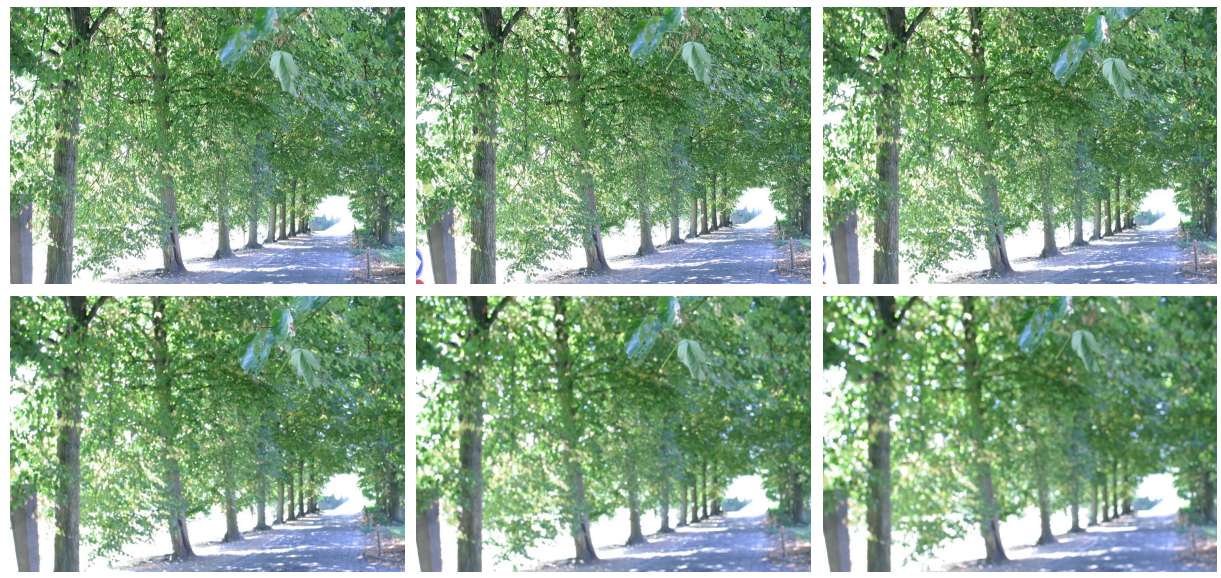

Figura 4.6. Conjunto de imagens trees imagens texturizadas com variação de borramento.
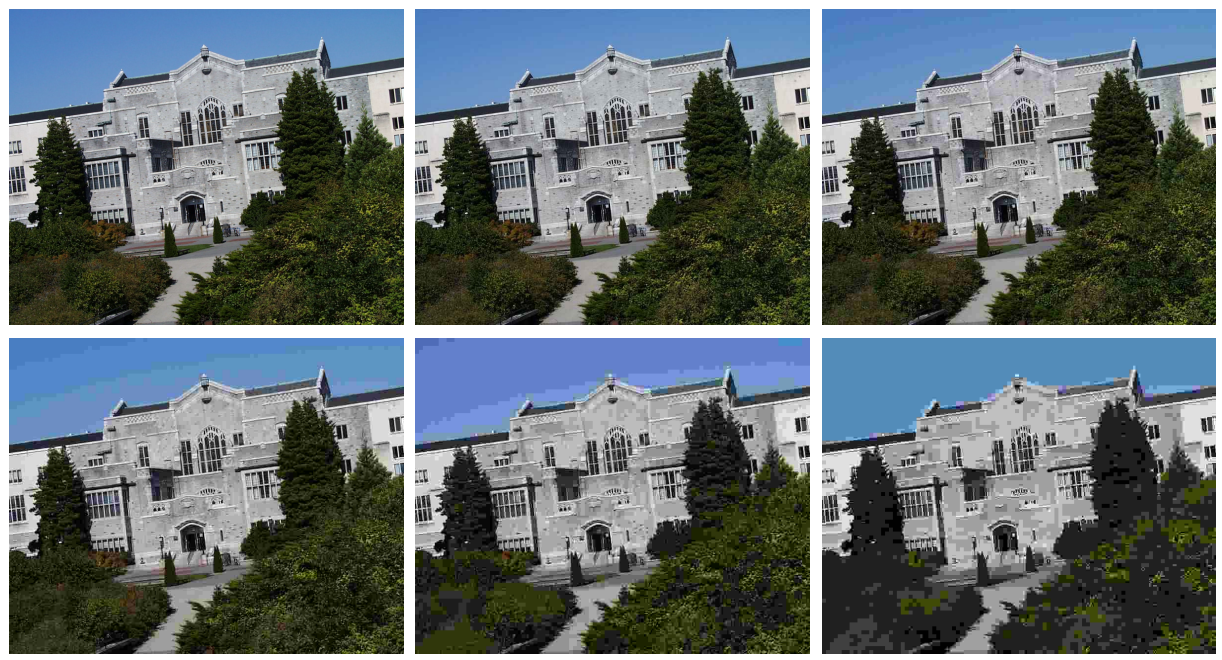

Figura 4.7. Conjunto de imagens $u b c$ imagens com variação de compressão.

Recortamos os modelos para aproximar mais o conjunto de imagens ao caso de detecção de objetos em fundos complexos: o recorte reduz significativamente o número de pontos-chave da cena que não possuem nenhuma correspondência no modelo, aumentando a dificuldade em particular para as imagens texturizadas. A medida de acurácia escolhida foi a curva de revocação- 

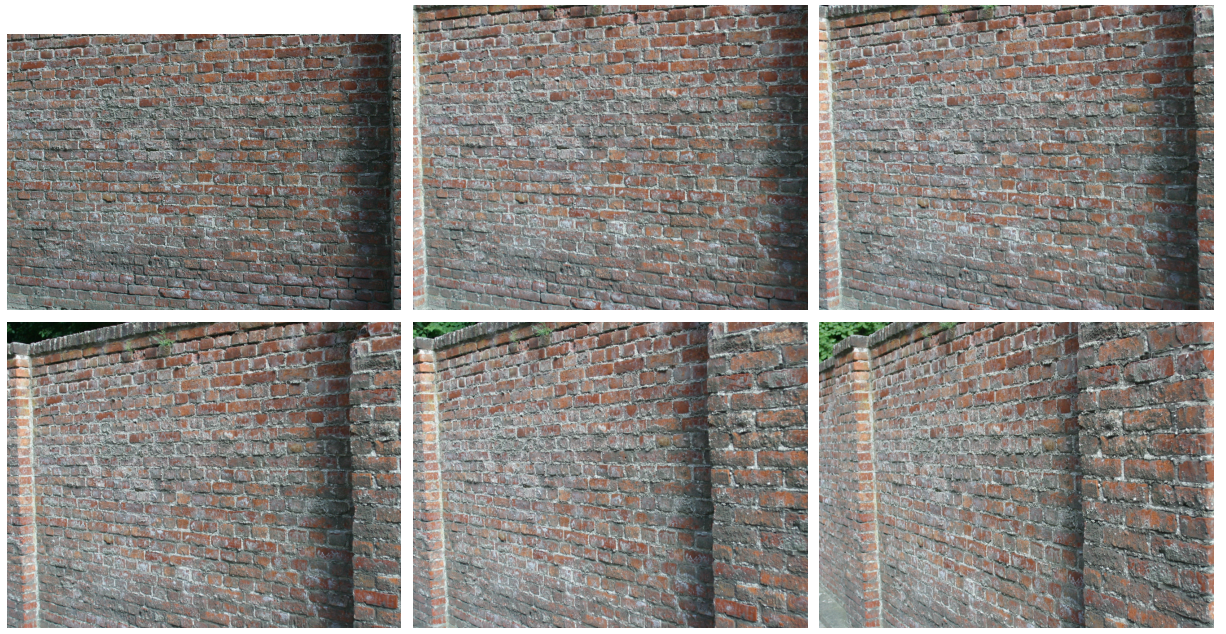

Figura 4.8. Conjunto de imagens wall imagens texturizadas com variação de perspectiva.
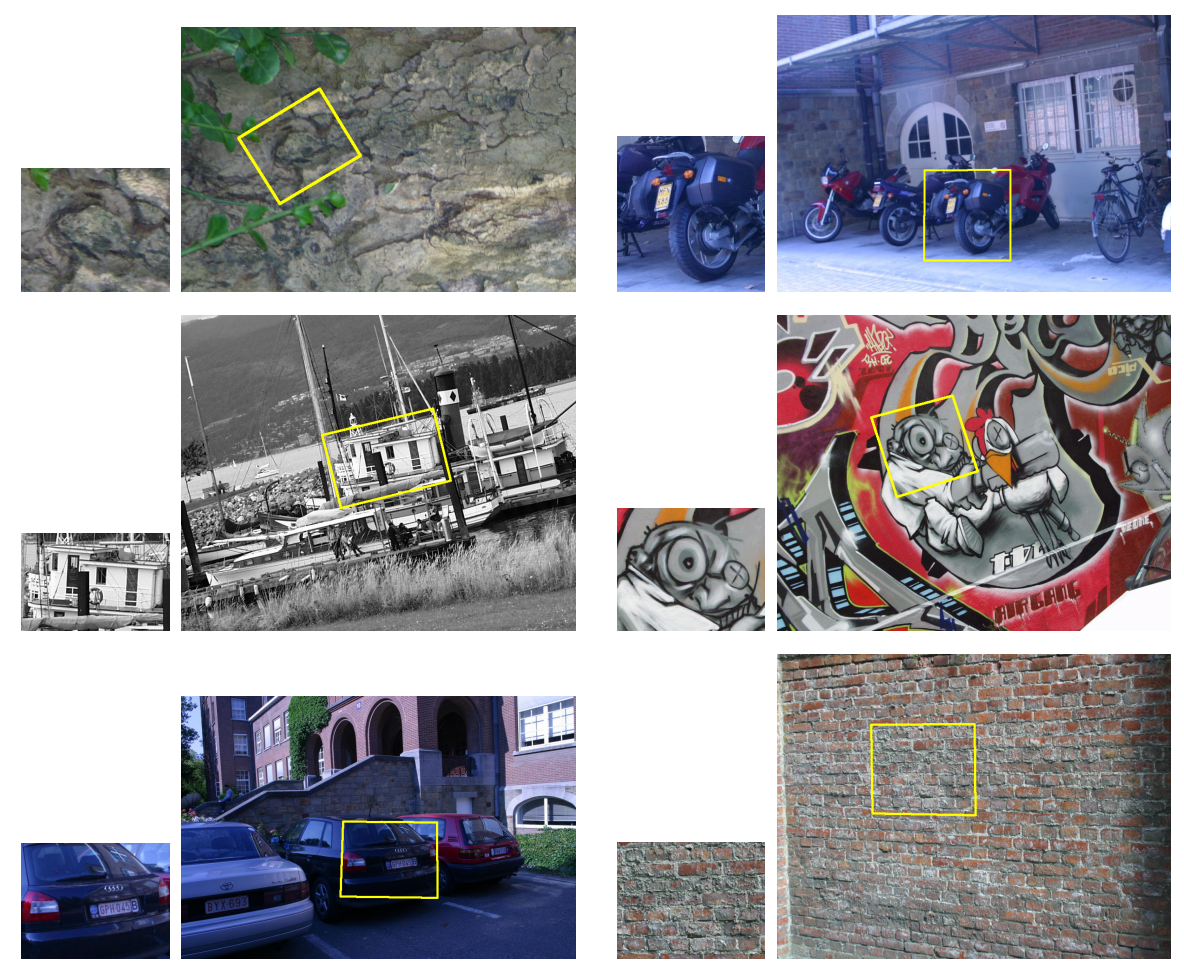

Figura 4.9. Pares de imagens utilizados no primeiro experimento, com representações visuais das homografias.

precisão: revocação é a fração de correspondências corretas que foi selecionada e precisão é a fração de correspondências selecionadas que são corretas. Esses dois valores são computados para diferentes limiares para se obter a curva.

Como também estamos interessados em comparar o arcabouço de grafos-chave com o arcabouço de pontos-chave, também obtivemos a curva de revocação-precisão para correspondências de pontos-chave individuais. O descritor de pontos-chave escolhido para selecionar essas correspondências foi o SIFT. Para evitar viés em nosso favor, estabelecemos que a revocação é sempre computada a partir de correspondências de pontos-chave: no caso de grafos-chave, essas correspondências são obtidas a partir da equação (3.2). 
Finalmente, também estabelecemos que uma correspondência de grafos-chave está correta se todas as correspondências de pontos-chave que ela implica estão corretas. Uma correspondência de pontos-chave, por sua vez, está correta se a distância Euclidiana ao gabarito for menor que 3 pixels. Esse valor foi escolhido empiricamente. A Figura 4.10 mostra os resultados para duas sequências de medidas: uma com descritores SIFT nos vértices e uma com descritores de Fourier nos arcos. Para ambas as sequências o detector de pontos-chave foi o algoritmo Hessian-Affine e a medida de dissimilaridade foi a distância Euclidiana.

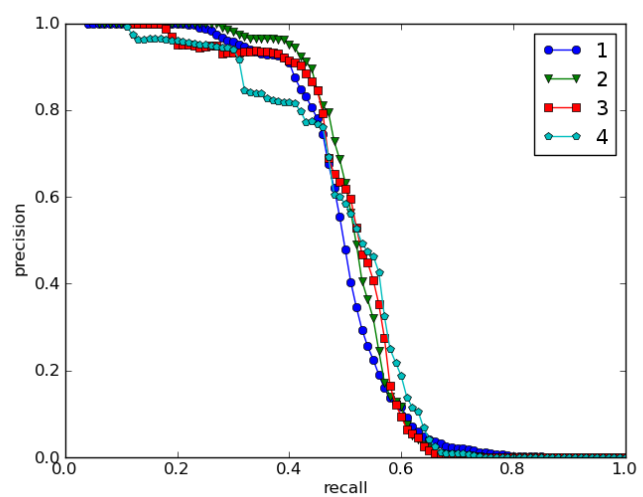

(a) vértices com SIFT

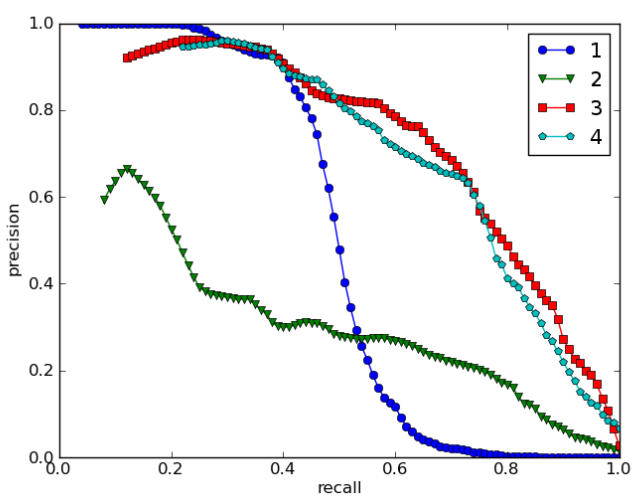

(b) arcos com Fourier

Figura 4.10. Resultados para as duas sequências de medidas do primeiro experimento: (a) para vértices com SIFT e (b) para arcos com Fourier. O nome de cada curva representa o número de vértices na estrutura: a primeira é a curva de comparação para correspondências de pontos-chave individuais, portanto igual em ambas as sequências, e as outras três referem-se às três estruturas mostradas na Seção 3.3. Cada curva é a média sobre todos os pares de imagens.

Para vértices com SIFT, a similaridade de todas as curvas mostra que utilizar ingenuamente um descritor de pontos-chave do estado-da-arte no arcabouço de grafos-chave não é necessariamente a melhor abordagem. Para arcos com descritores de Fourier, observamos que grafos-chave possuem precisões consistentemente piores para revocações baixas mas consistentemente melhores para revocações altas. Isso foi verdade mesmo para a estrutura mais simples com dois vértices, que não possui as vantagens de posicionamento relativo, embora a precisão geral tenha sido bem pior. Observamos também que as curvas para os dois circuitos foram bem similares. Isso nos desencorajou a tentar circuitos maiores, pois a diferença em acurácia não pareceu justificar o aumento em tempo de execução.

\subsection{Experimento exaustivo}

Devido ao seu equilíbrio entre acurácia e eficiência, circuitos com três vértices foram escolhidos para representar grafos-chave no segundo experimento. Nesse experimento, o objetivo foi comparar exaustivamente o arcabouço de grafos-chave com o arcabouço de pontos-chave. Mantivemos o conjunto de imagens anterior e a ideia de recortar, mas utilizamos todos os 5 graus de todas as 8 distorções e, em vez de recortar manualmente, fizemos 10 recortes aleatórios para cada subconjunto. Isso foi feito para permitir uma avaliação de performance mais extensiva, com um numero maior de casos. A Figura 4.11 mostra os modelos para um dos subconjuntos.

Além disso, fizemos uma sequência de medidas com o detector Hessian-Affine e uma sequência de medidas com o detector MSER. Ao todo, 800 medidas foram feitas e seus resultados são mostrados na Figura 4.12. Esse segundo experimento confirmou que grafos-chave fornecem precisão superior para revocações maiores. 


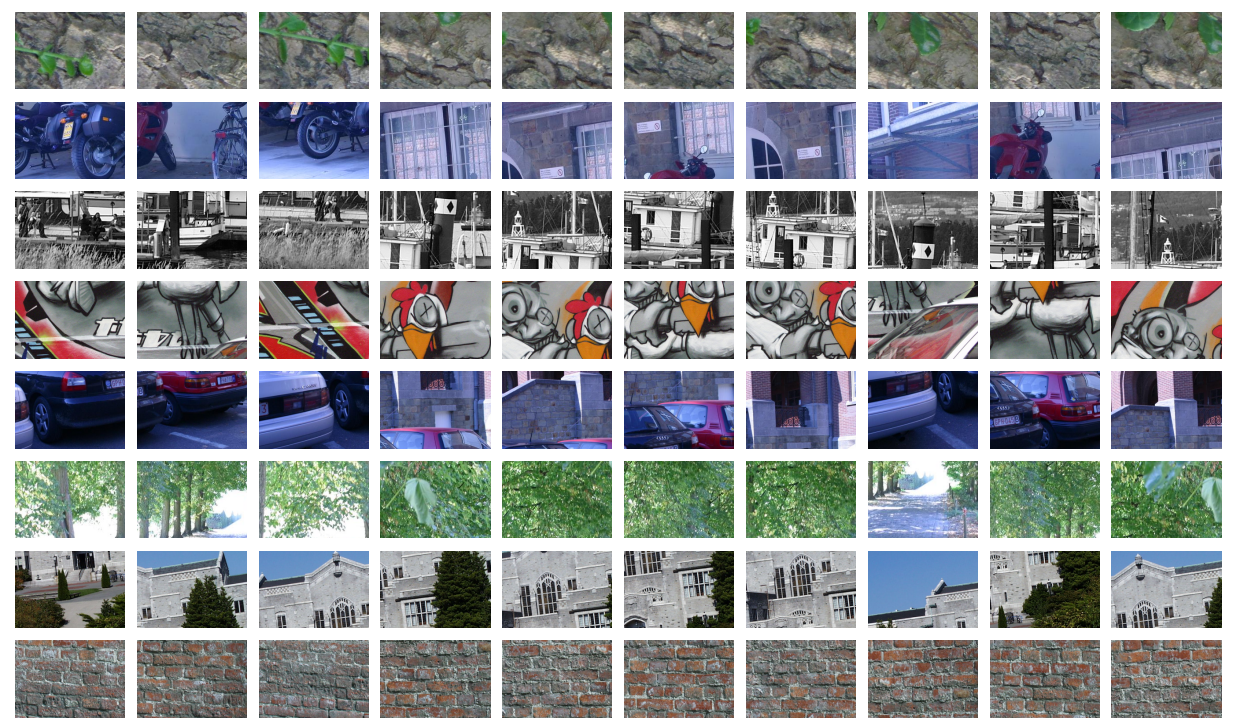

Figura 4.11. Modelos para o segundo experimento.
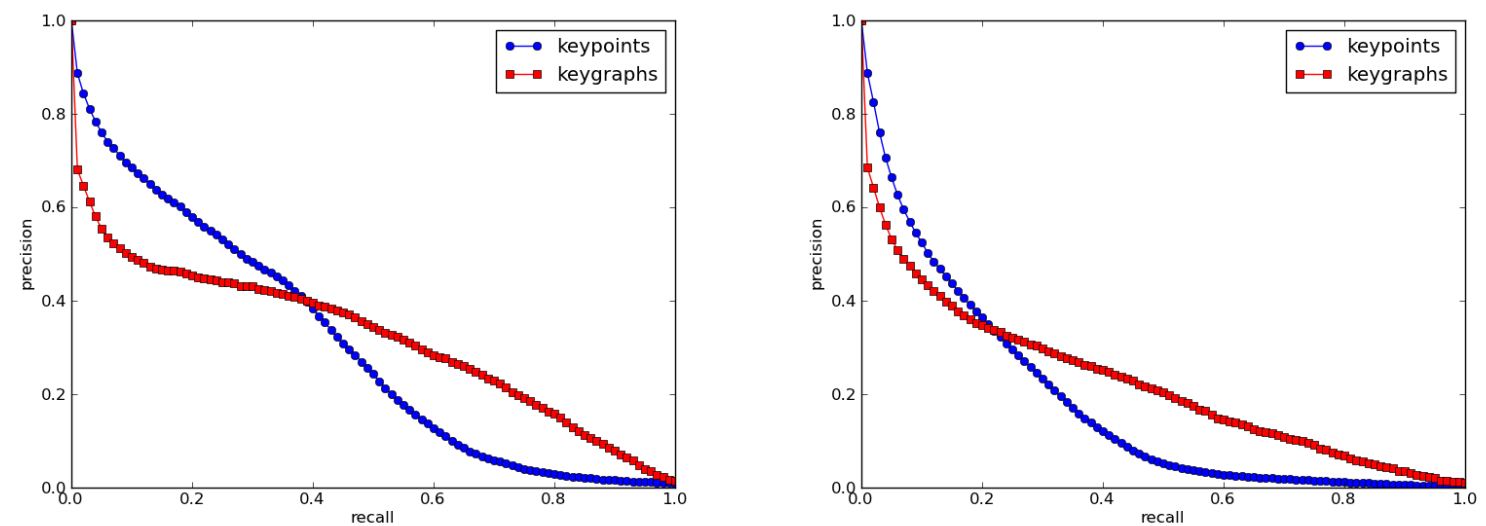

Figura 4.12. Resultados para as duas sequências de medidas no segundo experimento: (a) para Hessian-Affine e (b) para MSER. Cada curva é a média das 200 medidas tomadas para cada detector de pontos-chave.

No entanto, a revocação específica na qual as curvas se intersectam não foi estável ao longo de subconjuntos e detectores. A Figura 4.13 mostra que, para graf e $u b c$, os grafos-chave tiveram desempenho consistente melhor com o Hessian-Affine. Em contraste, para bikes e leuven, os grafos-chave tiveram desempenho consistentemente pior com o Hessian-Affine.

Com o MSER os resultados para os mesmos subconjuntos foram mais similares à média, como ilustrado pela Figura 4.14.

Essas diferenças são particularmente interessantes porque são consequências diretas das vantagens de cada detector de pontos-chave. No estudo comparativo de Mikolajczyk et al. [51], o Hessian-Affine teve desempenho pior precisamente nos subconjuntos bikes e leuven. Isso mostra que o arcabouço de grafos-chave é diretamente influenciado pela repetibilidade do detector de pontos-chave escolhido. Mas quando uma boa repetibilidade é garantida, então grafos-chave apresentam melhor precisão para revocações maiores.

Mas isso não significa que detectores com menor repetibilidade devem ser necessariamente desconsiderados. Quando utilizamos o RANSAC, mais importante que a precisão $p$ é o número 

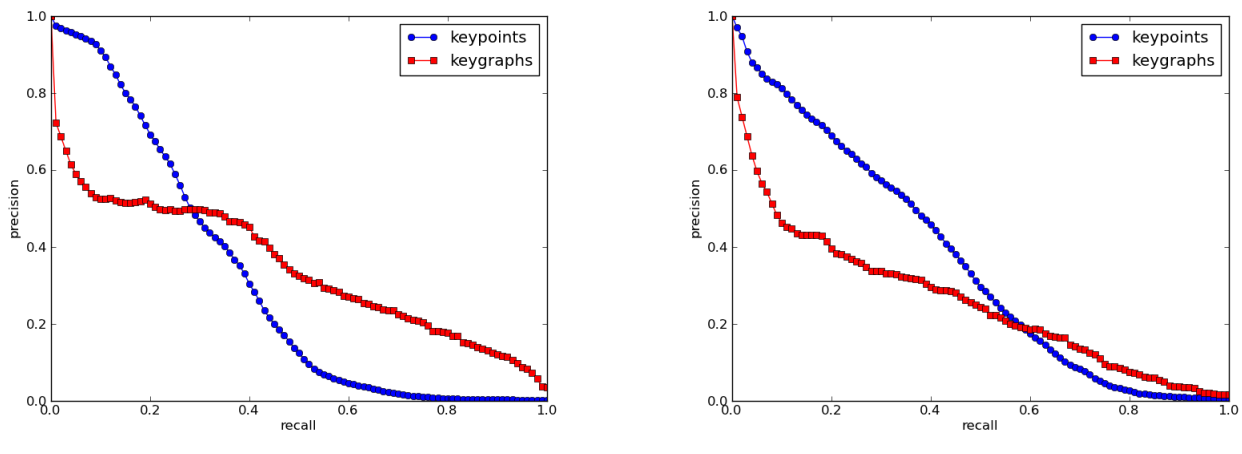

bark

bikes
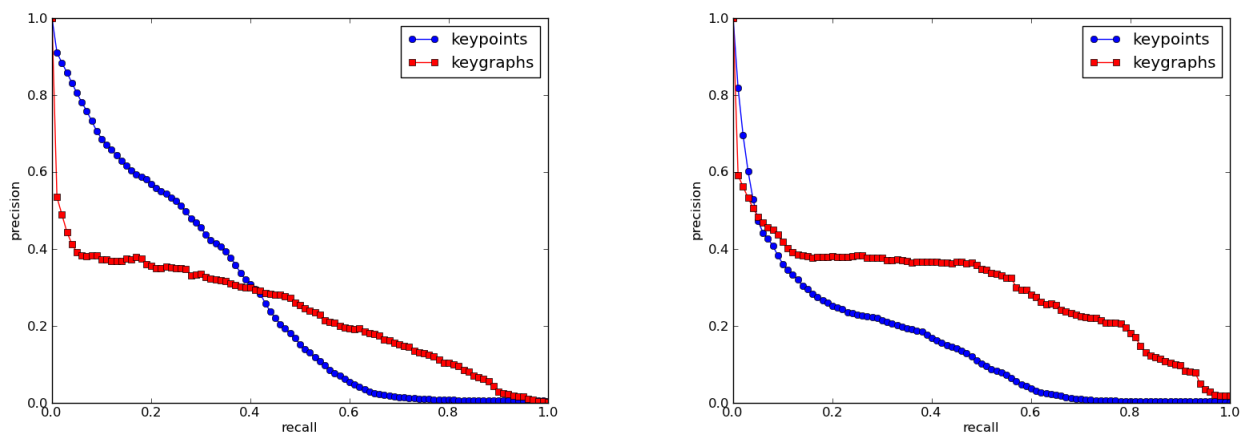

boat

graf
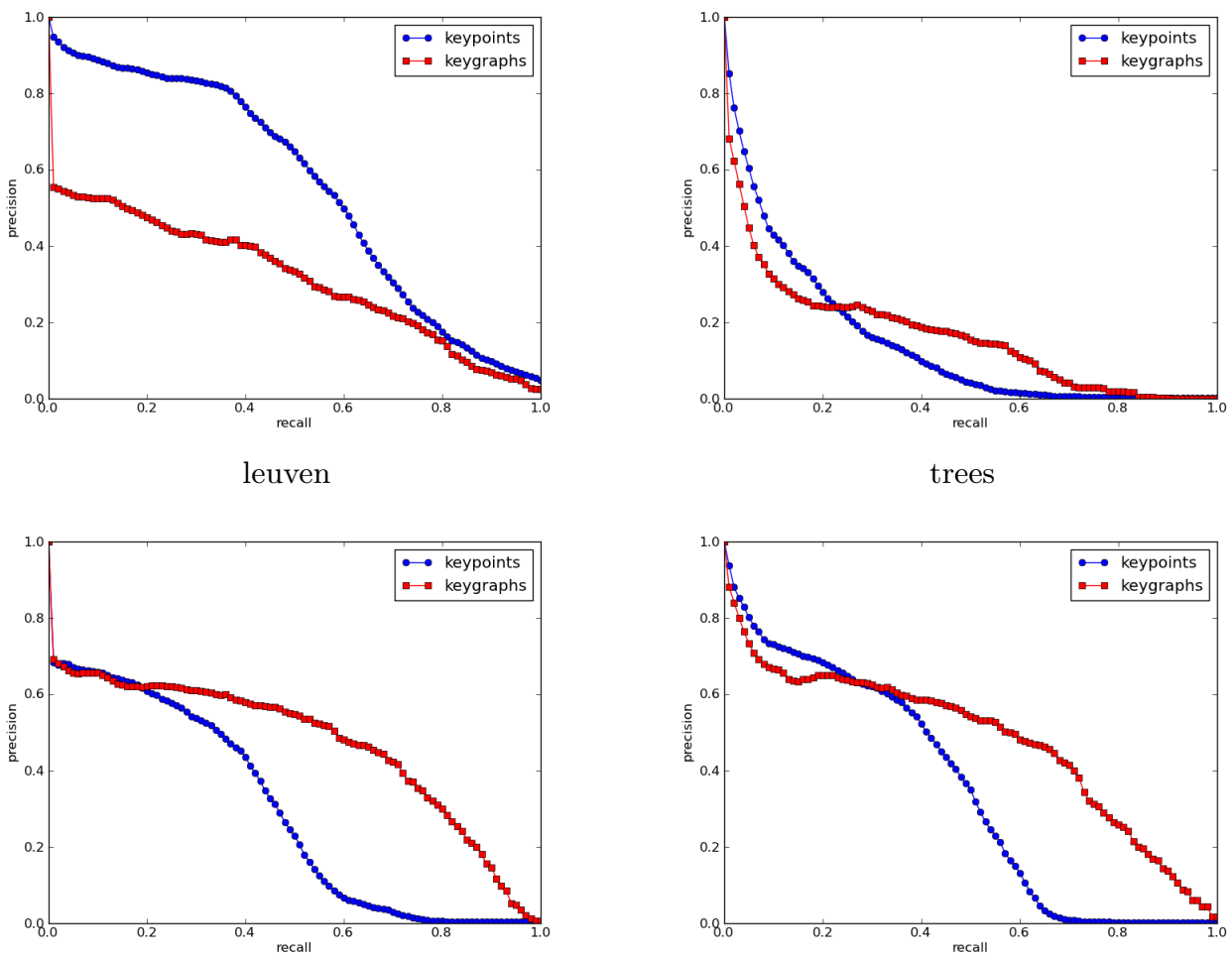

ubc

wall

Figura 4.13. Resultados para o segundo experimento, especificamente para Hessian-Affine. Cada curva é a média de 50 medidas. 

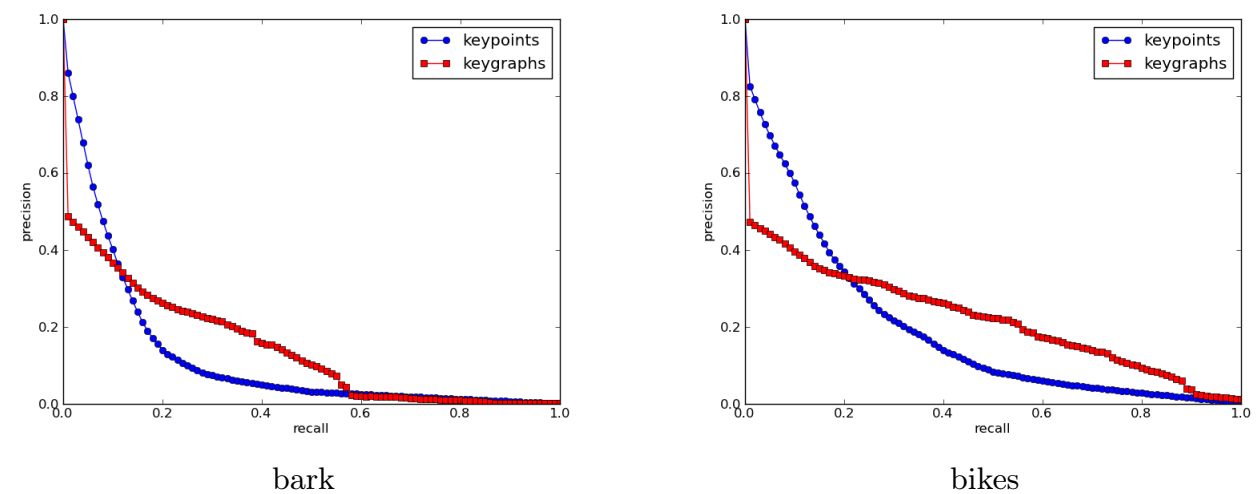

bikes
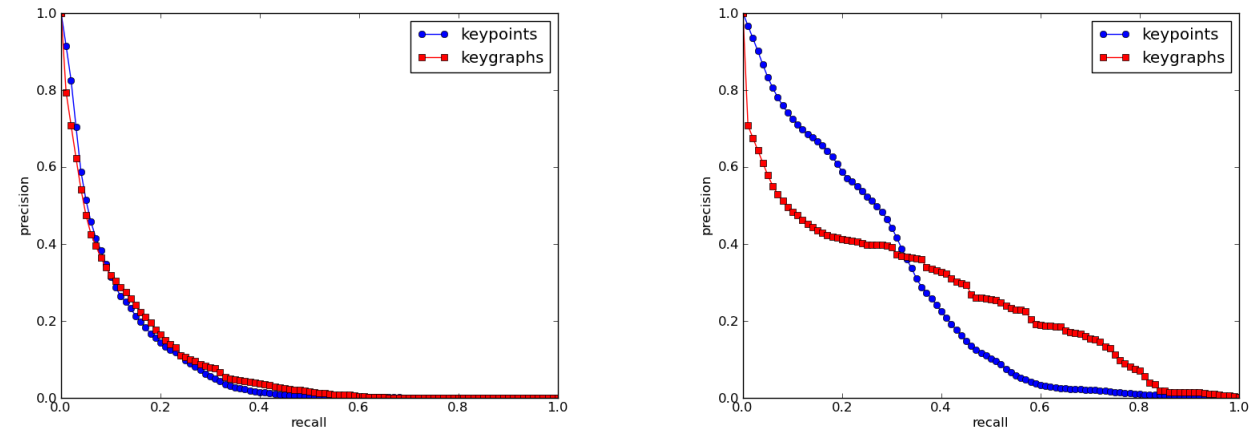

boat
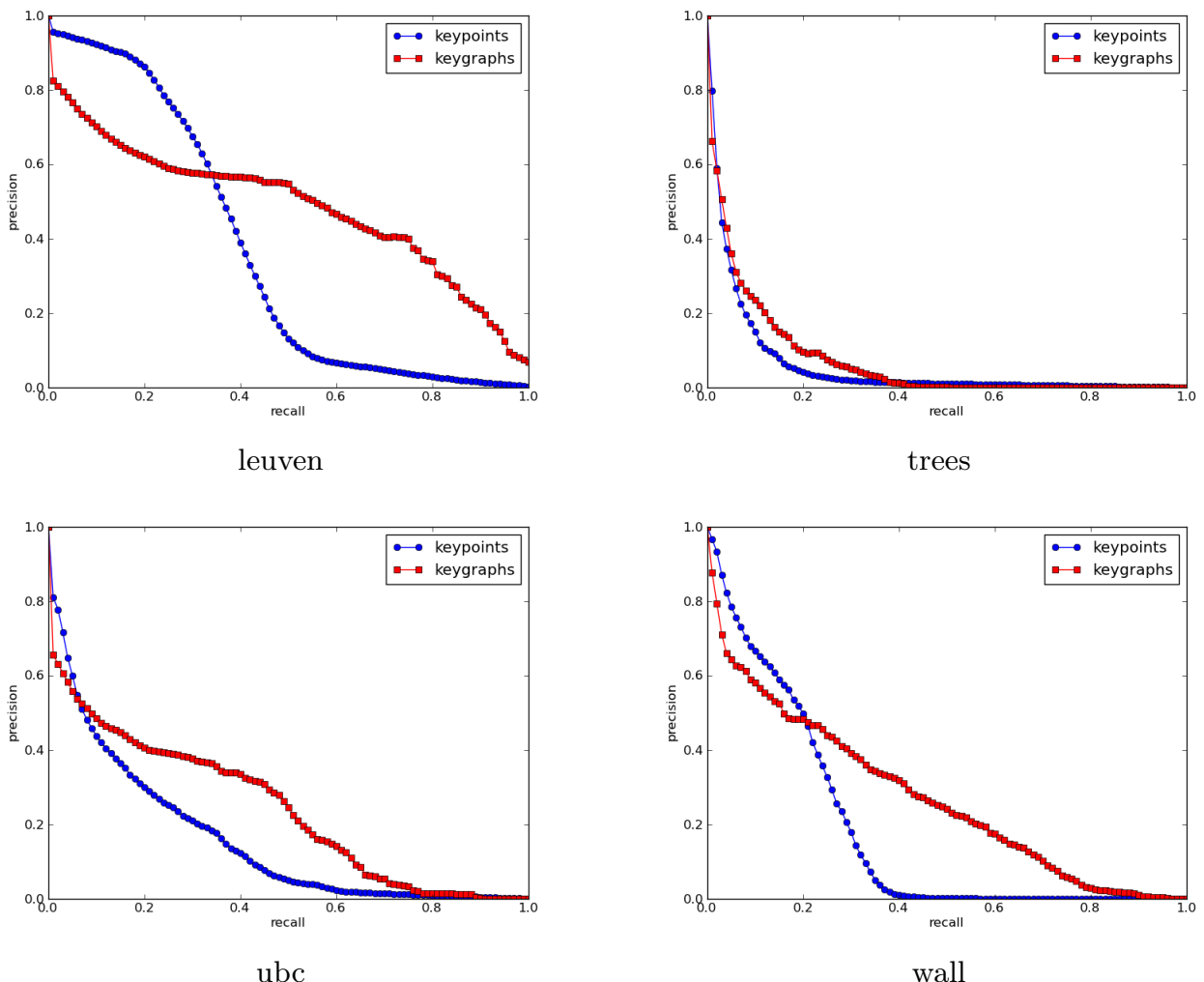

Figura 4.14. Resultados para o segundo experimento, especificamente para MSER. Cada curva é a média de 50 medidas. 
esperado de iterações que pode ser aproximado por

$$
\frac{\log (1-\mathbb{P})}{\log \left(1-p^{h}\right)}
$$

onde $h$ é o tamanho do conjunto de correspondências necessário para estimar um candidato a pose e $\mathbb{P}$ é a probabilidade de acerto que desejamos que a execução tenha. O valor de $h$ é a diferença fundamental entre pontos-chave e grafos-chave: para estimar uma homografia, quatro correspondências de pontos-chave são necessárias. Portanto, $h=4$ para pontos-chave e $h=3$ para circuitos com três vértices. A diferença no número de iterações pode ser vista na Figura 4.15.
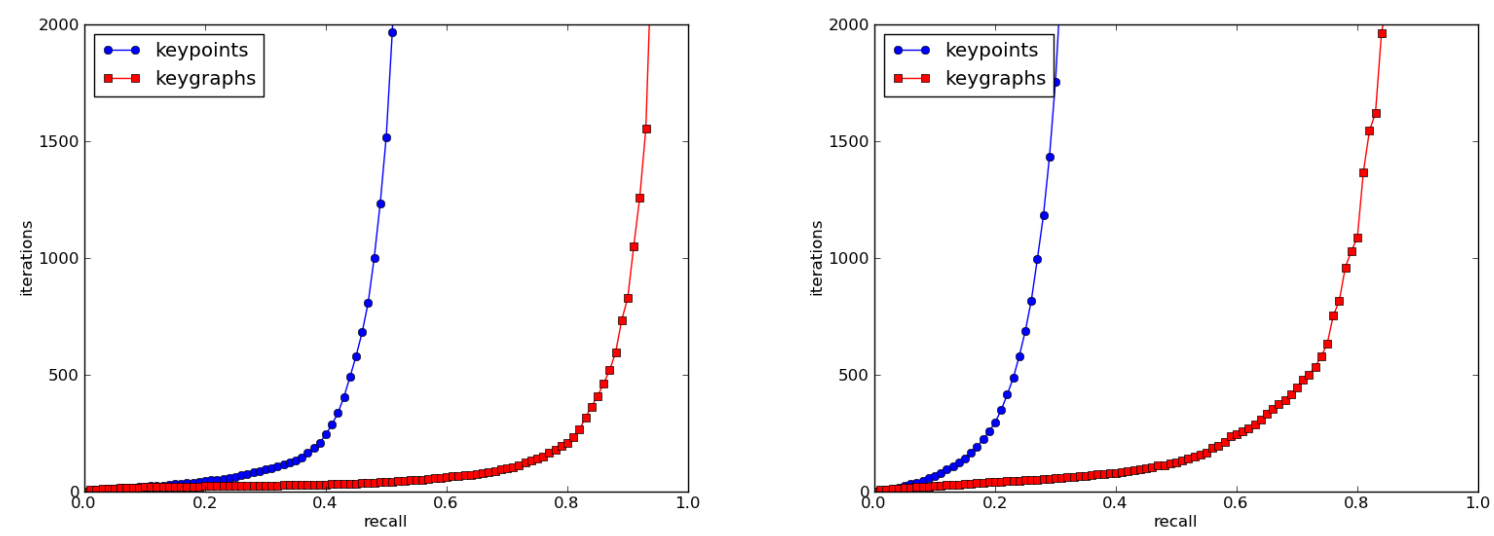

Figura 4.15. Resultados para as duas sequências de medidas no segundo experimento: (a) para Hessian-Affine e (b) para MSER. Cada curva é a média das 200 medidas tomadas para cada detector de pontos-chave.

Como pode ser visto nas Figuras 4.16 e 4.17, mesmo para os subconjuntos onde grafoschave apresentaram uma precisão consistentemente pior, eles ainda apresentaram um número de iterações consistentemente melhor.

\subsection{Detecção em tempo real}

O objetivo do terceiro e último experimento foi avaliar o tempo de execução do arcabouço de grafos-chave e sua viabilidade para aplicações de tempo real. Queríamos verificar se a implementação era capaz de detectar um objeto em cada quadro dado por uma câmera em tempo razoável. Duas sequências de testes foram feitas: uma com uma webcam de laptop fixa, cujas capturas de tela podem ser vistas na Figura 4.18, e uma com uma câmera PlayStation Eye, cujas capturas de tela são mostradas na Figura 4.19.

Ambas as câmeras foram configuradas para quadros de resolução $640 \times 480$ e todos os testes foram feitos em um laptop com um Intel Core i5. Como a versão da OpenCV utilizada não foi compilada com suporte a paralelismo, o processamento foi feito por um único core de 2.0 GHz. Para indexar os grafos-chave, indexamos os descritores de Fourier dos arcos utilizando a biblioteca FLANN [56] e para cada tupla-chave $\left(a_{s}, b_{s}, c_{S}\right)$ adotamos o seguinte procedimento:

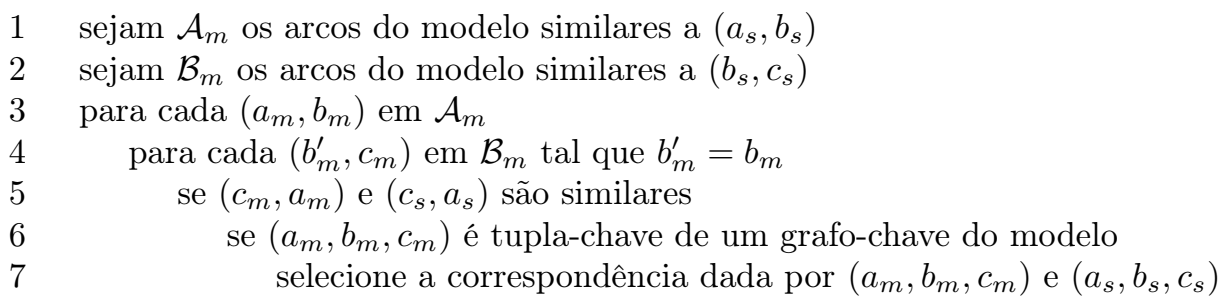




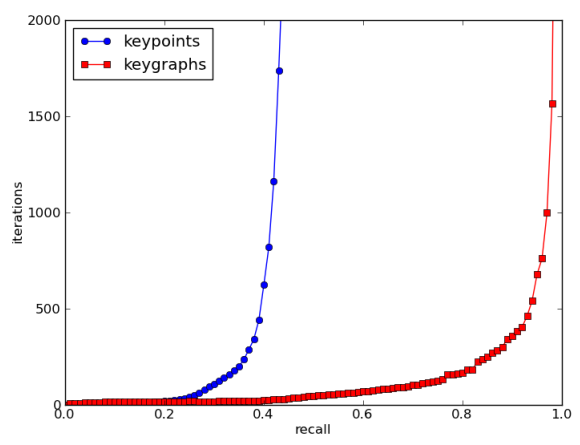

bark

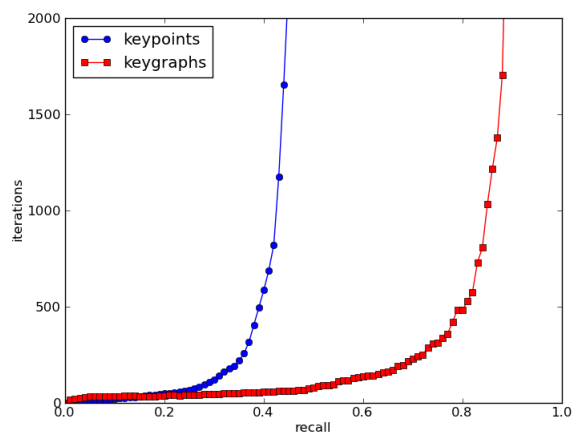

boat

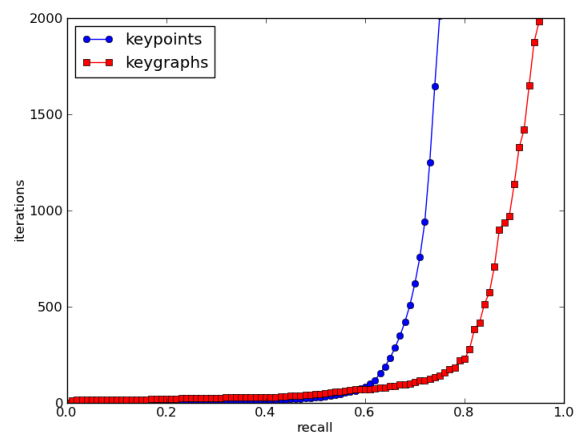

leuven

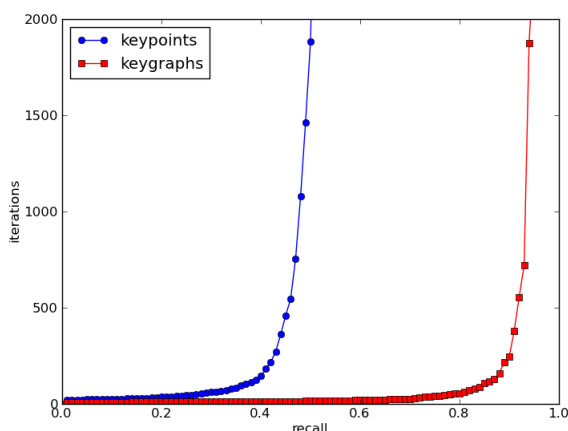

ubc

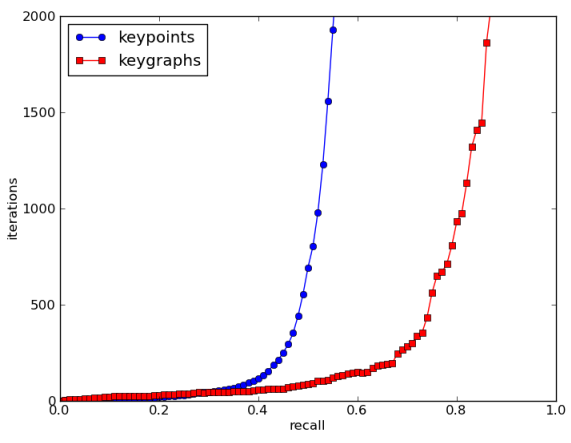

bikes

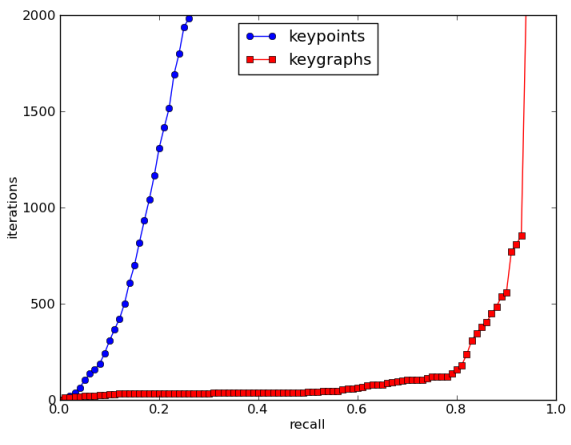

graf

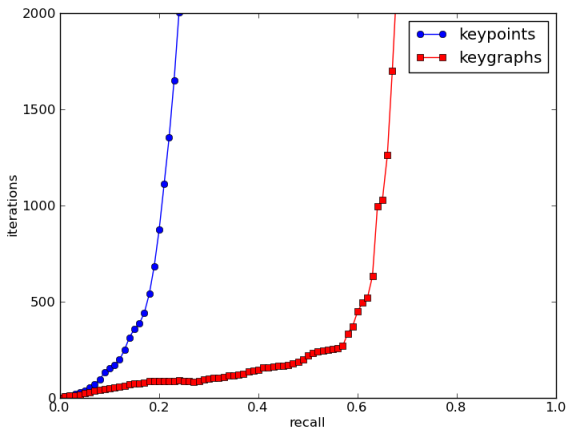

trees

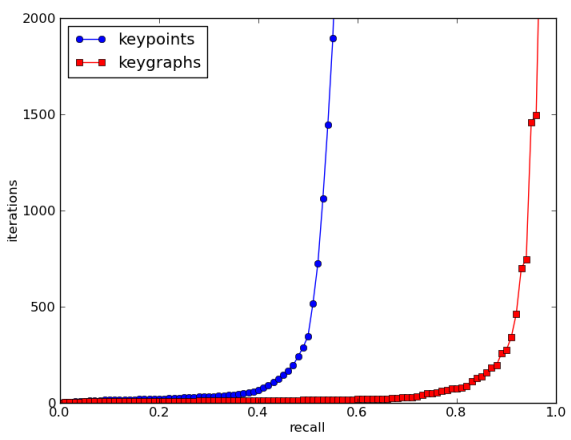

wall

Figura 4.16. Resultados para o segundo experimento, especificamente para Hessian-Affine. Cada curva é a média de 50 medidas. 


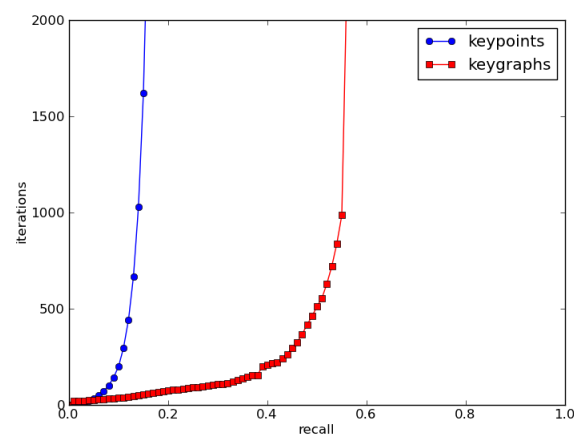

bark

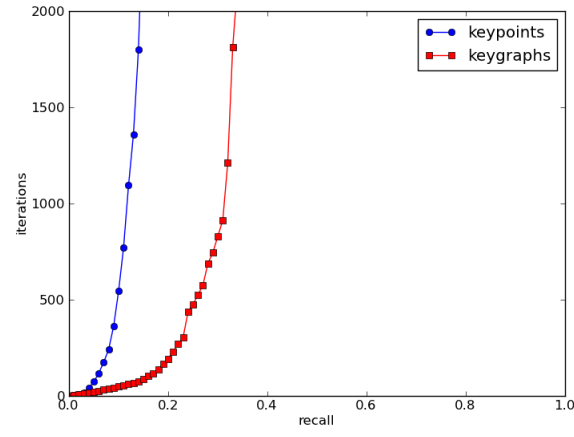

boat

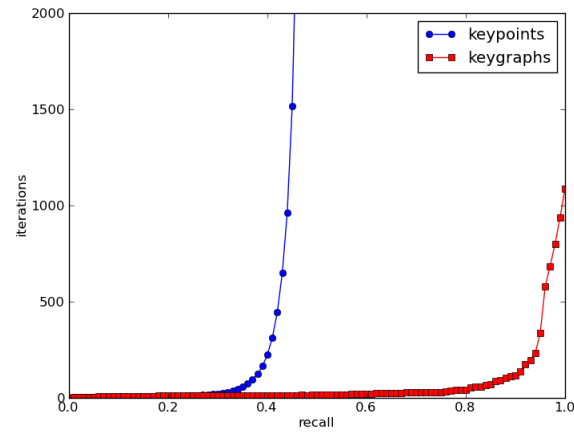

leuven

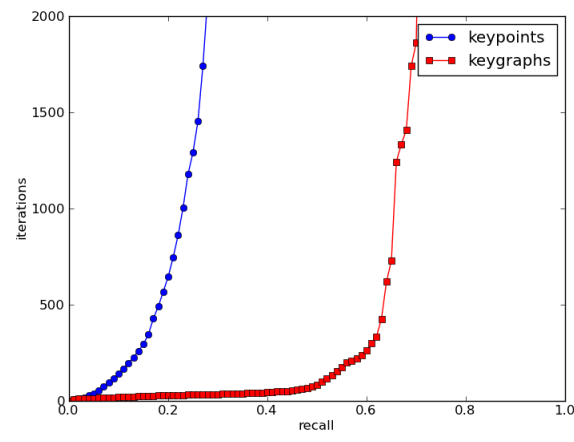

ubc

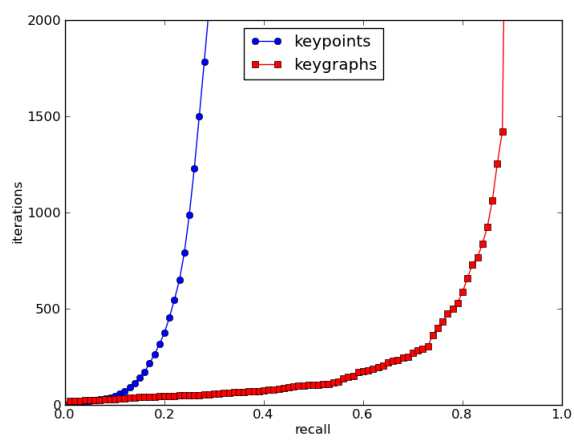

bikes

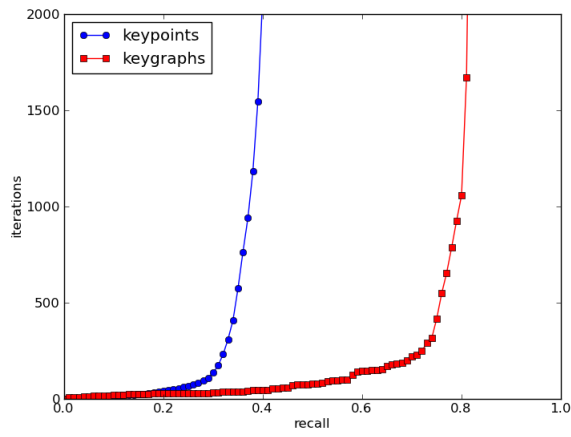

graf

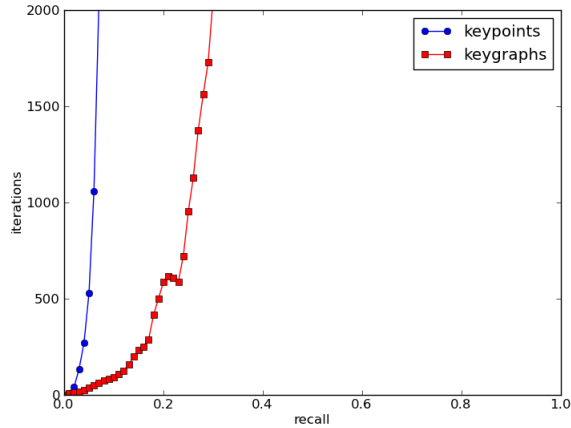

trees

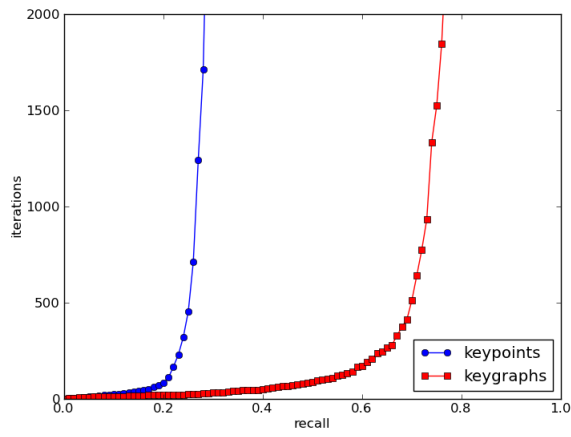

wall

Figura 4.17. Resultados para o segundo experimento, especificamente para MSER. Cada curva é a média de 50 medidas. 

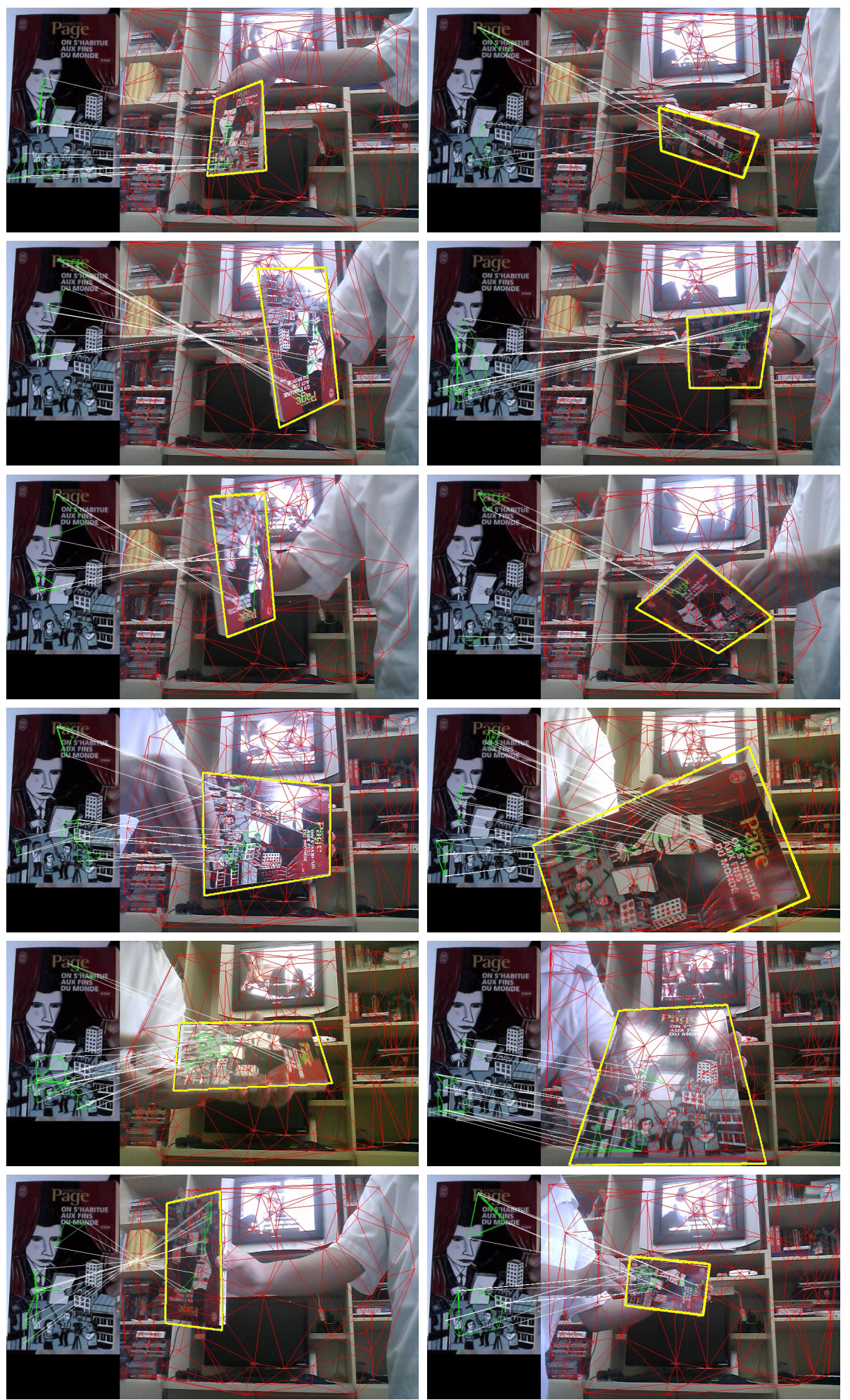

Figura 4.18. Capturas de tela da detecção de objeto com uma câmera de laptop fixa.

O limiar aplicado à distância Euclidiana dos descritores de Fourier para decidir se dois arcos são similares foi 0.5. Para ambos os testes, o tempo médio para processar cada quadro foi abaixo de $30 \mathrm{~ms}$, o que garante pelo menos 30 quadros por segundo. Utilizar técnicas de rastreamento clássicas como filtragem estatística certamente poderia reduzir ainda mais o tempo. 

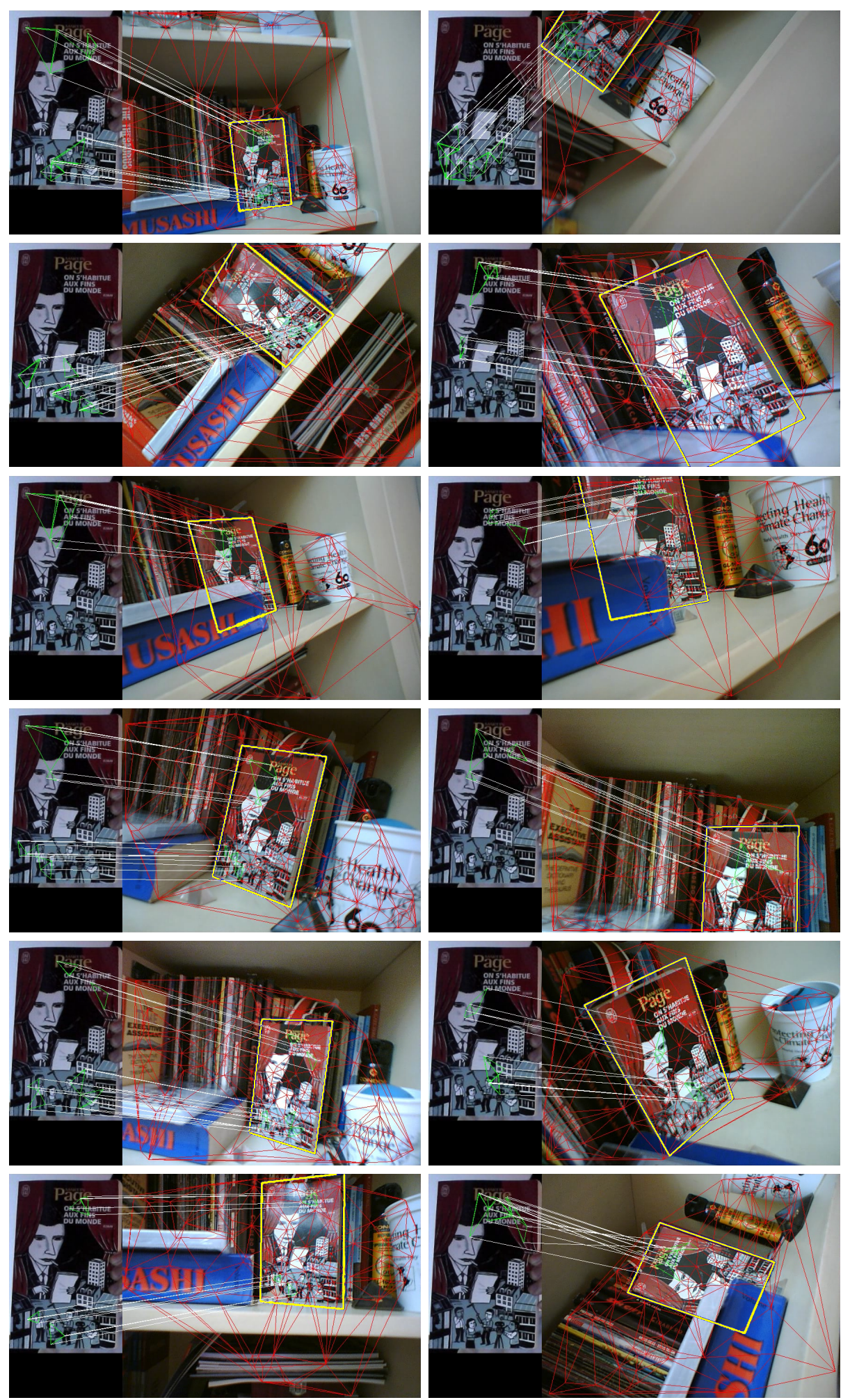

Figura 4.19. Capturas de tela da detecção de objeto com uma câmera PlayStation Eye.

\subsection{Aplicação em localização}

Nesta seção, apresentamos uma aplicação de grafos-chave em localização assistida por dispositivos móveis. Este trabalho foi realizado em cooperação com Henrique Morimitsu, Rodrigo 
Bernardo Pimentel e Roberto Hirata Junior.

Localização assistida é um problema importante de acessibilidade, cuja pesquisa remonta à Segunda Guerra [25]. Devido à necessidade de execução em tempo real, muitos trabalhos utilizam recursos como marcadores artificiais [57], para simplificar os algoritmos, ou servidores externos [23], para reduzir o processamento no dispositivo móvel. No entanto, avanços tecnológicos estão permitindo a execução de algoritmos cada vez mais complexos no próprio dispositivo: atualmente, além de maior capacidade de processamento e armazenamento, há maior variedade de acessórios disponíveis mesmo em dispositivos não-especializados como smartphones.

Um exemplo desses acessórios é o receptor $W i$ - Fi, pois os sinais podem ser utilizados para localização. Na literatura, existem abordagens baseadas em trilateração [83] e impressão digital [84]. A primeira consiste em medir a intensidade dos sinais de emissores em posições conhecidas, enquanto a segunda consiste em utilizar classificação supervisionada. Cada abordagem possui suas próprias vantagens e desvantagens, mas ambas são sensíveis a atenuação e instabilidade. De fato, embora sejam eficientes, ambas podem apresentar erros da ordem de metros [43].

Outro exemplo de acessório é a câmera, pois as imagens capturadas permitem a utilização de algoritmos de visão computacional [3, 59, 73]. No entanto, embora sejam precisos, muitos desses algoritmos exigem capacidade excessiva de processamento e armazenamento.

No trabalho proposto [54, 55], consideramos uma abordagem híbrida de localização assistida que utiliza tanto sinais Wi-Fi como visão computacional. A motivação é compensar as desvantagens de um com as vantagens do outro: a localização por sinais Wi-Fi não é suficientemente precisa mas restringe significativamente o espaço de busca, reduzindo o processamento e o armazenamento necessários para uma localização mais precisa por visão computacional.

\section{Aquisição dos dados}

O ambiente escolhido para validar a abordagem foi um corredor do Instituto de Matemática e Estatística da Universidade de São Paulo. Para aquisição dos dados, um laptop foi posicionado sobre uma estrutura móvel a aproximadamente $160 \mathrm{~cm}$ do solo. Tal estrutura foi movida em linha reta ao longo do corredor, em intervalos de $60 \mathrm{~cm}$. A cada intervalo, uma imagem do corredor foi capturada pela câmera do laptop e propriedades dos sinais Wi-Fi disponíveis foram medida por seu receptor. Ao todo, 134 intervalos foram considerados. A Figura 4.20 mostra exemplos de imagens capturadas pela câmera e a Figura 4.21 mostra as intensidades dos sinais Wi-Fi.
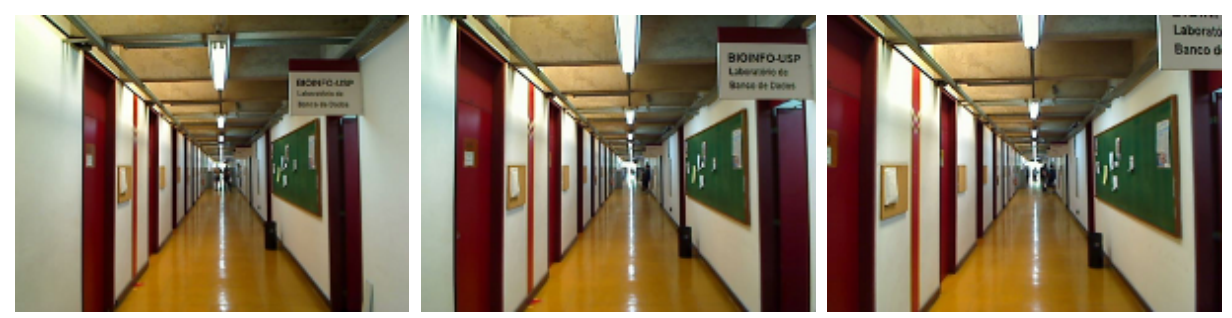

Figura 4.20. Exemplos de imagens capturadas pela câmera. Reproduzida de [55].

\section{Localização por sinais Wi-Fi}

A abordagem de impressão digital consiste em reduzir localização a um problema de classificação supervisionada: classes representam posições do usuário, características são mapeadas a redes Wi-Fi e dados são calculados a partir das intensidades e frequências captadas pelo receptor do dispositivo móvel. Neste trabalho, escolhemos utilizar um classificador Bayesiano ingênuo para classificar intensidades normalizadas. 


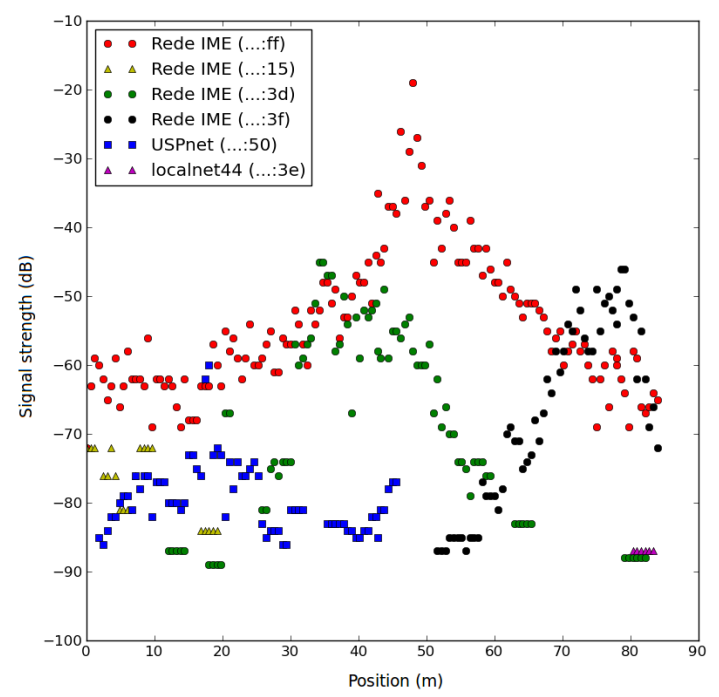

Figura 4.21. Intensidades dos sinais Wi-Fi. Reproduzida de [61].

A motivação para a escolha e a natureza da normalização não estão no escopo desta tese. Para mais detalhes, recomendamos a dissertação de mestrado de Rodrigo Bernardo Pimentel [61].

\section{Localização por visão computacional}

No contexto de deteç̧ão de objetos, as imagens capturadas pela câmera do dispositivo móvel são cenas. Neste trabalho, o procedimento de localização para cada cena consiste em dois passos:

1. detectar objetos que pertencem ao corredor;

2. caso a instância de algum objeto pertença à cena, estimar a posição do usuário comparando a pose dessa instância com dados das imagens capturadas pela câmera do laptop.

Para garantir que a abordagem fosse o menos intrusiva possível, consideramos objetos que pertencem naturalmente ao corredor em vez de depender da instalação de marcadores artificiais. Mais especificamente, consideramos as placas que identificam as salas do corredor. A Figura 4.22 mostra exemplos de modelos dessas placas.
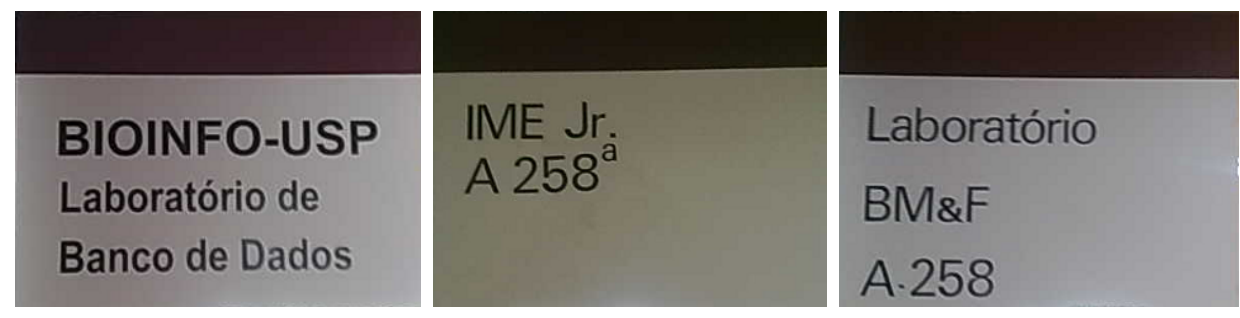

Figura 4.22. Exemplos de modelos das placas do corredor. Reproduzida de [54].

Para estimar a posição do usuário dada a pose da instância de uma placa, utilizamos um procedimento matematicamente simples mas suficientemente robusto. Primeiramente, calculamos a razão $r$ entre a área da placa na cena e a área total da cena. Em seguida, a posição é estimada por uma fórmula fechada que mapeia cada valor possível de $r$ a uma distância entre o usuário e a posição da placa detectada. Tais fórmulas são aproximadas por um procedimento de mínimos quadrados baseado nas imagens capturadas pelo laptop. A Figura 4.23 mostra um exemplo. 


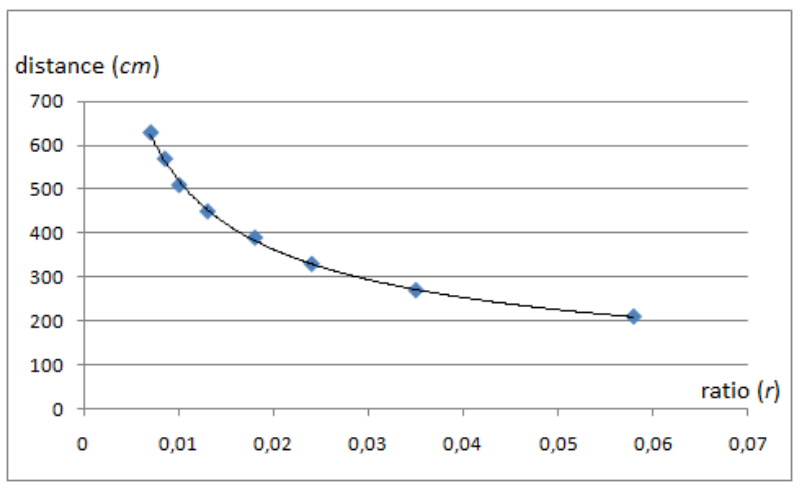

Figura 4.23. Exemplo de fórmula que mapeia razões de área a distâncias. Os pontos representam os dados das imagens capturadas e a curva representa a aproximação por mínimos quadrados. Reproduzida de [54].

\section{Detalhes de implementação}

Devido às especificações inferiores dos dispositivos móveis, algumas restrições específicas para esta aplicação foram adicionadas à detecção de objetos após avaliações empíricas.

1. Cada modelo foi redimensionado manualmente para garantir que o maior lado possuísse no máximo 500 pixels.

2. Para detectar pontos-chave, utilizamos o MSER com parâmetros ajustados manualmente para garantir que cada modelo possuísse no máximo 70 pontos-chave.

3. Para cada modelo, em vez de considerar todos os grafos-chave, consideramos a união dos conjuntos obtidos a partir de múltiplas triangulações de Delaunay. Cada triangulação foi calculada a partir de uma metade dos pontos-chave escolhida aleatoriamente. Consideramos 10 dessas subtriangulações, além da triangulação original.

4. Evitamos detectar todas as placas para cada cena utilizando informação temporal: se existe uma instância da placa na cena anterior, supomos automaticamente que também existe uma instância da placa na cena atual se o número de correspondências selecionadas contendo grafos-chave do modelo dessa placa é pelo menos $50 \%$ do número anterior.

Uma interface mostrando a posição estimada do usuário do corredor, quando a instância de uma placa pertence à cena, foi adicionada à implementação e pode ser vista na Figura 4.24.

\section{Avaliação da localização}

Para executar a localização por visão computacional, utilizamos um smartphone Nokia N900. Esse dispositivo possui um processador ARM Cortex $A 8$ de $600 \mathrm{Mhz}, 256 \mathrm{MB}$ de RAM e o sistema operacional Maemo 5. Como esse sistema é baseado no Debian Linux, nossa implementação original em C++ foi portada sem modificações significativas. A Figura 4.25 mostra que a deteç̧ão de uma placa pode ser robusta mesmo com as restrições adicionais mencionadas anteriormente.

Infelizmente, o receptor Wi-Fi desse dispositivo demonstrou instabilidade excessiva mesmo diante de emissores bem comportados. Como consequência, o erro médio da localização por sinais Wi-Fi foi de inaceitáveis $10.9 \mathrm{~m}$. Para obter resultados mais confiáveis, repetimos o procedimento em um smartphone HTC Dream com sistema operacional Android 2.2. Para esse dispositivo o erro médio foi de $1.4 \mathrm{~m}$, resultado mais consistente com a literatura [43]. 


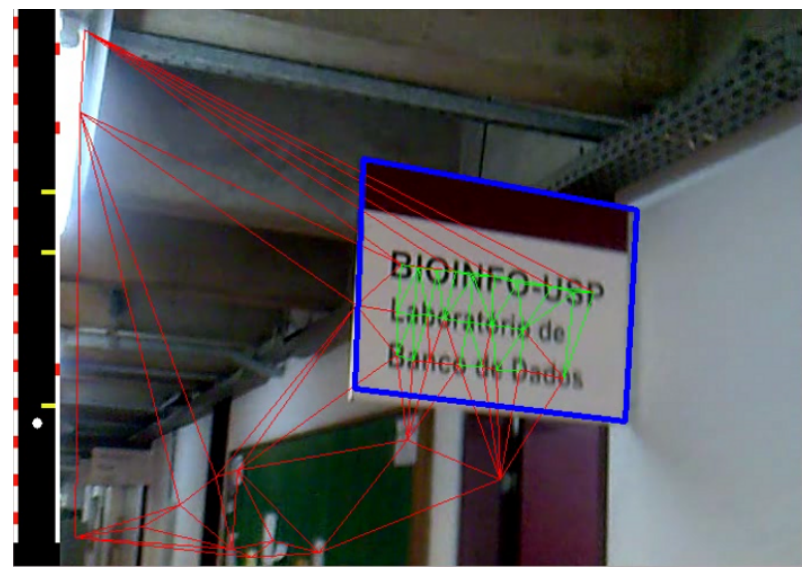

Figura 4.24. Interface da localização por detecção de placas. Reproduzida de [54].
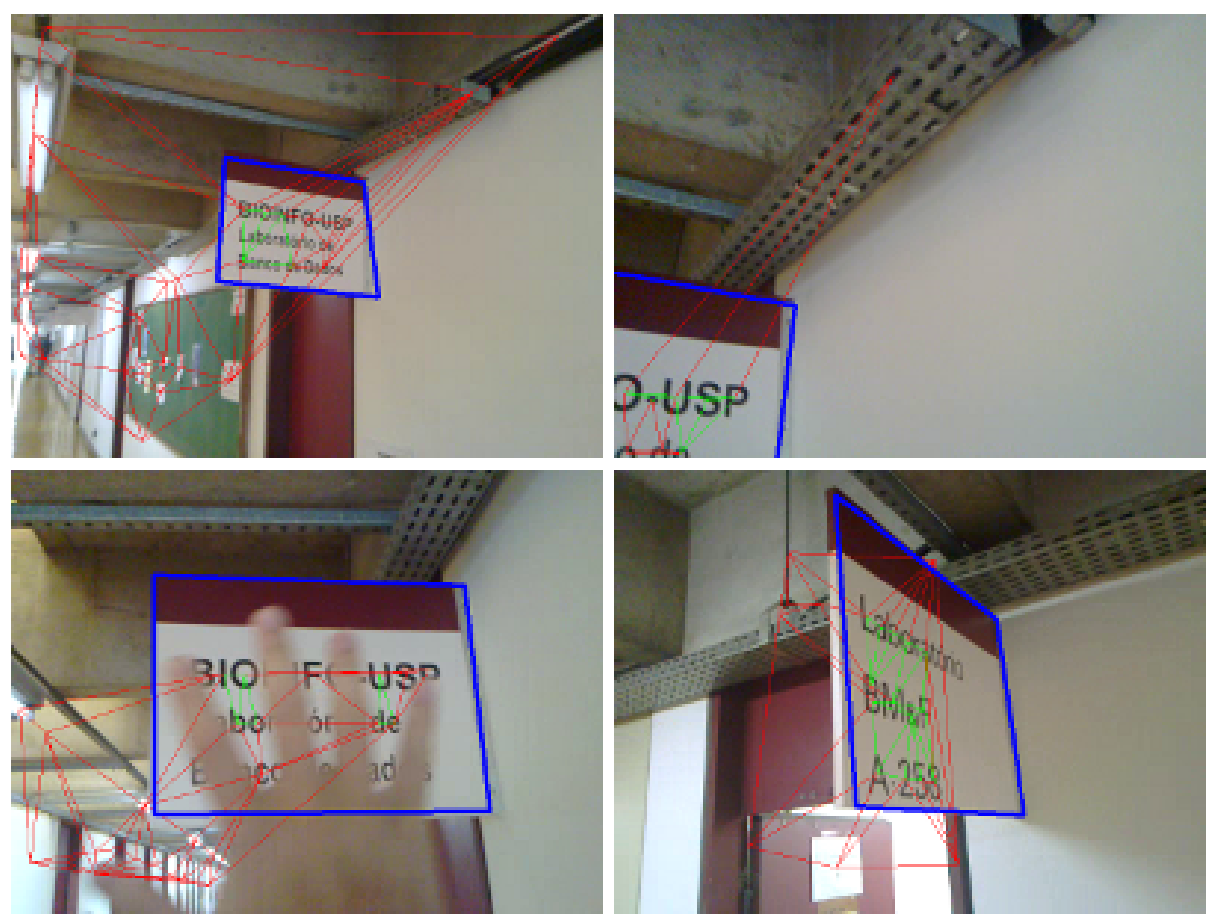

Figura 4.25. Robustez da detecção de uma placa. Reproduzida de [55].

Como esperado, a localização por visão computacional foi significativamente mais precisa: o erro médio foi de $18.6 \mathrm{~cm}$, com desvio padrão de $9.7 \mathrm{~cm}$. A Figura 4.26 mostra o resultado completo. Verificamos também que a detecção de cada placa ocorreu apenas quando o usuário estava a no máximo $2.5 \mathrm{~m}$ dela. Esse valor é particularmente relevante, pois é superior a $1.4 \mathrm{~m}$ e portanto valida a abordagem híbrida.

Para concluir, analisamos a eficiência e a escalabilidade da localização comparando os tempos de execução para diferentes conjuntos de modelos. O primeiro conjunto consiste nos três modelos da Figura 4.22. Para obter o segundo conjunto, adicionamos ao primeiro 47 modelos de objetos arbitrários. Para obter o terceiro, redimensionamos cada um dos 50 modelos do segundo para 20 proporções diferentes obtendo 1000 modelos ao todo. O tempo de execução médio para cada cena foi $620 \mathrm{~ms}$ para o primeiro conjunto, $657 \mathrm{~ms}$ para o segundo conjunto e $788 \mathrm{~ms}$ para o terceiro conjunto. A baixa variação demonstra a escalabilidade da abordagem. 


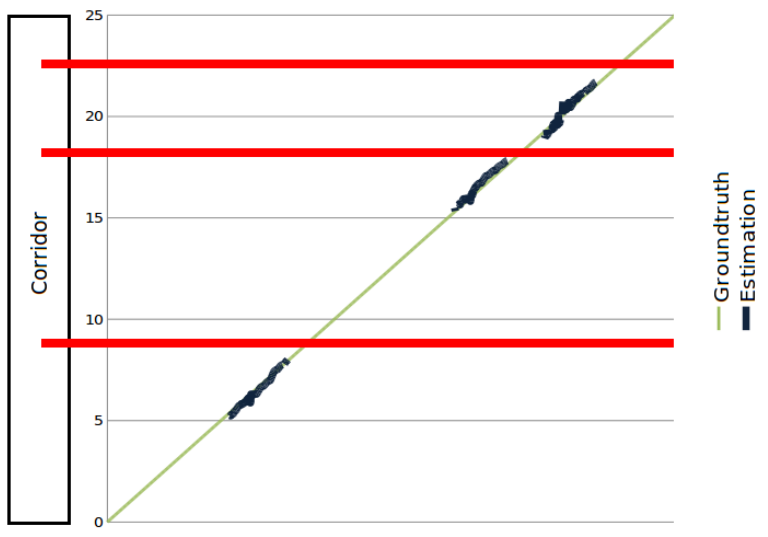

Figura 4.26. Precisão da localização por deteç̧ão de placas. As linhas vermelhas representam as posições das placas, a linha verde representa o padrão-ouro e os pontos representam os resultados. Reproduzida de [55].

\subsection{Aplicação em recuperação}

Nesta seção, apresentamos resultados preliminares da aplicação de grafos-chave em recuperação de imagens baseada em conteúdo. Este trabalho está sendo realizado sob co-orientação da Profa. Dra. Valérie Gouet-Brunet do Conservatoire National des Arts et Métiers.

Detecção, reconhecimento e recuperação são os três problemas clássicos de visão computacional envolvendo objetos e cenas. Reconhecimento consiste em decidir se uma cena contém instâncias de uma categoria de objetos, não de um objeto específico. Por exemplo, decidir se uma cena contém "motos", "casas" ou "barcos". Essa maior abrangência exige caracterizações mais flexíveis do que as utilizadas em deteç̧ão. Recuperação consiste em decidir quais cenas de um banco de imagens contêm instâncias de um objeto. Uma diferença fundamental é a disponibilização das cenas a priori.

Treinamento baseado nessa disponibilização é essencial na prática, pois aplicações de recuperação podem envolver bancos extremamente grandes. De fato, as principais aplicações são motores de busca online, que precisam verificar milhões de imagens em menos de um segundo. Tal eficiência exige a construção de estruturas de indexação. Em particular, estruturas otimizadas para armazenamento em disco, pois a quantidade de dados pode ser excessivamente grande para a memória de acesso aleatório.

Como a literatura de recuperação de imagens baseada em conteúdo é bastante rica, uma revisão geral está fora do escopo desta tese. No entanto, a presença de pontos-chave nessa literatura é antiga. O trabalho seminal de Schmid e Mohr [65] que citamos na Seção 2.1, por exemplo, foi motivado por recuperação.

No trabalho proposto, exploramos a informação estrutural de pontos-chave em recuperação, da mesma maneira que a exploramos em detecção nas seções anteriores desta tese.

\section{Recuperação por palavras visuais}

Como mencionado, a presença de pontos-chave em recuperação é antiga. No entanto, são particularmente bem-sucedidos os algoritmos baseados em palavras visuais [71, 60]. Como o nome indica, esses algoritmos foram inspirados em busca textual. Especificamente, em recuperação de documentos por frequência de termos. O arcabouço pode ser definido da seguinte maneira.

1. Detectar o conjunto de pontos-chave de cada cena do banco. 
2. Calcular o descritor de cada ponto-chave.

3. Utilizar um procedimento de classificação não-supervisionada sobre o conjunto de descritores. As classes obtidas formam um vocabulário visual: uma imagem representa um documento cujas palavras são as classes dos descritores de seus pontos-chave.

4. Calcular os descritores do modelo e das cenas, analisando a frequência de palavras no documento representado.

5. Calcular a similaridade entre o descritor do modelo e o descritor de cada cena.

O procedimento de classificação, a análise de frequências e o cálculo de similaridade variam de acordo com o algoritmo. Podemos, por exemplo, utilizar $k$-médias para classificar, $t f-i d f$ para analisar frequências e distância Euclidiana para calcular similaridade [71]. A medida tf-idf (term frequency - inverted document frequency) é bastante popular em busca textual e consiste na razão entre a frequência de um termo no documento e o logaritmo do inverso da frequência dos documentos que contêm o termo. Estruturas como arquivos invertidos permitem indexar frequências por palavra, não por documento, garantindo armazenamento eficiente.

As similaridades não apenas permitem decidir quais cenas contêm instâncias do objeto, por exemplo utilizando limiarização, mas também permitem ordenar as cenas por relevância. Essa apresentação é particularmente útil em motores de busca online.

O sucesso da abordagem depende de um bom número de classes. O vocabulário precisa ser suficientemente grande para garantir precisão e suficientemente pequeno para garantir eficiência.

\section{Recuperação por estrutura de palavras visuais}

O arcabouço descrito anteriormente não considera informação estrutural dos pontos-chave. De fato, os trabalhos originais consideram informação estrutural apenas durante uma segunda etapa de reindexação. Dentre as propostas de estrutura para a primeira indexação, podemos destacar os doublets [70], as frases visuais [86], o TSR [62] e o $\Delta$-TSR [30].

Os doublets são, como o nome indica, palavras visuais representadas por pares das classes obtidas pelo classificador não-supervisionado. A abordagem é especificamente projetada para detectores de pontos-chave capazes de associar uma região elíptica a cada ponto-chave: dois pontos representam uma palavra se e somente se estão espacialmente próximos e suas regiões são geometricamente similares.

As frases visuais são obtidas a partir das palavras visuais, a partir de uma série de análises estatísticas dos grupos de pontos-chave espacialmente próximos. Essas análises consideram grupos com mais de 2 pontos e são especificamente refinadas para lidarem com problemas inerentes à perda de localidade, como intersecção e oclusão.

O TSR (Triangular Spatial Relationship) é uma quádrupla que consiste em três palavras visuais e um ângulo específico do triângulo formado pelos pontos que as representam. Restrições baseadas em distâncias espaciais e na ordem das palavras são impostas para garantir robustez a translação, escala, rotação e espelhamento. Por fim, uma chave única é calculada para cada quádrupla, a partir de um mapeamento das palavras nos inteiros e uma discretização dos ângulos. As frequências das chaves são utilizadas para caracterizar as imagens e uma Árvore-B permite armazenamento eficiente.

Finalmente, o $\Delta$-TSR é uma generalização do TSR que permite medidas de similaridade mais robustas. Múltiplas versões são propostas: $\Delta-T S R_{1 D}, \Delta-T S R_{3 D}, \Delta-T S R_{5 D}$ e $\Delta-P S R$. O $\Delta$ - $^{-} \mathbf{S R}_{1 D}$ é simplesmente uma tripla de palavras. O $\Delta$ - $\mathbf{T S R}_{3 D}$ é uma tripla que consiste em dois ângulos e uma chave única calculada a partir das palavras. O $\Delta$ - $\mathbf{T S R}_{5 D}$ é uma quíntupla formada pelos mesmos ângulos e chave, além de duas diferenças de ângulos calculadas a partir 
das orientações das palavras. Exige, portanto, a utilização de um detector de pontos-chave que associa orientações a cada ponto, como por exemplo o SIFT. Por fim, o $\Delta$-PSR generaliza o $\Delta-\mathrm{TSR}_{5 D}$ para polígonos arbitrários.

Uma diferença fundamental de todas as propostas, exceto a $\Delta-\mathrm{TSR}_{1 D}$, é o cálculo de similaridade que não depende apenas de frequências. A similaridade entre duas imagens é calculada a partir de subsimilaridades entre pares de $\Delta$-TSRs que possuem a mesma chave.

Existem muitos paralelos entre $\Delta$-TSRs e grafos-chave, pois ambos são estruturas semi-locais que generalizam abordagens baseadas em pontos-chave explorando informação estrutural. Em particular, $\Delta$-TSRs demonstram que é possível recuperar imagens eficientemente a partir de correspondências entre essas estruturas, sem a necessidade de simplificações como análise de frequência. Isso nos encorajou a tentar adaptar os algoritmos de grafos-chave ao contexto de recuperação.

\section{Bancos de imagens}

Até o momento, consideramos dois bancos de imagens em nossos experimentos. O primeiro é a coleção $D B_{600}$, que consiste em imagens sintéticas originalmente geradas para avaliar o $\Delta$-TSR. Cada imagem consiste em um modelo do conhecido banco de imagens COIL-100 [58], inserido artificialmente em uma fotografia aleatória de 352x288 pixels. Para cada pose de cada objeto, 10 fotografias são utilizadas. São ao todo 20 objetos, cada um com 3 poses, totalizando 600 imagens. A Figura 4.27 mostra alguns exemplos.
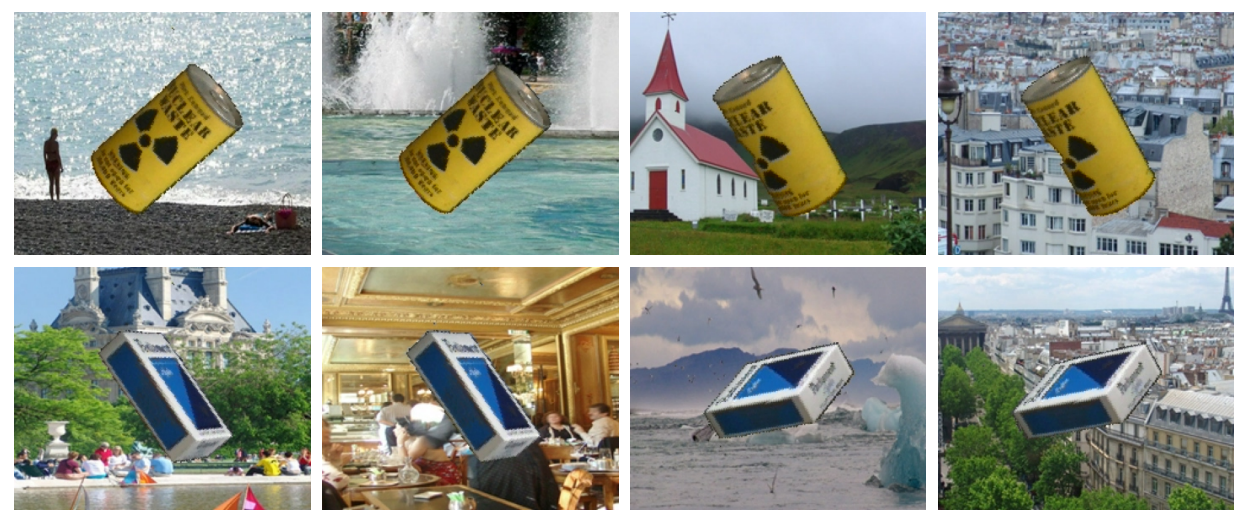

Figura 4.27. Exemplos da coleção $\mathrm{DB}_{600}$. Reproduzida de [30].

O segundo é o Oxford Buildings Dataset [60], que consiste em 5062 imagens do sítio Flickr, com pontos-chave Hessian-Affine e descritores SIFT. A presença de 11 pontos de referência da cidade de Oxford foi anotada manualmente. A Figura 4.28 mostra alguns exemplos.

\section{Experimentos preliminares}

Para avaliar o potencial de grafos-chave em recuperação de imagens baseada em conteúdo, implementamos as seguintes adaptações do arcabouço.

1. Indexamos os grafos-chave do banco de imagens em vez dos grafos-chave do modelo.

2. A cada correspondência de grafos-chave associamos uma dissimilaridade global, definida simplesmente como a média das dissimilaridades locais.

3. Definimos a similaridade entre duas imagens como o inverso da média das dissimilaridades globais das correspondências selecionadas. 


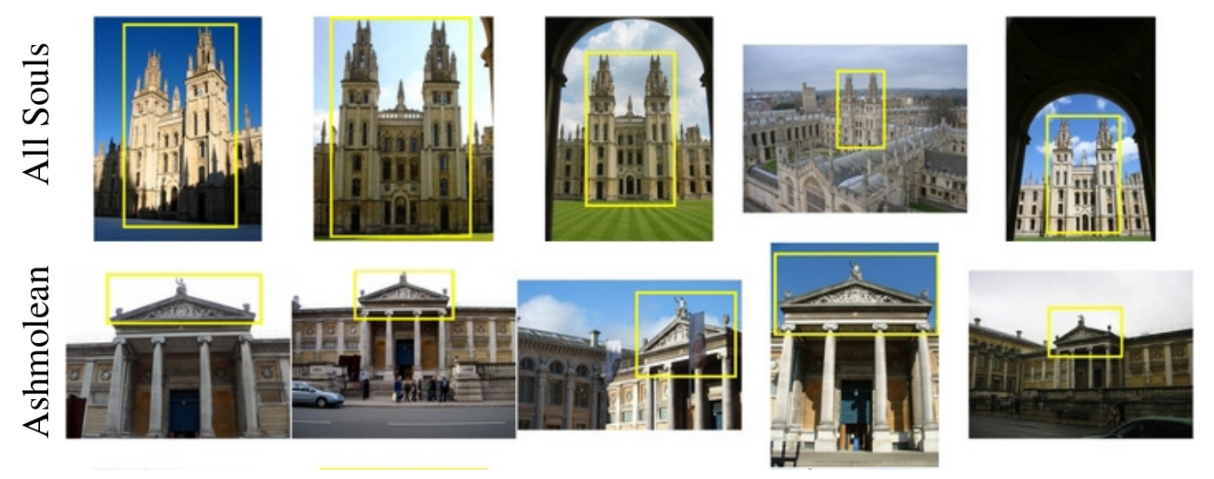

Figura 4.28. Exemplos do Oxford buildings dataset. Reproduzida de [60].

4. Para reduzir o impacto de correspondências incorretas na similaridade, utilizamos um critério mais rígido para selecionar correspondências: para cada grafo-chave do modelo, consideramos apenas a correspondência com menor dissimilaridade global, ou seja, o vizinho mais próximo.

Essas adaptações são suficientes para, dado um modelo, ordenar as imagens do banco em ordem de relevância. A partir dessa ordem, um gráfico de revocação-precisão pode ser obtido para cada busca. Para visualizar os resultados, calculamos o gráfico de revocação-precisão médio relativo a uma sequência de buscas.

Ao longo dos experimentos, muitas outras adaptações foram realizadas seguindo os resultados.

- Para reduzir o tempo de execução dos experimentos, o detector de pontos-chave utilizado foi o SURF [6]. Para o Oxford Buildings Dataset, também realizamos experimentos utilizando os pontos-chave Hessian-Affine disponíveis no próprio banco de imagens.

- Reintroduzimos descritores de pontos. Especificamente, utilizamos o descritor SURF [6]. Para o Oxford Buildings Dataset, também realizamos experimentos utilizando os descritores SIFT disponíveis no próprio banco de imagens.

- Introduzimos um descritor de arcos baseado em uma versão unidimensional do SURF.

- Introduzimos descritores de triângulos, baseados na região interna. Especificamente, utilizamos histogramas tradicionais, coeficientes de Fourier e histogramas OSID [74].

- Realizamos experimentos com diferentes combinações dos três tipos de descritor, além de diferentes combinações de limiar.

- Como utilizamos descritores de pontos e triângulos, não foi possível utilizar a mesma indexação da Seção 4.4. Em vez disso, em cada experimento um dos três tipos de descritor foi escolhido para ser indexado com pelo algoritmo E2LSH [2], uma implementação específica do LSH [24] que estima parâmetros automaticamente.

- No caso dos pontos e arcos, foram indexados vetores obtidos a partir da concatenação dos três descritores de um mesmo grafo. Esse procedimento não é matematicamente equivalente a limiarizar cada um dos três descritores individualmente, mas não houve variação de precisão na prática. No entanto, verificamos que executar as limiarizações parciais sobre as respostas do E2LSH melhorou o tempo de execução.

- Realizamos experimentos nos quais a detecção exaustiva de grafos-chave do modelo foi substituída pela deteç̧ão baseada em múltiplas triangulações de Delaunay, descrita na 
Seção 4.5. De fato, essa detecção foi originalmente proposta nesta pesquisa e posteriormente aplicada em localização.

- Como a triangulação de Delaunay garante que cada arco da cena pertence a um e somente um grafo-chave, realizamos um experimentos nos quais utilizamos três estruturas E2LSH em vez de uma: indexamos separadamente os "primeiros arcos", os "segundos arcos" e os "terceiros arcos" dos grafos-chave. No entanto, devido a motivos que serão explicados na próxima subseção, essa modificação reduziu a eficiência em vez de aumentá-la.

A Figura 4.29 mostra um dos gráficos de revocação-precisão obtidos para o $\mathrm{DB}_{600}$. As melhores combinações de parâmetros permitiram uma precisão média de 0,72 , mas exigiram um tempo de execução inaceitavelmente alto, da ordem de vários segundos. Resultados preliminares para o Oxford Buildings Dataset exigiram um tempo ainda maior, pois as imagens contém muito mais pontos-chave.

Uma adaptação direta do arcabouço para recuperação, portanto, parece impraticável. Uma das principais dificuldades está na impossibilidade de aplicar o mesmo princípio de assimetria que utilizamos em deteç̧ão: idealmente deveríamos detectar exaustivamente os grafos-chave das cenas, mas o espaço necessário seria impraticável.

Atualmente, estamos pesquisando maneiras de adaptar o processo original de classificação não-supervisionada ao conjunto de descritores disponíveis em grafos-chave.

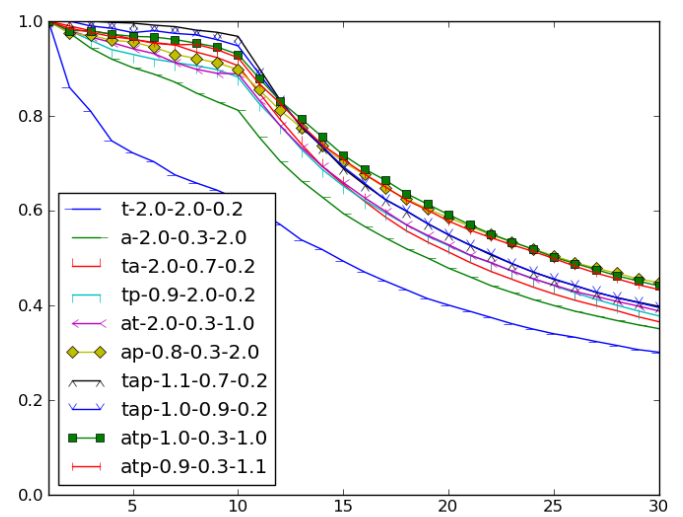

Figura 4.29. Gráfico de revocação-precisão para o $\mathrm{DB}_{600}$. As letras iniciais indicam quais descritores foram usados dentre pontos, arcos e triângulos. O primeiro é o que foi indexado. Os números indicam os limiares utilizados para cada descritor, na respectiva ordem.

\section{Avaliação de descritores}

Paralelamente aos gráficos de revocação-precisão, obtivemos histogramas de distância dos descritores. Esses histogramas são uma ferramenta popular para avaliar indexabilidade [5, 4], pois caracteriza a distribuição do espaço de características. Eles são obtidos calculando-se a distância de todos os pares de todos os descritores das imagens do banco.

A Figura 4.30 mostra alguns exemplos de histogramas de distância, calculados a partir do $\mathrm{DB}_{600}$. Analisando os histogramas, é possível avaliar por exemplo se um determinado limiar elimina correspondências eficientemente.

Dentro do contexto de nossos experimentos, os histogramas também mostram o impacto da concatenação de descritores. A Figura 4.31 mostra os histogramas de distâncias dos descritores de arco individuais e concatenados. A versão concatenada permite uma maior eliminação de 


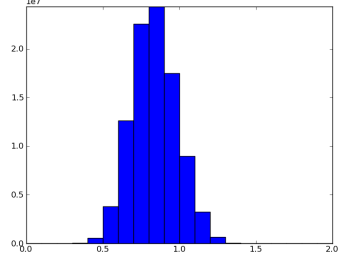

(a)

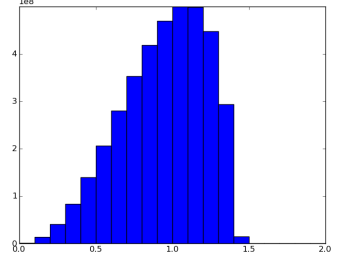

(b)

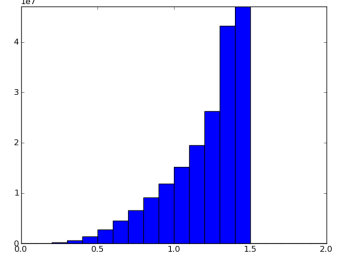

(c)

Figura 4.30. Exemplos de histogramas de distância. (a) Distâncias de descritores de pontos, especificamente SURF. (b) Distâncias de descritores de arco, especificamente a versão unidimensional do SURF. (c) Distâncias de descritores de triângulo, especificamente histogramas tradicionais.

correspondências para limiares mais baixos. Isso é consistente com os resultados piores que obtivemos com a ideia de indexar separadamente "primeiros arcos", "segundos arcos" e "terceiros arcos".

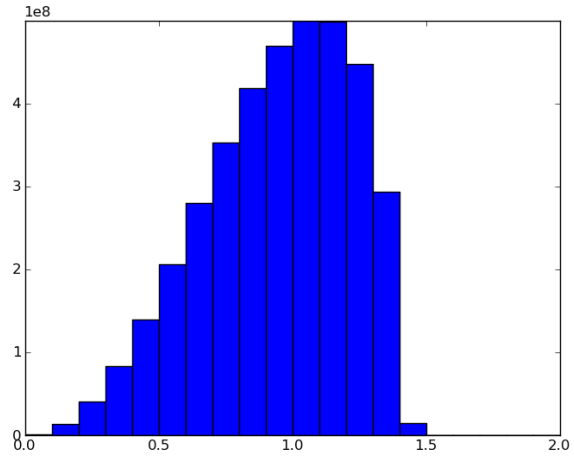

não-concatenados

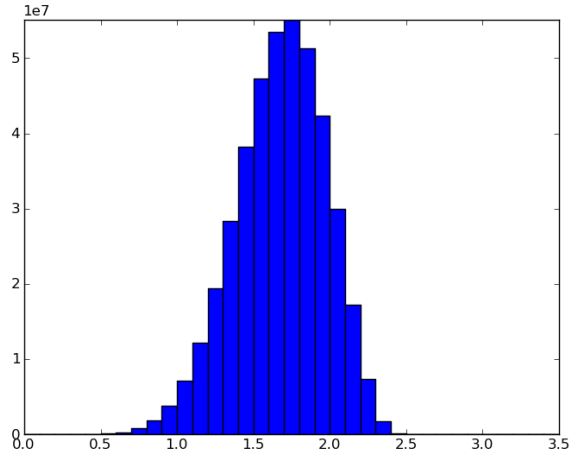

concatenados

Figura 4.31. Comparação dos histogramas de distâncias de arcos. 



\section{Capítulo 5}

\section{Conclusão}

\subsection{Comentários finais}

Nesta tese, propomos um arcabouço para detecção de objetos baseado em uma generalização de correspondências de pontos-chave em correspondências de grafos-chave. A principal diferença de nossa abordagem para outras na literatura está no fato de que cada passo lida diretamente com grafos: a descrição não precisa de descritores de região, a comparação leva toda a estrutura em consideração e a estimação de pose utiliza correspondências de grafos diretamente em vez de convertê-las através de uma tabela de votação. Para demonstrar a viabilidade do arcabouço, propusemos uma implementação com baixa complexidade teórica e realizamos experimentos para validar sua precisão e eficiência.

\subsection{Perspectivas}

Esta seção contém algumas possibilidades futuras de pesquisa que consideramos particularmente interessantes.

- Hipergrafos. O arcabouço atualmente utiliza descritores de vértices e arcos. Em outras palavras, pontos e pares de pontos. Futuramente, podemos considerar descritores de conjuntos maiores. Formalmente, estaríamos estendendo o arcabouço para hipergrafos.

- Objetos deformáveis. Em nossos exemplos lidamos apenas com modelos rígidos, cujos grafos-chave podem ser caracterizados a partir de propriedades geométricas. Para adaptar o arcabouço a objetos deformáveis, será necessário considerar propriedades topológicas. Relações espaciais fuzzy [8] são uma maneira natural de modelar e medir tais propriedades.

- Rastreamento verdadeiro. Nossas implementações atuais permitem rastrear um objeto em um vídeo detectando-o a cada quadro. Isso desperdiça informação temporal. Pode ser interessante pesquisar como as técnicas consagradas de rastreamento, como por exemplo filtros estatísticos, podem ser utilizadas no contexto de grafos-chave.

- Casamento de grafos. Existe muita literatura disponível a respeito de algoritmos baseados em casamento de grafos. Se considerarmos o diagrama de Voronoi que é o grafo dual da triangulação de Delaunay, temos um grafo cujos vértices são grafos-chave. Esse pode ser um ponto de partida para adaptar os algoritmos de casamento de grafos.

- Métodos hierárquicos. Muitos métodos baseados em variar a granularidade da análise da imagem estão sendo desenvolvidos atualmente. É possível que alguns possam ser adaptados 
a grafos-chave. Por exemplo, quanta informação podemos obter a partir de um grafo extraídos de uma triangulação aplicada sobre os centroides das faces de outra triangulação?

- Malhas estáveis. Avaliando as implementações atuais no contexto de vídeos, percebemos que muitos problemas são causados pela instabilidade da triangulação de Delaunay. Pesquisar métodos mais estáveis para obter grafos planares pode ser útil. Em particular, trabalhos sobre construção de malhas em computação gráfica podem representar um ponto de partida.

- Detecção especial. Uma possibilidade interessante é desenvolver detectores de pontoschave especificamente adequados para construir bons grafos-chave. Um bom passo nessa direção são as critical nets recentemente propostas por Gu et al. [26]. 


\section{Referências Bibliográficas}

[1] M. Agrawal, K. Konolige e M. R. Blas, CenSurE: Center Surround Extremas for realtime feature detection and matching, Proceedings of the 10th European Conference on Computer Vision: Part IV (D. Forsyth, P. Torr e A Zisserman, eds.), Lecture Notes in Computer Science, vol. 5305, Springer, 2008, págs. 102-115. 9, 14, 26

[2] A. Andoni e P. Indyk, Near-optimal hashing algorithms for approximate nearest neighbor in high dimensions, Communications of the ACM 51 (2008), no. 1, 117-122. 49

[3] C. Arth, D. Wagner, M. Klopschitz, A. Irschara e D. Schmalstieg, Wide area localization on mobile phones, Proceedings of 2009 IEEE International Symposium on Mixed and Augmented Reality, IEEE Computer Society Press, 2009, págs. 73-82. 42

[4] S. Barton, V. Gouet-Brunet, M. Rukoz, C. Charbuillet e G. Peeters, Estimating the indexability of multimedia descriptors for similarity searching, Proceedings of the 9th International Conference on Adaptivity, Personalization and Fusion of Heterogeneous Information, 2010, págs. 1-12. 26, 50

[5] _ Qualitative comparison of audio and visual descriptors distributions, Proceedings of the 2010 International Conference on Multimedia Computing and Information Technology, 2010, págs. 101-104. 26, 50

[6] H. Bay, T. Tuytelaars e L. van Gool, SURF: Speeded Up Robust Features, Computer Vision and Image Understanding 110 (2008), no. 3, 346-359. 8, 9, 14, 26, 49

[7] S. Belongie, J. Malik e J. Puzicha, Shape matching and object recognition using shape contexts, IEEE Transactions on Pattern Analysis and Machine Intelligence 24 (2002), no. 4, 509-522. 14, 15, 16

[8] I. Bloch, Fuzzy spatial relationships for image processing and interpretation: a review, Image and Vision Computing 23 (2005), no. 2, 89-110. 53

[9] G. Bouchard e B. Triggs, Hierarchical part-based visual object categorization, Proceedings of the 2005 IEEE Computer Society Conference on Computer Vision and Pattern Recognition, vol. 1, IEEE Computer Society Press, 2005, págs. 710-715. 15

[10] G. Bradski e A. Kaehler, Learning OpenCV: Computer vision with the OpenCV library, O'Reilly Media, 2008. 29

[11] J. E. Bresenham, Algorithm for computer control of a digital plotter, IBM Systems Journal 4 (1965), no. $1,25-30.23$

[12] T. S. Caetano, L. Cheng, Q. V. Le e A. J. Smola, Learning graph matching, Proceedings of the 11th IEEE International Conference on Computer Vision, IEEE Computer Society Press, 2007, págs. 1-8. 16 
[13] G. Carneiro e D. Lowe, Sparse flexible models of local features, Proceedings of the 9th European Conference on Computer Vision: Part III (A. Leonardis, H. Bischof e A. Pinz, eds.), Lecture Notes in Computer Science, vol. 3953, Springer, 2006, págs. 29-43. 15

[14] R. M. Cesar Jr., E. Bengoetxea, I. Bloch e P. Larranaga, Inexact graph matching for modelbased recognition: evaluation and comparison of optimization algorithms, Pattern Recognition 38 (2005), no. 11, 2099-2113. 18

[15] D. Crandall, P. Felzenszwalb e D. Huttenlocher, Spatial priors for part-based recognition using statistical models, Proceedings of the 2005 IEEE Computer Society Conference on Computer Vision and Pattern Recognition, vol. 1, IEEE Computer Society Press, 2005, págs. 10-17. 15

[16] J. L. Crowley e A. C. Sanderson, Multiple resolution representation and probabilistic matching of 2D gray-scale shape, IEEE Transactions on Pattern Analysis and Machine Intelligence 9 (1987), no. 1, 113-121. 13

[17] M. de Berg, O. Cheong, M. van Krefeld e M. Overmars, Computational geometry: Algorithms and applications, third edition, Springer, 2008. 24

[18] Y. Dufournaud, C. Schmid e R. Horaud, Matching images with different resolutions, Proceedings of the 2000 IEEE Computer Society Conference on Computer Vision and Pattern Recognition, IEEE Computer Society Press, 2000, págs. 612-618. 13

[19] M. Ebrahimi e W. W. Mayol-Cuevas, SUSurE: Speeded Up Surround Extrema feature detector and descriptor for realtime applications, Proceedings of the 2009 IEEE Computer Society Conference on Computer Vision and Pattern Recognition, IEEE Computer Society Press, 2009, págs. 9-14. 14, 26

[20] M. A. Fischler e R. C. Bolles, Random Sample Consensus: a paradigm for model fitting with applications to image analysis and automated cartography, Communications of the ACM $\mathbf{2 4}$ (1981), no. 6, 381-395. 9

[21] S. Fortune, A sweepline algorithm for Voronoi diagrams, Proceedings of the 2nd Annual Symposium on Computational Geometry, ACM Press, 1986, págs. 313-322. 24

[22] M. Frigo e S. G. Johnson, The design and implementation of FFTW3, Proceedings of the IEEE 93 (2005), no. 2, 216-231. 29

[23] S. Gammeter, A. Gassmann, L. Bossard, T. Quack e L. van Gool, Server-side object recognition and client-side object tracking for mobile augmented reality, Proceedings of the 2010 IEEE Computer Society Conference on Computer Vision and Pattern Recognition Workshops, IEEE Computer Society Press, 2010, págs. 1-8. 42

[24] A. Gionis, P. Indyk e R. Motwani, Similarity search in high dimensions via hashing, Proceedings of 25th International Conference on Very Large Data Bases (M. P. Atkinson, M. E. Orlowska, P. Valduriez, S. B. Zdonik e M. L. Brodie, eds.), Morgan Kaufmann, 1999, pág. 518-529. 49

[25] P. D. Groves, Principals of gnss, inertial, and multisensor integrated navigation systems, Arthech House, 2008. 42

[26] S. Gu, Y. Zheng e C. Tomasi, Critical nets and beta-stable features for image matching, Proceedings of the 11th European Conference on Computer Vision: Part III (K. Daniilidis, 
P. Maragos e N. Paragios, eds.), Lecture Notes in Computer Science, vol. 6313, Springer, 2010, págs. 663-676. 54

[27] C. G. Harris e M. J. Stephens, A combined corner and edge detector, Proceedings of the 4th Alvey Vision Conference, University of Sheffield Printing Unit, 1988, págs. 147-152. 12, 13, 26

[28] M. Hashimoto e R. M. Cesar Jr., Object detection by keygraph classification, Proceedings of the 7th IAPR-TC-15 International Workshop on Graph-Based Representations in Pattern Recognition (A. Torsello, F. Escolano e L. Brun, eds.), Lecture Notes in Computer Science, vol. 5534, Springer, 2009, págs. 223-232. 22

[29] S. Hinterstoisser, S. Benhimane e N. Navab, N3M: Natural 3D Markers for real-time object detection and pose estimation, Proceedings of the 11th IEEE International Conference on Computer Vision, IEEE Computer Society Press, 2007, págs. 1-7. 16

[30] N. V. Hoang, V. Gouet-Brunet, M. Rukoz e M. Manouvrier, Embedding spatial information into image content description for scene retrieval (in press), Pattern Recognition 43 (2010), no. 9, 3013-3024. 16, 47, 48

[31] J. Illingworth e J. Kittler, A survey of the Hough transform, Computer Vision, Graphics and Image Processing 44 (1988), no. 1, 87-116. 9

[32] Y. Kanazawa e K. Uemura, Wide baseline matching using triplet vector descriptor, Proceedings of the 17th British Machine Vision Conference, vol. I, British Machine Vision Association, 2006, págs. 267-276. 16, 28

[33] A. Kandel, H. Bunke e M. Last, Applied graph theory in computer vision and pattern recognition, Studies in Computational Intelligence, vol. 52, Springer, 2007. 16

[34] Y. Ke e R. Sukthankar, PCA-SIFT: a more distinctive representation for local image descriptors, Proceedings of the 2004 IEEE Computer Society Conference on Computer Vision and Pattern Recognition, vol. 2, IEEE Computer Society Press, 2004, págs. 506-513. 14, 26

[35] W. G. Kropatsch, Benchmarking graph matching algorithms: a complementary view, Proceedings of the 3rd IAPR-TC-15 International Workshop on Graph-Based Representations in Pattern Recognition (J.-M. Jolion, W. G. Kropatsch e M. Vento, eds.), CUEN, 2001, págs. 210-216. 16

[36] S. Lazebnik, C. Schmid e J. Ponce, Beyond bags of features: spatial pyramid matching for recognizing natural scene categories, Proceedings of the 2006 IEEE Computer Society Conference on Computer Vision and Pattern Recognition, vol. 2, IEEE Computer Society Press, 2006, págs. 2169-2178. 16

[37] M. Leordeanu, M. Hebert e R. Sukthankar, Beyond local appearance: category recognition from pairwise interactions of simple features, Proceedings of the 2007 IEEE Computer Society Conference on Computer Vision and Pattern Recognition, IEEE Computer Society Press, 2007, págs. 1-8. 15

[38] V. Lepetit e P. Fua, Keypoint recognition using randomized trees, IEEE Transactions on Pattern Analysis and Machine Intelligence 28 (2006), no. 9, 1465-1479. 8, 15, 20

[39] K. Levenberg, A method for the solution of certain non-linear problems in least squares, Quarterly of Applied Mathematics 2 (1944), no. 2, 164-168. 29 
[40] T. Lindeberg, Detecting salient blob-like image structures and their scales with a scale-space primal sketch: a method for focus-of-attention, International Journal of Computer Vision 11 (1993), no. 3, 283-318. 13

[41] _ Scale-space theory: a basic tool for analysing structures at different scales, Journal of Applied Statistics 21 (1994), no. 2, 224-270. 13

[42] _ Feature detection with automatic scale selection, International Journal of Computer Vision 30 (1998), no. 2, 79-116. 13

[43] H. Liu, H. Darabi, P. Banerjee e J. Liu, Survey of wireless indoor positioning techniques and systems, IEEE Transactions on Systems, Man and Cybernetics, Part C: Applications and Reviews 37 (2007), no. 6, 1067-1080. 42, 44

[44] D. Lowe, Object recognition from local scale-invariant features, Proceedings of the 7th IEEE International Conference on Computer Vision, vol. 2, IEEE Computer Society Press, 1999, págs. 1150-1157. 16, 20, 25, 26

[45] _ Distinctive image features from scale-invariant keypoints, International Journal of Computer Vision 20 (2004), no. 2, 91-110. 8, 13, 14, 15, 16, 20, 25, 26

[46] B. D. Lucas e T. Kanade, An iterative image registration technique with an application to stereo vision, Proceedings of the 7th International Joint Conference on Artificial Intelligence (P. J. Hayes, ed.), William Kaufmann, 1981, págs. 674-679. 9, 12

[47] D. Marquardt, An algorithm for least-squares estimation of nonlinear parameters, SIAM Journal on Applied Mathematics 11 (1963), no. 2, 431-441. 29

[48] J. Matas, O. Chum, M. Urban e T. Pajdla, Robust wide baseline stereo from maximally stable extremal regions, Proceedings of the 13th British Machine Vision Conference (D. Marshall e P. L. Rosin, eds.), British Machine Vision Association, 2002, págs. 384-396. 9, 14, 22, 26

[49] K. Mikolajczyk e C. Schmid, Scale $\& 3$ affine invariant interest point detectors, International Journal of Computer Vision 60 (2004), no. 1, 63-86. 13, 22, 26

[50] _ A performance evaluation of local descriptors, IEEE Transactions on Pattern Analysis and Machine Intelligence 27 (2005), no. 10, 1615-1630. 14, 25, 26, 29

[51] K. Mikolajczyk, T. Tuytelaars, C. Schmid, A. Zisserman, J. Matas, F. Schaffalitzky, T. Kadir e L. van Gool, A comparison of affine region detectors, International Journal of Computer Vision 65 (2005), no. 1-2, 43-72. 12, 22, 26, 34

[52] H. Moravec, Obstacle avoidance and navigation in the real world by a seeing robot rover, tese de doutorado, Artificial Intelligence Laboratory, Stanford University, 1980. 9, 12, 13

[53] J. Morel e G. Yu, ASIFT: a new framework for fully affine invariant image comparison, SIAM Journal on Imaging Sciences 2 (2009), no. 2, 438-469. 8

[54] H. Morimitsu, M. Hashimoto, R. B. Pimentel, R. M. Cesar Jr. e R. Hirata Jr., Keygraphs for sign detection in indoor environments by mobile phones, Proceedings of the 8th IAPR-TC-15 International Workshop on Graph-Based Representations in Pattern Recognition (X. Jiang, M. Ferrer e A. Torsello, eds.), Lecture Notes in Computer Science, vol. 6658, Springer, 2011, págs. 315-324. 42, 43, 44, 45 
[55] H. Morimitsu, R. B. Pimentel, M. Hashimoto, R. M. Cesar Jr. e R. Hirata Jr., Wi-fi and keygraphs for localization with cell phones, Proceedings of the 13th IEEE International Conference on Computer Vision Workshops, IEEE Computer Society Press, 2011, págs. 92-99. $42,45,46$

[56] M. Muja e D. G. Lowe, Fast approximate nearest neighbors with automatic algorithm configuration, Proceedings of the 4th International Conference on Computer Vision Theory and Applications (A. Ranchordas e H. Araújo, eds.), vol. 1, INSTICC Press, 2009, págs. 331-340. 26,37

[57] A. Mulloni, D. Wagner, I. Barakonyi e D. Schmalstieg, Indoor positioning and navigation with camera phones, IEEE Pervasive Computing 8 (2009), no. 2, 22-31. 42

[58] S. A. Nene, S. K. Nayar e H. Murase, Columbia Object Image Library (COIL-100), Tech. report, Department of Computer Science, Columbia University, 1996. 48

[59] R. Paucher e M. Turk, Location-based augmented reality on mobile phones, Proceedings of the 2010 IEEE Computer Society Conference on Computer Vision and Pattern Recognition Workshops, IEEE Computer Society Press, 2010, págs. 9-16. 42

[60] J. Philbin, O. Chum, M. Isard, J. Sivic e A. Zisserman, Object retrieval with large vocabularies and fast spatial matching, Proceedings of the 2007 IEEE Computer Society Conference on Computer Vision and Pattern Recognition, IEEE Computer Society Press, 2007, págs. 1-8. $16,46,48,49$

[61] R. B. Pimentel, Localização em dispositivos móveis utilizando sinais de redes wi-fi, dissertação de mestrado, Instituto de Matemática e Estatística, Universidade de São Paulo, 2011. 43

[62] P. Punitha e D. S. Guru, Symbolic image indexing and retrieval by spatial similarity: an approach based on B-tree, Pattern Recognition 41 (2008), no. 6, 2068-2085. 16, 47

[63] J. Rabin, J. Delon e Y. Gousseau, Circular Earth Mover's Distance for the comparison of local features, Proceedings of the 19th International Conference on Pattern Recognition, IEEE Computer Society Press, 2008, págs. 1-4. 15

[64] E. Rosten e T. Drummond, Machine learning for high-speed corner detection, Proceedings of the 9th European Conference on Computer Vision: Part I (A. Leonardis, H. Bischof e A. Pinz, eds.), Lecture Notes in Computer Science, vol. 3951, Springer, 2006, págs. 430-443. $14,15,20$

[65] C. Schmid e R. Mohr, Local grayvalue invariants for image retrieval, IEEE Transactions on Pattern Analysis and Machine Intelligence 19 (1997), no. 5, 530-535. 9, 14, 16, 46

[66] J. R. Shewchuk, Triangle: engineering a 2D quality mesh generator and Delaunay triangulator, Applied Computational Geometry: Towards Geometric Engineering ( $\mathrm{M}>$ C. Lin e D. Manocha, eds.), Lecture Notes in Computer Science, vol. 1148, Springer, 1996, págs. 203222. 29

[67] J. Shi e C. Tomasi, Good features to track, Proceedings of the 1994 IEEE Computer Society Conference on Computer Vision and Pattern Recognition, IEEE Computer Society Press, 1994, págs. 593-600. 9, 12, 13, 22 
[68] C. Silpa-Anan e R. Hartley, Optimised KD-trees for fast image descriptor matching, Proceedings of the 2008 IEEE Computer Society Conference on Computer Vision and Pattern Recognition, IEEE Computer Society Press, 2008, págs. 1-8. 26

[69] B. Sirmacek e C. Unsalan, Urban area and building detection using SIFT keypoints and graph theory, IEEE Transactions on Geoscience and Remote Sensing 47 (2009), no. 4, 1156-1167. 16

[70] J. Sivic, B. C. Russell, A. A. Efros, A. Zisserman e W. T. Freeman, Discovering objects and their location in images, Proceedings of the 10th IEEE International Conference on Computer Vision, vol. 2, IEEE Computer Society Press, 2005, págs. 370-377. 16, 47

[71] J. Sivic e A. Zisserman, Video Google: efficient visual search of videos, Toward CategoryLevel Object Recognition (J. Ponce, M. Hebert, C. Schmid e A. Zisserman, eds.), Lecture Notes in Computer Science, vol. 4170, Springer, 2006, págs. 127-144. 16, 46, 47

[72] S. M. Smith e J. M. Brady, SUSAN: a new approach to low level image processing, International Journal of Computer Vision 23 (1997), no. 1, 45-78. 14

[73] G. Takacs, V. Chandrasekhar, N. Gelfand, Y. Xiong, W.-C. Chen, T. Bismpigiannis, R. Grzeszczuk, K. Pulli e B. Girod, Outdoors augmented reality on mobile phones using loxel-based visual feature organization, Proceedings of the 1st ACM Internation Conference on Multimedia Information Retrieval, ACM Press, 2008, págs. 427-434. 42

[74] F. Tang, S. H. Lim, N. L. Chang e H. Tao, A novel feature descriptor invariant to complex brightness changes, Proceedings of the 2009 IEEE Computer Society Conference on Computer Vision and Pattern Recognition, IEEE Computer Society Press, 2009, págs. 26312638. 49

[75] F. Tang e H. Tao, Object tracking with dynamic feature graph, Proceedings of the 2nd Joint IEEE International Workshop on Visual Surveillance and Performance Evaluation of Tracking and Surveillance, IEEE Computer Society Press, 2005, págs. 25-32. 16

[76] D. Tell e S. Carlsson, Wide baseline point matching using affine invariants computed from intensity profiles, Proceedings of the 6th European Conference on Computer Vision: Part I (A. Heyden, G. Sparr, M. Nielsen e P. Johansen, eds.), Lecture Notes in Computer Science, vol. 1842, Springer, 2000, págs. 814-828. 16, 25, 28

[77] _ Combining appearance and topology for wide baseline matching, Proceedings of the 7th European Conference on Computer Vision: Part I (D. Vernon, ed.), Lecture Notes in Computer Science, vol. 2350, Springer, 2002, págs. 68-81. 16, 25, 28

[78] E. Tola, V. Lepetit e P. Fua, DAISY: an efficient dense descriptor applied to wide baseline stereo, IEEE Transactions on Pattern Analysis and Machine Intelligence 32 (2010), no. 5, 815-830. 9, 14, 26

[79] C. Tomasi e T. Kanade, Detection and tracking of point features, Tech. report, School of Computer Science, Carnegie-Mellon University, 1991. 9, 12

[80] T. Tuytelaars e K. Mikolajczyk, Local invariant feature detectors: a survey, Foundations and Trends in Computer Graphics and Vision 3 (2008), no. 3, 177-280. 12

[81] T. Tuytelaars e L. van Gool, Content-based image retrieval based on local affinely invariant regions, Proceedings of the International Conference on Visual Information Systems, 1999, págs. 493-500. 14 
[82] __ Wide baseline stereo matching based on local, affinely invariant regions, Proceedings of the 11th British Machine Vision Conference, British Machine Vision Association, 2000, págs. 412-425. 14

[83] Y. Wang, X. Jia, H. K. Lee e G. Y. Li, An indoors wireless positioning system based on wireless local area network infrastructure, Proceedings of the 6th International Symposium on Satellite Navigation Technology Including Mobile Positioning \& Location Services, 2003, págs. 22-25. 42

[84] C. J. Wayn, B. Li, A. G. Dempster e C. Rizos, GPS/WiFi real-time positioning device: an initial outcome, Location Based Services and TeleCartography II: From Sensor Fusion to Context Models (G. Gartner e K. Rehrl, eds.), Lecture Notes in Geoinformation and Cartography, Springer, 2008, págs. 439-456. 42

[85] M. Weber, M. Welling e P. Perona, Unsupervised learning of models for recognition, Proceedings of the 6th European Conference on Computer Vision: Part I (D. Vernon, ed.), Lecture Notes in Computer Science, vol. 1842, Springer, 2000, págs. 18-32. 15

[86] J. Yuan, Y. Wu e M. Yang, Discovery of collocation patterns: from visual words to visual phrases, Proceedings of the 2007 IEEE Computer Society Conference on Computer Vision and Pattern Recognition, IEEE Computer Society Press, 2007, págs. 1-8. 16, 47 